NBSIR 84-2841

\title{
Buoyancy-Induced Wall Flow Due to Fire in A Room
}

U.S. DEPARTMENT OF COMMERCE

National Bureau of Standards

National Engineering Laboratory

Center for Fire Research

Washington, DC 20234

May 1984

Final Report

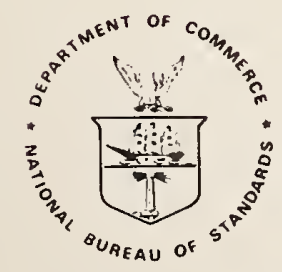

U.S. DEPARTMENT OF COMMERCE

NATIONAL BUREAU OF STANDARDS

100

.456

$34-2841$

1934 

NBSIR 84-2841

\section{BUOYANCY-INDUCED WALL FLOW \\ DUE TO FIRE IN A ROOM}

Yogesh Jaluria

Mechanical and Aerospace

Engineering Department

Rutgers University

U.S. DEPARTMENT OF COMMERCE

National Bureau of Standards

National Engineering Laboratory

Center for Fire Research

Washington, DC 20234

May 1984

Final Report

U.S. DEPARTMENT OF COMMERCE, Malcolm Baldrigo, Secretary NATIONAL BUREAU OF STANDARDS. Emeat Ambler, Diroctor 

TABLE OF CONTENTS

$\underline{\text { Page }}$

LIST OF FIGURES.................................. iv

NOMENCLATURE.................................... vi

Abstract $\quad \ldots \ldots \ldots \ldots \ldots \ldots \ldots \ldots \ldots \ldots \ldots \ldots \ldots \ldots \ldots \ldots \ldots \ldots \ldots \ldots \ldots \ldots \ldots \ldots \ldots$

1. INTRODUCTION.................................. 3

2. THE PROBLEM................................... 5

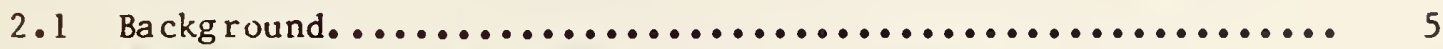

2.2 Objectives of the Study......................... 7

3. EXPERIMENTAL RESULTS.............................. 8

4. RELATIVE MAGNITUDE OF WALl Flows...................... 12

5. WALL FLOW PENETRATION ACROSS THE INTERFACE............... 21

5.1 Fl ow in Stratified and Negatively-Buoyant Sltuations..... 21

5.2 Penetration in a Three-Layer system.................. 24

5.3 Penetration in a Two-Layer System.................... 28

5.4 Concluding Remarks on Penetration................... 30

6. FLOW OF FIRE PLUME ACROSS THE INTERFACE................... 30

7. ESTIMATION OF WALL FLOW EFFECTS ..................... 37

8. SUMMARY AND CONCLUSIONS............................ 45

9. FUTURE WORK ..................................... 48

10. ACKNOWLEDGEMENTS................................ 51

11. REFERENCES.................................... 52 
Figure 1. Flow configuration considered.................. 57

Figure 2. Sketch of the temperature distribution in a two-layer

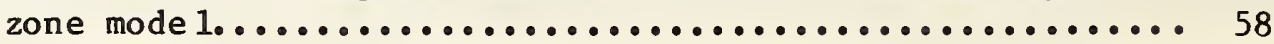

Figure 3. Sketch of the velocity and temperature profiles in the

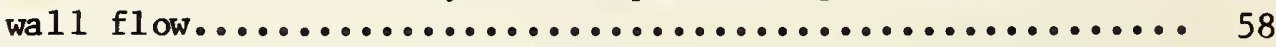

Figure 4. Flow in the negatively-buoyant wall flow and in a corresponding jet......................... 59

Figure 5. Interaction of opposing wall flows................ 59

Figure 6. Interaction of a fire plume with the stably stratified upper layer................................... 60

Figure 7. Experimental arrangement....................... 61

Figure 8. Measured gas and wall temperatures in the room for a

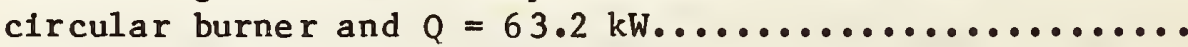

Figure 9. Measured gas and wall temperatures in the room for a circular burner and $Q=63.2 \mathrm{~kW}$, at a different

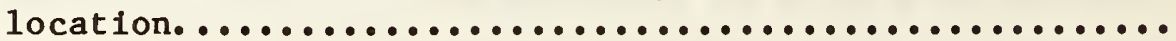

Figure 10. Measured gas and wall temperatures for a single line

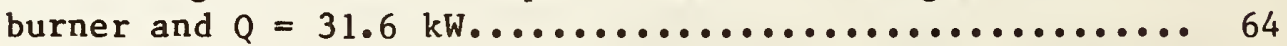

Figure 11. Measured gas and wall temperatures for the line burner at various door openings and heat input values......... 65

Figure 12. Transient wa 11 and gas temperatures for a line burner and $Q=31.6 \mathrm{~kW}$, with a $1.83 \mathrm{~m} \times 0.24 \mathrm{~m}$ door opening.... 66

Figure 13. Actual and idealized temperature profiles............ 67

Figure 14. Actual and idealized boundary layer wall flow........ 67

Figure 15. Mass flow rate in the wall flow, as a function of the

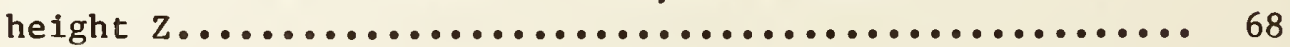

Figure 16. A comparison between the wall flow rate and the plume flow rate, for a circular burner at $Q=63.2 \mathrm{~kW}$ and a

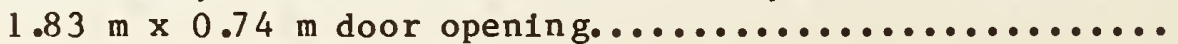

Figure 17. Mass flow rate and the momentum flow rate in the laminar wall flow, for various models considered in the negatively-buoyant region, employing values from Fig. $8 . \ldots \ldots \ldots \ldots \ldots \ldots \ldots \ldots \ldots \ldots \ldots \ldots \ldots \ldots \ldots \ldots \ldots \ldots \ldots \ldots$ 
Figure 18. Momentum flow rate for various heights $\mathrm{L}_{1}$ of the isothermal lower region, considering laminar flow

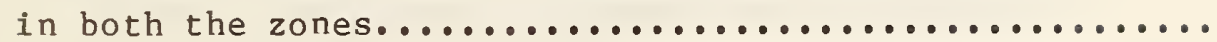

Figure 19. Momentum flow rate for turbulent flow in the two zones...

Figure 20. Mass flow for laminar and turbulent flow, as a function of the height $L_{1}$ of the lower isothermal zone...........

Figure 21. Dependence of the location of the separation point on

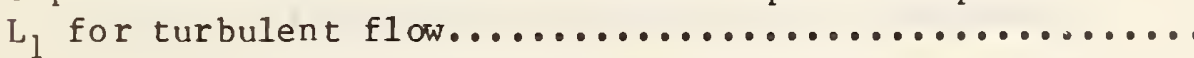

Figure 22. Momentum flow at various values of $L_{1}$ and $L_{2}$ for

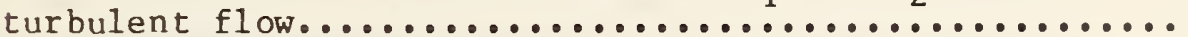

Figure 23. Dependence of the height of the separation point on the height $L_{2}$ of the stratified intermediate laye $r . . . . . .$.

Figure 24. Variaton of the mass and momentum flow across the

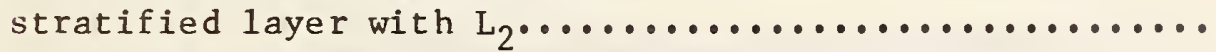

Figure 25. Mass and momentum flow for a two-layer system in laminar flow, considering various models for the negatively-

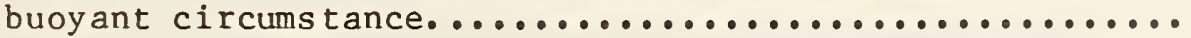

Figure 26. Mass and momentum flow for a two-layer system in

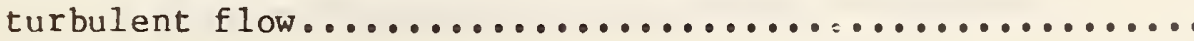

Figure 27. Penetration depth as a function of interface height

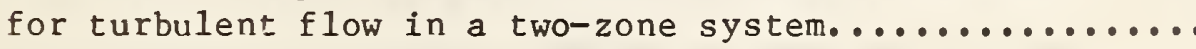

Figure 28. Sketch of the temperature and velocity profiles as the fire plume flows across the interface................

Figure 29. Mass flow rate as the wall flow penetrates the stratified intermediate layer.

Figure 30. Velocity profiles, for the inviscid and the viscous models, as the wall flow penetrates the stratified

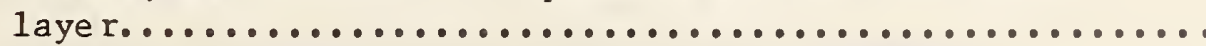

Figure 31. Mass flow rate in the plume as it flows across the stratified layer for various values of $L_{1}$ and maximum temperature defect $D_{T}$, at $Q=63.2 \mathrm{~kW} . \ldots \ldots \ldots \ldots \ldots . . . . .$.

Figure 32. Mass flow rate in the plume for various values of the temperature defect $D_{T}$ for $Q=63.2 \mathrm{~kW} \ldots \ldots \ldots \ldots \ldots$

Figure 33. Results for plume flow across the interface, from the integral model of Ref. [38] for $Q=63.2 \mathrm{~kW} . \ldots \ldots \ldots \ldots$

Figure 34. Variation of the upward penetrating wall flow rate with the interface height $z_{i}$ for a two-zone mode1........... 
d

F

g

Gr

$\mathrm{Gr}_{\mathrm{c}}$

h

L

$\mathrm{L}_{1}$

$\mathrm{L}_{2}$

m

$\dot{\mathrm{m}}_{\mathrm{w}}$

$\stackrel{\mathrm{m}}{\mathrm{m}}_{\mathrm{a}}, \stackrel{\mathrm{m}}{\mathrm{e}}_{\mathrm{j}}, \dot{\mathrm{m}}_{\mathrm{j}}$

$\dot{\mathrm{m}}_{\mathrm{f}}$

$\dot{\mathrm{m}}_{\mathrm{o}}$

$\stackrel{\circ}{\mathrm{m}}$

$\dot{\mathrm{m}}_{\mathrm{P}}^{\prime}$

M

M

n

P

$\operatorname{Pr}$

Q

$Q_{c}$

horizontal cross-sectional area of the room, $\mathrm{m}^{2}$

specific heat at constant pressure, $\mathrm{J} / \mathrm{kgK}$

width of the fire plume, defined in Eqn. (25), m

heat input parameter, defined in Eqn. (24)

magnitude of gravitationa 1 acceleration, $\mathrm{m} / \mathrm{s}^{2}$

Grashof number, defined in Eqn. (17)

Grashof number at transition from laminar to turbulent flow

convective heat transfer coefficient at the floor, $W / m^{2} \mathrm{~K}$

height of the room, m

height of lower isothermal layer, m

height of intermediate stratified layer, m

mass flow rate in the wall flow per unit flow perimeter, $\mathrm{kg} / \mathrm{ms}$

total mass flow rate in the wall $\mathrm{f} 1 \mathrm{ow}, \mathrm{kg} / \mathrm{s}$

mass flow rates defined in Fig. $1, \mathrm{~kg} / \mathrm{s}$

mass flow rate of the fue $1, \mathrm{~kg} / \mathrm{s}$

outflow mass flow rate at the opening, $\mathrm{kg} / \mathrm{s}$

mass flow rate in the plume entering the upper layer, $\mathrm{kg} / \mathrm{s}$

mass flow peeled off from the plume at the interface, $\mathrm{kg} / \mathrm{s}$

momentum flow rate in the wall flow per unit perimeter, $\mathrm{kg} / \mathrm{s}^{2}$

total momentum flow rate in the wall flow, $\mathrm{kg} \mathrm{m} / \mathrm{s}^{2}$

coefficient which gives the variation of flow region thickness

with height, $\delta a z^{n}$

flow perimeter for the wall flow, m

Prandt 1 number, $\operatorname{Pr}=v \tilde{\alpha}$

heat input into the fire, $\mathrm{kW}$

convective heat input into the plume, $\mathrm{kW}$ 
convective energy flux in wall flow per unit perimeter, $\mathrm{W} / \mathrm{m}$ total convective energy flux in wall flow, W radial distance from fire plume axis, m temperature, $\mathrm{K}$ difference between wall and gas temperatures, $\mathrm{K}$ floor temperature, $\mathrm{k}$ outside ambient temerature, $\mathrm{K}$ vertical velocity, $\mathrm{m} / \mathrm{s}$ vertical velocity parameter in Eqns. (4) and $(12), \mathrm{m} / \mathrm{s}$ centerline velocity in the plume vertical distance above the top of the lower isothermal layer, horizontal coordinate distance from the walls, m vertical coordinate distance from room floor, m interface height, $m$ entrainment coefficient, Eqn. (21) thermal diffusivity, $\mathrm{m}^{2} / \mathrm{s}$ coefficient of thermal expansion, $\beta=1 / T$ for perfect gas, $K^{-1}$ boundary layer thickness, m constant, defined in Eqn. (25) kinematic viscosity, $\mathrm{m}^{2} / \mathrm{s}$ density, $\mathrm{kg} / \mathrm{m}^{3}$ time, s 


\section{Subscripts}

$\mathbf{u}$

1

g

W

$\infty$

0

c upper layer

lower layer

gas

wa11

local conditions outside the flow region

conditions at the level of the heat source

centerline conditions in the plume 


\section{BUOYANCY-INDUCED WALL FLOW DUE TO FIRE IN A ROOM \\ Yogesh Jaluria}

Abstract

A study of the buoyancy-driven flow generated adjacent to the vertical walls of a room due to fire in the room has been carried out. Considering a room with a single opening, experimental measurements of the wall and the gas temperatures in the room were made. Though the emphasis was on the steady and quasi-steady state situations, some measurements were also taken at the very early stages of the fire to consider the transient variation of the temperature levels. The boundary layer flow that arises over the vertical walls due to the resulting difference between the wall and gas temperatures was analyzed, employing the integral analysis method. The flow rate, momentum and convected energy in the downward flow that arises in the heated upper layer and those in the upward flow that is generated in the cooler lower layer were determined. As the fluid flows from one layer into the other, through an intermediate stratified region with large temperature gradients, it becomes negatively buoyant, penetrates to a finite distance and then falls back due to negative buoyancy. These circumstances are also analyzed by the use of an integral analysis and calculations are carried out for selected experimental results. The flow is predicted to separate from the wall at the location where the downward and the upward momenta of the two opposing flows are equal. The separation point and the region near it where the flow starts separating from the wall are studied. Results are obtained for a three-layer model, which incorporates an intermediate stratified layer lying between two isothermal regions, and are eventually considered in terms of the two-layer approxi- 
mation used in zone models. The penetration of the fire plume into the upper layer is also considered in terms of the integral approach and a simple model based on the dynamics of the fluid elements in the flow.

For the range of experimental data considered, it is found from this analysis that the wall flow is quite significant as compared to the flow in the plume and should, in general, be taken into account in the mass balance considerations of the two layers. The energy transfer across the interface due to the wall flow is relatively small and may often be neglected. Depending on the temperature levels and the height of the interface, the upward flow in the lower region may penetrate into the upper layer or the downward flow in the upper layer may be injected into the lower layer. The study indicates the method for determining the direction and magnitude of the penetrating flow. Though more detailed and more accurate computations are included, an approximate method for evaluating the wall effects for a twolayer model and for an experimental study is outlined. The penetration of the plume into the upper layer is studied and it is found that only a small fraction of the flow is unable to penetrate the intermediate stratified layer. As a first approximation, the mass flow rate may be taken as unaltered across the interface. Employing this approximation, results are presented on the plume flow in the upper layer, as obtained from the integral analysis. Finally, the study indicates future experimental and analytical work that may be carried out to answer some of the basic questions raised here and to provide further information on the wall and plume flow penetration across the interface.

Key words: wall flows, plume penetration, enclosure fires, zonemodeling, stratified media, density interface. 


\section{INTRODUCTION}

In recent years, there has been a considerable interest and research activity in the buoyancy-driven flow of air and gases in room fires, with a view to determine the changing environment within the enclosure and to provide inputs for the eventual spread of combustion products into other connected enclosures [1-4]. Much of the present information on the development of the fire, with respect to the temperatures in the room and the movement of gases, has been obtained from zone modeling, which divides the room into distinct homogeneous regions, generally the hot upper gas zone and the cooler lower zone [5-7]. The zone models have received corroboration from detailed experimental measurements of temperature and velocity distributions in enclosures with ventilation from single openings [8-11]. The zone models predict the average gas and wall temperatures in the various regions and do not provide information on local conditions, which may be obtained from field model studies which have also been carried out in recent years $[12,13]$.

The basic features of the zone model for fire in a room with an opening, such as a door or a window, are shown in Fig. 1. As a fire starts in a room, buoyant hot fluid rises from the fire, entrains fresh air from the room and moves towards the ceiling in the form of a buoyant plume. This flow generates a distinct layer of hot and, thus, lighter gas below the ceiling. The layer increases in thickness as the plume brings more hot fluid into the layer. The hot gases eventually start flowing out of the room, while the cold air from outside flows into the room due to the resulting pressure difference. As estimated by zone modeling studies and also observed in several experiments, fires of any thermal significance ( $>10 \mathrm{~kW}$ ) in typical residential rooms 
display a rapid increase in the upper layer thickness, its interface with the lower layer reaching the opening in a matter of seconds. However, conventional walls have a much slower time response than the gas layers [2] and, following the rapid increase in the temperatures in the two layers, the walls continue to increase in temperature at a very gradual rate. Therefore, an initially rapid increase in the gas temperatures is followed by slowly varying wall and gas temperatures. This has led to the modeling of many practical circumstances as quasi-steady, with the flow and temperature distributions progressing from one essentially steady situation to another, until rapid pyrolysis of combustible material in the room, followed by room flashover, occurs.

The air entrainment by the plume and the flow rate through room openings are important inputs into the modeling of fires in enclosures. Several studies of entrainment in fire plumes have been carried out $[14,15]$ and the results have been compared with those for an idealized point source plume. A larger entrainment has been obtained in the actual case and the entrainment has been found to be influenced by the size of the source, by disturbances in the room, by the incoming air flow through the openings, by the proximity to walls and by several other effects $[16,17]$. It $1 \mathrm{~s}$, therefore, important to develop analytical procedures for an accurate determination of plume entrainment under various operating conditions. In addition, the flow of the plume across the interface, between the upper and lower layers, is important for modeling of the flow.

Due to the difference between the temperatures of the gas and the adjacent walls that are being heated up due to convective and radiative heat 
transfer, a significant buoyancy-induced flow may arise adjacent to the walls and may lead to additional mixing across the interface. At the initial stages of the fire in a room, the upper layer generates a downward flow adjacent to the cooler upper region of the wall. The flow emerges from the upper layer, becomes negatively buoyant in the lower layer and rises towards the interface to cause greater mixing in the lower zone, near the interface. At later stages, the lower region of the wall, in contact with the lower layer, heats up and an upward flow is also generated in the cooler lower layer. These opposing streams of wall flows may be important in the mass and energy balances of the zones for modeling. The present study was undertaken to study the wall flows thus generated in enclosure fires. Also of interest were the nature of the interface between the two layers, with respect to temperature distributions in an actual full-scale experimental system, and the penetration of the buoyancy-driven wall flows and of the fire plume across the interface.

\section{THE PROBLEM}

\subsection{Background}

Let us consider some of the important physical aspects relevant to a study of temperatures and flows due to fire in an enclosure. In terms of a two-layer zone model, the upper layer is characterized by a uniform average temperature $\mathrm{T}_{\mathrm{g}, \mathrm{u}}$ and the lower layer by $\mathrm{T}_{\mathrm{g}, 1}$, as shown in Fig. 2. Simllarly, the wall temperatures may be considered in terms of an upper region value $\mathrm{T}_{w, u}$ and a lower region value $\mathrm{T}_{\mathrm{w}, 1}$. Thus, a step change in the temperatures 18 assumed to occur at the interface height $Z_{i}$. In actual practice, of course, a step change would be replaced by a more gradual variation, as shown in Flg. 1 
and discussed later in terms of experimental results. Now, as is evident from Fig. 2, the wall temperature is higher than the adjacent gas temperature in the lower layer and lower in the upper layer. Therefore, a buoyancy-induced wall flow rises in the lower layer and descends in the upper layer. The boundary layer flows that arise adjacent to heated or cooled vertical surfaces have been studied extensively [18]. A qualitative sketch of these flows is shown in Fig. 3, along with the corresponding velocity and temperature distributions.

In the absence of the upper opposing flow, a buoyant lower flow arises in the lower layer, penetrates the interface, becomes negatively buoyant as it encounters the high temperature in the upper layer, stagnates at a certain height and drops towards the interface due to the negative buoyancy. This is similar to the case of a negatively buoyant jet, as shown in Fig. 4 [19-22]. In the presence of an opposing stream, the flow stagnates and separates from the wa11, either above or below the interface, as shown in Fig. 5. The fire plume is, on the other hand, generally, buoyant with respect to the upper layer and rises in the upper layer towards the ceiling. It may, however, shed some flow at the interface due to negative buoyancy in the outer regions of the plume. This "peeling of $f$ " phenomenon can manifest itself as a multi-layer counter current stratified flow as has been observed in several experimental studies [1,23] Also, if the heat input into the fire is reduced after the layers are established, the plume may be unable to penetrate into the upper layer, as shown in Fig. $6[24,25]$.

There are several important questions that must be answered in a consideration of wall flows. The most significant one relates to the magnitude of 
the flow generated in an actual room fire situation. The wall flow rate may be compared with the flow in the fire plume and also with that entering through the opening to determine the importance of this effect. The second question is whether this flow is able to enter the hot upper layer, despite the opposing descending wall flow and the stable thermal stratification that exists in the room. The third question relates to how these considerations modify the present two-layer zone models and experimental studies of enclosure fires. Besides these three crucial questions, there are several related considerations. It is important to consider the nature of the interface in an actual fire situation and to determine the mixing across it due to wall flows. Also of interest is the penetration of the fire plume across the interface and the determination of the magnitude of the flow that is unable to penetrate into the upper layer.

\subsection{Objectives of the Study}

This study was undertaken to determine the nature and magnitude of the buoyancy-driven wall flows generated by fire in an enclosure. It is to be ascertained whether the effects due to these flows are important in the consideration of the mass and energy balances in the present two-layer models, which are employed to predict temerature levels and flows in the room. To the author's knowledge, all existing zone models neglect the wall flow.

In addition to the above consideration of the wall flow effects, it is also desirable to determine the magnitude of the fire plume flow which does not penetrate into the upper layer, since this flow should also be included in the overall energy and mass balances. A consideration of the experimentally 
observed interface region in terms of the step change assumed by a two-layer model is also needed. Such discrimination bears on the whole concept of penetration across the interface.

In summary, the basic objectives of the study are to develop a methodology to evaluate the wall flow effects, in terms of their magnitude and penetration across the interface, and to employ the methodology in an analysis of recent full-scale enclosure fire experiments and in incorporating these effects in existing two-layer zone models for enclosure fires.

\section{EXPERIMENTAL RESULTS}

The study considers steady and quasi-steady situations that arise in an enclosure fire. This will be based on fires of 30 to $130 \mathrm{~kW}$ energy release in a typical residential room with a single opening. The analysis and the results obtained are not expected to apply for the very early stages of the fire, following ignition, since transient effects are important and may have to be included for a realistic analysis of the flow. For the experimental arrangement considered in this study, it can be shown, employing the results presented in Ref. [18], that the boundary layer flow takes about 2 seconds to be established. This is of the same order as the time taken for the interface to descend to the door soffit. For the experimental arrangement considered in Refs. $[10,11]$ and employed here, a steady state circumstance is attained, for a constant heat release fire, after the transient heating of the walls is complete. Therefore, this study examines wall flows for such steady or quasisteady cases. 
Experimental work was carried out to determine the wall and gas temperature profiles generated by fire in a room. The experiments were conducted in a $2.8 \mathrm{~m} \times 2.8 \mathrm{~m} \times 2.18 \mathrm{~m}$ room shown in Fig. 7. Essentially steady state conditions are attained in this arrangement within about 30 minutes following ignition of the burner. The experiments employed circular and line burners, the latter being a long slot supplied by an array of circular holes. The gas flow rate and the length of the line burner could be adjusted. Velocity and temperature measurements were taken by means of bidirectional velocity probes and thermocouples. Bare thermocouples were 1mbedded in the walls and the ceiling to obtain wall temperature data. Further details on the experimental arrangement and the measurement techniques may be obtained from Refs. $[10,11]$.

Several experiments were carried out with various burner locations and configurations, door openings and fire heat inputs. Some of the typical results obtained are shown in Figs. 8-11 (the room symbol on the figures indicates the burner location and door size $[10,11]$ ) and Table 1 for the two burner configurations. It is apparent that the results depend on the heat input, the door opening, the dimensions of which are given in terms of the notation included in Table 1, and the burner location. However, the basic form of the profiles is similar in all the cases shown. The wall temperature increases gradually from the floor and then more sharply as the upper layer is approached, attaining essentially uniform temperature in the upper layer in most cases. The gas temperature shows greater uniformty in the two layers and a much sharper temperature rise from the lower to the upper layer. The gas temperature starts increasing gradually as the upper layer is approached and then rises very rapidly, over relatively a very short distance. It then gradually attains the upper layer temperature. Even the region of rapld 
temperature variation spreads over a distance of about $20 \mathrm{~cm}$, being smaller in some cases and much larger in others, particularly at small door openings which give rise to much greater mixing in the room [11]. Only a few profiles are shown here for brevity and similar trends were observed at other operating conditions.

It is evident from the results presented that a two-layer zone model can be employed to obtain average temperatures in the two zones. Gas temperatures are fairly uniform in the two layers and quite a sharp change in the temperature occurs in going from one layer to the other. However, it is not clear where one might locate the interface for a two-layer model. Following a suggestion by Emmons [52], Steckler [10] has considered this question in detail. In replacing the actual measured profile with an idealized two-layer profile, the two profiles are made equivalent by requiring equal mass and equal values of the integral $\int \mathrm{Tdz}$. The second condition is, therefore, arbitrary, though for a constant density fluid it would imply equal thermal energy in the two profiles. For gases, since the product of density and temperature is essentially a constant, a similar constraint on energy does not lead to any useful constraint on the choice of the idealized profile. The method discussed by Steckler [10] was shown to yield satisfactory results with respect to flow rates and other physical variables measured experimentally.

Some experimental observations were also made in order to determine the position of the interface as indicated by the occurrence of a stable stratification. Employing smoke, introduced into the upper layer, a fairly distinct interface was observed. The upper region was seen to be fairly disturbed and the lower region, away from the plume, relatively quiescent. A comparison was 
made between the interface height observed by means of the smoke and the measured temperature profile. The interface observed with smoke was found to be quite close to that obtained by the method outlined above [10]. The height in the former case versus that in the latter for four experiments yielded $1.27,1.09,1.38,1.04 \mathrm{~m}$ as compared to the corresponding values of $1.4,1.1$, $1.38,1.15 \mathrm{~m}$. Obviously, more work is needed on the relationship between the interface as defined by a two-layer temperature profile and observations of stable stratification by some visualization technique is needed. Some visualization of the wall flows, by means of a mineral ofl smoke generator, was also attempted in this study. A downward flow adjacent to the wall was observed in the upper region and an upward flow in the lower reglon. The region near the interface was found to be very disturbed and a distinct flow direction could not be discerned.

The experimental study also measured opening flow rates, as outlined in Ref. [11]. Table 1 shows the results for a few configurations and heat inputs. Tlme-dependent temperature distributions were also measured. It was observed that the upper layer descends to the door soffit within a few seconds, generally 2-5 seconds. This is followed by a transient process while the walls, floor and the celling are heated. Whthin about 30 minutes, the variation in the temperature profiles was found to become quite small. During a typical experiment, such as that shown in FIg. 8, wall temeratures in the upper and lower reglons varled by only about $5 \%$ over a period of more than 30 minutes following the inftial transient. Therefore, measurements were taken in an essentially steady-state situation. Following the inftial transient of a few minutes, the interface is more or less established and a quasi-steady approach would be quite appropriate while the walls are heating up. After 
about 30 minutes, the conditions may be taken as steady. Fig. 12 shows the measured variation with time of the gas and wall temperatures in the upper and lower layers for a single line burner, with $31.6 \mathrm{~kW}$ input and $1.83 \mathrm{~m} \times 0.24 \mathrm{~m}$ door opening. It is seen that the system may be taken as quasi-steady after a few minutes. These experimental results will serve as the basis for analysis. The next section describes the computational methods employed for estimating the wall flow rate and the degree of its penetration across the hot-cold interface and for considering the nature of plume flow across the interface. Wall and gas temperature profiles representative of Fig. 8 will be used as the conditions of stratification. For this experiment, the values of $T_{g, u}, T_{W, u}$, $\mathrm{T}_{\mathrm{w}, \ell}, \mathrm{T}_{\mathrm{g}, \ell}$ and $\mathrm{z}_{\mathrm{i}}$ are obtained as $241^{\circ} \mathrm{C}, 184^{\circ} \mathrm{C}, 110^{\circ} \mathrm{C}, 50^{\circ} \mathrm{C}$ and $1.42 \mathrm{~m}$, respectively. Variations from these experimental data will also be considered.

\section{RELATIVE MAGNITUDE OF WALL FLOWS}

With information now available on the temperature profiles, we may proceed to a consideration of the buoyancy-induced flows generated adjacent to the walls. The actual wall and gas temperature distributions are of the form shown in Fig. 13(a). The two-layer zone model requires an idealized distribution of the form shown in Fig. 13(b). Though our interest lies mainly in this distribution for zone modeling purposes, the nature of flow penetration and various other aspects outlined earlier can be best considered in terms of a three-layer approximation, which considers uniform temperatures in the upper and lower regions and an intermediate region where sharp changes in the temperature occur from one region to the other. Though the actual profiles may be employed for such a consideration, a more convenient approach would be 
to consider a profile of the form shown in F1g. 13(c), where a linear temperature variation exists between the two layers. This approximation has been used by several researchers in the study of stratified water bodies, where zone models have yielded results which closely approximate the experimental results $[26-29]$.

The wall flows generated in the two isothermal regions may be analyzed as boundary layer flows adjacent to isothermal surfaces immersed in uniform temperature media. In the upper region the wall is colder than the ambient fluid and a downward flow arlses, whereas in the lower region an upward flow is generated. These flows encounter a stably-stratified region as they go from one layer to the other, through the step change of Fig. 13(b) or the more gradual variation of Fig. 13(c). Therefore, we need to consider the flow in the two isothermal regions, followed by a consideration of flow in the negatively-buoyant or stably-stratified regions.

A considerable amount of work has been done on laminar and turbulent natural convection flows adjacent to 1sothermal vertical surfaces in isothermal ambient media [18]. For the coordinate system of Fig. 14, the vertical velocity $u$ and the temperature distribution may be determined for laminar flow from similarity analysis $[30,31]$. One could then calculate the flow rate $\dot{\mathrm{m}}$, convected energy $\mathrm{q}$ and momentum $M$ in the boundary layer. These are obtained, per unit flow perimeter, from the following expressions:

$$
\begin{aligned}
\dot{\mathrm{m}} & =\int_{0}^{\delta} \rho \mathrm{udy} \\
\mathrm{q} & =\int_{0}^{\delta} \rho \mathrm{C}_{\mathrm{p}} \mathrm{u}\left(\mathrm{T}-\mathrm{T}_{\infty}\right) d y
\end{aligned}
$$




$$
M=\int_{0}^{\delta} \rho u^{2} d y
$$

where $C_{p}$ is the fluid specific heat at constant pressure, $T_{\infty}$ is the local gas temperature, $\rho$ is the fluid density, which varies as $1 / T$ for the assumed perfect gas, and $\delta$ is the boundary layer thickness. For the exact boundary layer similarity analysis, $\delta$ is replaced by infinity and the velocity and temperature distributions from the numerical solution of the governing equations are employed. An approximate integral analysis has also been carried out [32]. It yields results quite close to the exact analysis for laminar flow. The integral analysis is probably more appropriate here, since there is no satisfactory exact analysis for turbulent flow, which is of interest in many cases, and since the numerical values of the integrals required for determining the above physical quantities are not readily available.

The integral analysis assumes the velocity and temperature distributions, substitutes these in the governing integral equations and solves for the unknown quantities like $\delta$, maximum velocity, etc. The distributions employed for laminar flow are:

$$
u=U \frac{y}{\delta}\left(1-\frac{y}{\delta}\right)^{2}, \frac{T-T_{\infty}}{T_{w}-T_{\infty}}=\left(1-\frac{y}{\delta}\right)^{2}
$$

where $U$ and $\delta$ are functions of the height $Z$. The governing equations are obtained as ordinary differential equations for $U$ and $\delta$. These are:

$$
\begin{aligned}
& \frac{d}{d Z}\left(\delta U^{2} / 105\right)=\frac{g \beta\left(T_{w}-T_{\infty}\right)}{3}-\frac{v U}{\delta} \\
& \frac{d}{d Z}(\delta U / 30)=\frac{2 \tilde{\alpha}}{\delta}
\end{aligned}
$$


where the Boussinesq approximation, $\rho_{\infty}-\rho=\beta \rho\left(T-T_{\infty}\right)$, has been employed. Here, $g$ is the acceleration due to gravity, $\nu$ the fluid kinematic viscosity, $\tilde{\alpha}$ its thermal diffusivity and $\beta$ the coefficient of thermal expansion. For the temperature differences, $\Delta T=T_{w}-T_{\infty}$, observed in the experimental study, the Boussinesq approximation is quite satisfactory. These equations yield U and $\delta$ as:

$$
\begin{aligned}
& U=5.17 v\left(\operatorname{Pr}+\frac{20}{21}\right)^{-1 / 2}\left(\frac{g \beta \Delta \mathrm{T}}{v^{2}}\right)^{1 / 2} \mathrm{z}^{1 / 2} \\
& \delta=3.93 \mathrm{Pr}^{-1 / 2}\left(\operatorname{Pr}+\frac{20}{21}\right)^{1 / 4}\left(\frac{g \beta \Delta \mathrm{T}}{v^{2}}\right)^{-1 / 4} \mathrm{z}^{1 / 4}
\end{aligned}
$$

where, $\operatorname{Pr}$ is the Prandt 1 number and $i s$ given by $\operatorname{Pr}=\nu \tilde{\alpha}$. Similarly, $\dot{m}, M$ and $q$ may be determined. From the above integral expressions, these are obtained for the constant density approximation as:

$$
\begin{aligned}
& \dot{\mathrm{m}}=\rho \delta \mathrm{U} / 12 \\
& \mathrm{M}=\rho \delta \mathrm{U}^{2} / 105 \\
& q=\rho C_{p} \delta U \mathrm{~T} / 30
\end{aligned}
$$

In this study, $\rho$ was taken as constant in each of the two regions, with different values, evaluated at the average of the wall and gas temperatures, being employed for each layer.

Similarly, for turbulent flow, various analyses have been carried out [33-35], supported by various experimental studies $[18,36]$. The profiles employed by several workers are [33]: 


$$
u=U\left(\frac{y}{\delta}\right)^{1 / 7}\left(1-\frac{y}{\delta}\right)^{4}, \frac{T-T_{\infty}}{T_{w}-T_{\infty}}=1-\left(\frac{y}{\delta}\right)^{1 / 7}
$$

The governing ordinary differential equations are obtained as:

$$
\begin{aligned}
& 0.0523 \frac{d}{d Z}\left(\delta U^{2}\right)=0.125 g B \Delta T \delta-0.0225 U^{2}\left(\frac{\nu}{U \delta}\right)^{1 / 4} \\
& 0.0366 \frac{d}{d Z}(\delta U)=0.0225 U\left(\frac{U}{U \delta}\right)^{1 / 4} \mathrm{Pr}^{-2 / 3}
\end{aligned}
$$

If the boundary layer is assumed to be fully turbulent from the leading edge, $Z=0$, the expressions for $U$ and $\delta$ are obtained as:

$$
\begin{aligned}
& U=1.185 \frac{\nu}{Z}(\mathrm{Gr})^{1 / 2}\left[1+0.494(\mathrm{Pr})^{2 / 3}\right]^{-1 / 2} \\
& \delta=0.565 \mathrm{Z}(\mathrm{Gr})^{-1 / 10} \mathrm{Pr}^{-8 / 15}\left[1+0.494(\mathrm{Pr})^{2 / 3}\right]^{1 / 10}
\end{aligned}
$$

where $\mathrm{Gr}$ is the Grashof number and is given by

$$
\mathrm{Gr}=\mathrm{g} \beta \Delta \mathrm{T} \mathrm{z}^{3} / \mathrm{\nu}^{2}
$$

Again the net flow rate, momentum and convected energy in the boundary layer may be obtained, per unit perimeter of the flow region, as:

$$
\begin{aligned}
& \dot{\mathrm{m}}=0.1463 \rho \delta \mathrm{U} \\
& M=0.0523 \rho \delta \mathrm{U}^{2}
\end{aligned}
$$




$$
q=0.0366 \rho C_{p} \delta U \mathrm{~T}
$$

The maximum vertical velocity $u_{\max }$ is obtained as $0.537 \mathrm{U}$.

Therefore, the physical quantities of interest may be obtained from the above expressions for heat, mass and momentum. More accurate results may be obtained from the other analytical and experimental studies mentioned above. A question of accuracy may be raised regarding the application of the above boundary layer analysis since considerable turbulent flow and mixing occurs in the region away from the walls. To some extent, this effect can be taken into consideration by determining the location where the boundary layer flow undergoes transition to turbulence. Transition occurs earlier if the flow away from the walls is highly turbulent. In addition to this effect, the turbulent flow outside the boundary layer gives rise to a non-zero velocity in the ambient region. Consequently, a pure natural convection flow is not obtained and the mixed convection effects may have to be considered. As reviewed by Jaluria [18], this effect may be quantized and the overall variation in the flow rate, momentum flow rate and the convected thermal energy may be determined. For the range of velocities generally encountered in these flows, as estimated from the flow in the fire plume, it can be shown from current knowledge that the effect is not very large. However, a detalled numerical solution would be needed to account for the complete three-dimensional characteristics of this problem. A word may also be said about property variations. In the above expressions, fluid properties are taken as constant. The values were determined at the average of the local wall and gas temeratures. For the range of $\Delta \mathrm{T}$ observed experimentally, this approach is quite accurate [18]. If fluid property variations are to be incorporated in the analys1s, the governing equations and the results obtained would need to be sultably 
modified. However, it was numerically found to be a small effect for the experimental range of temperature difference considered for the wall flow.

In actual practice, the boundary layer is laminar near the leading edge, undergoes transition downstream and eventually attains fully-developed turbulence, as shown in Fig. 14. This problem is obviously a complicated one and a detailed study becomes quite involved [37]. One may assume laminar flow up to a certain point, followed by turbulent flow downstream. This implies a step change from laminar to turbulent flow and is an approximation of the actual circumstance. This requires a solution of the governing equations for turbulent flow, Eqns. (13) and (14), with inputs from the laminar flow which applies up to transition. A numerical solution, employing the Runge-Kutta method, was obtained. The values at the first step are obtained from the expressions for $\delta$ and $U$ given above and numerical solution of the equations yields the downstream values. For various values chosen for the Grashof number $\mathrm{Gr}_{\mathrm{c}}$ at which transition occurs, the numerical solution was obtained by matching the flow rate and the momentum across the transition location. Fig. 15 shows the flow rate in $\mathrm{kg} / \mathrm{s}$ per $\mathrm{m}$ of the flow perimeter for various conditions. The results are shown mainly for $\Delta T=60^{\circ} \mathrm{C}$, a typical value obtained from Fig. 8. One case for $\Delta \mathrm{T}=30^{\circ} \mathrm{C}$ is also shown.

It is obvious from Fig. 15 that the boundary layer mass flow rate depends strongly on the transitional Grashof number. Many earlier studies have indicated the value of $\mathrm{Gr}_{\mathrm{c}}$ to be around $5 \times 10^{9}$. However, it can be as large as $10^{10}$ and as low as $10^{9}$, depending on the background disturbance. For a relatively quiescent compartment fire problem, the former value is expected to apply and for a disturbed one, the latter. For the upper zone, the flow is 
generally very disturbed and a fully-turbulent flow may be expected over much of the region. It is, therefore, clear that there is uncertainty regarding the onset of turbulence. The two extreme cases of laminar and completely turbulent flow may be considered and an average taken to represent the resulting values. This approach appears reasonable in terms of the results shown in Fig. 15. One needs to know the position of the interface so that the expressions for laminar and turbulent flow, given above, may be employed to obtain the flow rate, momentum and convected energy due to the wall flow. Let us consider the data of Fig. 8 and determine the upward lower region flow at the interface. From Fig. 8, the interface for a two-layer model may be taken at a height of $1.42 \mathrm{~m}$, for which the laminar solution gives a flow rate in the lower region at the interface height of $0.0121 \mathrm{~kg} / \mathrm{ms}$ and the turbulent one of $0.0225 \mathrm{~kg} / \mathrm{ms}$. The opening flow measured from this case was $0.424 \mathrm{~kg} / \mathrm{s}$. For a flow perimeter of about $10 \mathrm{~m}$, which applies for the experimental arrangement, the upward wall flow in the lower region ranges from $28.5 \%$ to $53 \%$ of the opening flow rate. An average of the two gives a value of $41 \%$, which indicates the level of Importance of the wall flow in this case. This average value of the upward flow at the interface was obtained as $42.5,39.4$ and $21.6 \%$ for test numbers 169,300 and 303 of Table 1.

A similar comparison of the estimated wall flows may be made with the corresponding fire plume flow rate. Following the model of Morton, Taylor and Turner [38] for a point heat source, the plume width $d$, centerline velocity $U_{C}$ and the centerline density difference $\Delta \rho_{c}$ may be obtalned in terms of the heat input $Q_{c}$ into the convective flow. The relevant expressions are:

$$
d=\frac{6 \alpha}{5} \mathrm{Z}
$$




$$
\begin{aligned}
& U_{c}=\frac{5}{6 \alpha}\left(\frac{9}{5} F \alpha\right)^{1 / 3} \mathrm{z}^{-1 / 3} \\
& \rho_{\infty}-\rho_{c}=\rho_{0} \frac{5 F}{6 \alpha \lambda^{2} g}\left(\frac{9}{5} \mathrm{~F} \alpha\right)^{-1 / 3} \mathrm{z}^{-5 / 3}
\end{aligned}
$$

where

$$
F=\frac{g\left(\lambda^{2}+1\right) Q_{c}}{\pi \rho_{0} T_{0} C_{p}}
$$

Here, the subscript o refers to the ambient conditions at the level of the heat source, $\alpha$ is the entrainment coefficient and $\lambda$ a constant that compares the spread of the thermal field with that of the velocity field in the plume. The radial velocity and density distributions at any height $z$ have been assumed to the Gaussian, 1.e.,

$$
u=U_{c} \exp \left(-r^{2} / d^{2}\right), \rho_{\infty}-\rho=\left(\rho_{\infty}-\rho_{c}\right) \exp \left(-r^{2} / \lambda^{2} d^{2}\right)
$$

The constants $\alpha$ and $\lambda$ may be taken as 0.1042 and 1.15 , as based on the work of Yokoi [39] and Zukoski et al. [15] and derived by Evans [40]. The numerical results from this model were also compared with the measurements of Mccaffrey [14], Indicating a fairly good agreement far from the source.

As measured by McCaffrey [41], about $20 \%$ of the input energy is lost as radiation for a methane flame. Employing this result to determine the convected energy $Q_{c}$, the flow rate in the fire plume was determined. Fig. 16 shows a comparison between the wall flow rate and the plume flow rate, as a function of the height $z$. For the experimental interface location at $1.42 \mathrm{~m}$, corresponding to the data of Fig. 8, the fractional strength of the wall flow 
varies from $27.5 \%$ in laminar flow to $51 \%$ in fully turbulent flow, giving an average value of $39.3 \%$. At two values of $\mathrm{Gr}_{c}$, the corresponding results are also shown in Fig. 16. The relative significance of the wall flow increases as the interface height decreases, indicating the dominant effect of a decrease in entrainment height on the plume flow rate. These results are shown for $Q=63.2 \mathrm{~kW}$, at the conditions of Fig. 8, and the interface height obtained is around $1.42 \mathrm{~m}$. It is, therefore, seen that a significant flow rate, as compared to the flow in the fire plume and to that through the opening, is generated adjacent to the walls. If this flow penetrates into the upper layer from below or the lower layer from the upper region, it conveys air and gases across the interface. This implies a transport of mass and energy from one layer to the other and should be included with other mechanisms of transport across the interface. The next step in our consideration of the wall flows is a study of the penetration of these flows across the interface. We need to determine if the flows do penetrate, under what conditions they do so and what the magnitude of the penetrating flow is. These questions are considered in detail in the next section.

\section{WALL FLOW PENETRATION ACROSS THE INTERFACE}

\subsection{Flow in Stratified and Negatively-Buoyant Situations}

As mentioned in the preceding section and as seen in Fig. 13(c), the wall flow rising in the lower region, or descending in the upper region, encounters a stably stratifled region before it emerges in another 1sothermal region where it is negatively buoyant. In fact, the flow is buoyant as it inftially enters the stratifled region, between the upper and lower isothermal regions, 
and as it moves downstream, its buoyancy decreases, becomes zero and then negative. Some flow may be shed in this region and the flow that does penetrate into the isothermal region would turn back after attaining a certain helght of penetration. For the idealized two-layer system of Fig. 13(b), the stratified region is of zero thickness and a step change in temperature is assumed. This implies a negatively buoyant flow as the flow moves from one layer to the other. Both these circumstances are considered here, the actual or the three-layer profile being of interest when experimental data are available on the profiles and the two-layer system being applicable to the zonemodeling studies. The two are obviously interrelated and the ultimate focus for modeling purposes is on the two-layer approximation.

Let us first consider the three-zone system of Fig. 13(c), which involves a linearly stratified region of height $\mathrm{L}_{2}$ lying between a lower isothermal region of height $L_{1}$, and an upper isothermal region of height $L-L_{1}-L_{2}$, where $L$ is the total height of the enclosure. Interest lies in studying the flow through this stratified region and then considering the situation as $\mathrm{L}_{2} \rightarrow 0$, the limiting case being the two-layer zone model of Fig. 13(b). This is clearly a very complex flow situation and boundary layer approximations will not apply when reverse flow or shedding occurs. A proper approach would be to consider the full governing partial differential equations and obtain the velocity and temperature fields numerically, employing various finite difference or finite element methods available. However, that would require a considerable effort. Approximate results may be obtained by employing integral methods, as outlined earlier. The relevant information on the profiles and other boundary layer variables may be obtained from earlier exact analysis of the boundary layer flow. This is the approach considered here. 
The natural convection flow over a heated surface immersed in a stablystratified medium has been considered by several investigators [42-45]. The problem has been treated in these studies as a boundary layer flow, with the ambient and surface temperatures varying as specified. The linear ambient temperature variation for an isothermal surface is of considerable practical interest and has received much of the attention in 1iterature. It can be seen from these studies that the velocity and the temperature distributions are similar in form to those for an isothermal medium over the considered parametric range. The temperature in the outer region of the flow has been found to be less than the local ambient temperature and this temperature defect has been observed to be on the order of $5 \%$ of the overall temperature difference across the flow. If this effect is neglected, which is justified when the parametric range of condition in the present work is compared with that of Ref. [43], the velocity and temperature distributions may be taken as:

$$
u=U \frac{y}{\delta}\left(1-\frac{y}{\delta}\right)^{2}, T-T_{g}=\left(T_{w}-T_{g}\right)\left(1-\frac{y}{\delta}\right)^{2}
$$

for laminar flow and, similarly, Eqn. (12) for turbulent flow. The above assumption clearly constrains the temperature variation in the flow, though the profiles have been found to be satisfactory for an unstratified medium. The variation of the gas temerature with height is numerically treated as steps of isothermal regions as is customary in a finite difference approximation. The solution of the governing momentum and energy equations, Eqns. (5) and (6) or Eqns. (13) and (14), is obtained numerically with these step changes. This procedure is often employed, with good success, with the moving boundary heat transfer problems. 


\subsection{Penetration in a Three-Layer System}

The laminar results for the mass flow rate per unit perimeter, $\dot{m}$, and for the momentum flow rate, $M$, are shown in Fig. 17. Here, $L_{1}$ is taken at a typical value of $1.2 \mathrm{~m}$ and $\mathrm{L}_{2}$ at $0.4 \mathrm{~m}$. Results for the unstratified, or isotherma 1 , ambient medium case are shown at $\mathrm{T}_{\mathrm{g}, 1}$. The temperature difference, $\mathrm{T}_{\mathrm{w}, 1}-\mathrm{T}_{\mathrm{g}, 1}$, is taken as $60^{\circ} \mathrm{C}$. The governing equations are first solved until the momentum and, hence, the flow becomes zero. This is shown as the boundary layer solution in Fig. 17 and is similar to the treatment for negatively buoyant plumes by Morton [21]. The flow continues to increase because of entrainment and the momentum decreases because of buoyancy, after an initial increase, since $\mathrm{T}_{\mathrm{w}}>\mathrm{T}_{\mathrm{g}}$ up to the point of crossover, beyond which $\mathrm{T}_{\mathrm{w}}<\mathrm{T}_{\mathrm{g}}$. Beyond a height of $\left(\mathrm{L}_{1}+\mathrm{L}_{2}\right),\left(\mathrm{T}_{\mathrm{g}}-\mathrm{T}_{\mathrm{w}}\right)$ is constant and taken as $57^{\circ} \mathrm{C}$. All the values employed here are typical values taken from the experimental results of Fig. 8. Therefore, the flow increases due to entrainment, while the momentum decreases sharply. Ultimately, the momentum becomes zero and the flow turns horizontally.

Obviously, the boundary layer treatment of the flow is not physically realistic. As pointed out in Ref. [46], shedding of the flow from the boundary layer must start before the stagnation point (beyond which no flow penetrates) is reached. The temperature of this shed flow is not known. But it will be cooler than the local ambient and would fall downwards. A vertically rising flow adjacent to the wall and a descending flow outside the rising flow region are expected to arise $[20,22]$. This is a complex nonboundary layer phenomenon, which requires a much more elaborate treatment than that outlined above. However, in order to approximate the flow and obtain 
estimates of the flow and momentum in this region, some further assumptions and approximations may be made. The validity of these assumptions can be ascertained by detailed experimentation or by an exact solution, analytical or numerical, of the governing elliptic partial differential equations.

An assumption is made regarding the variation of the boundary layer thickness $\delta$ in the region of negative buoyancy where $T_{w}$ becomes less than $\mathrm{T}_{\mathrm{g}}$. It is assumed that $\delta$ varies as $\mathrm{z}^{\mathrm{n}}$, where $\mathrm{n}$ is a constant. For the laminar boundary layer flow, it can be shown analytically that $n=0.25$ and for the turbulent flow, $n=0.7$ [18]. A Froude number dependence, based on local velocity and temperature levels, may also be employed [46], though that would also be arbitrary. With this assumption, the momentum decrease beyond the point where $T_{W}=T_{g}$ may be determined. The integral equation is:

$$
\frac{d}{d Z}\left[\int_{0}^{\delta} u^{2} d y\right]=g \beta \int_{0}^{\delta}\left(T-T_{\infty}\right) d y-\nu\left(\frac{\partial u}{\partial y}\right)_{0}
$$

This gives Eqn. (5) with the assumed profiles, which obviously do not take the shear due to the reversing shed flow into account. However, as seen for recirculating flow in enclosures [18], the reverse flow and the wall flow are generally separated by a relatively stagnant fluid. The flow shed from the wall flow may then be obtained from the assumed $\delta$ variation and the computed upward moment um. The temperature of the outflowing fluid, if needed, may be obtained from the integral energy equation. While several objections may be raised against this assumption, it is probably consistent with the approximate nature of this analysis and a much more elaborate analysis will be needed to consider the shed flow, its descent towards the interface and 1 ts consequent effect on the wall flow [47]. 
Fig. 17 shows the flow rate and the momentum flow rate at three values of $\mathrm{n}$. As $\mathrm{n}$ increases, the results approach that of the boundary layer analysis that gives an increasing flow which is finally turned horizontally when momentum becomes zero. The basic trends are similar and the $n=0.25$ case is simply the upstream boundary layer variation. It is this case which is considered in greater detail later because it is a more realistic variation [46]. For $n=0$, the boundary layer thickness remains constant after $T_{w}$ becomes less than $\mathrm{T}_{\mathrm{g}}$. For all these values of $\mathrm{n}$, the flow decreases along with the momentum, as may be realistically expected in a stratified flow. Fig. 18 shows the momentum flow rate at various values of $L_{1}$, the other variables being kept unaltered from those of Fig. 17. The downward flow momentum is also shown. The point where the two momenta are equal is predicted to be the separation point from the wall. Therefore, if the upward flow is stronger at the interface, the flow penetrates into the upper layer. Otherwise the downward flow mixes with the lower layer. The turning of the flow away from the wall would obviously occur upstream of the separation point. This distance may be expected to be of the order of the boundary layer thickness [48] and an estimate of the temperature and flow rate of the turned flow may be determined by considering a small control volume in the neighborhood of the separation point. It can be easily shown that the shed flow would be negatively buoyant and will flow towards the interface. In fact, if its temperature, which lies between $T_{w}$ and $T_{g}$, is assumed, the governing momentum and energy equations may be solved to yield results quite similar to those obtained with the above treatment.

The results for a fully turbulent wall flow were also obtained and Fig. 19 shows the variation of momentum for several values of $L_{1}$ and also for the 
downflow, thereby indicating the separation point. Fig. 20 shows the corresponding flow rates. The turbulent results are shown for $\mathrm{n}=0.7$, which applies for a turbulent boundary layer. Fig. 21 shows the dependence of the height of the separation point on $\mathrm{L}_{1}$. The results are quite similar for laminar and turbulent flow and the height of penetration, beyond $\mathrm{L}_{1}$, may be determined from these results.

Fig. 22 shows the dependence of penetration on both $\mathrm{L}_{1}$ and $\mathrm{L}_{2}$, the height of the stratified region. The temperature differences of Fig. 8 are employed. The results are shown at $\mathrm{L}_{1}=0.8,1.0$ and $1.2 \mathrm{~m}$. For the first value of $\mathrm{L}_{1}$, curves for $\mathrm{L}_{2}=0.2$ and $0.3 \mathrm{~m}$ are shown. For the second value of $\mathrm{L}_{1}$, results are shown for $\mathrm{L}_{2}=0.2 \mathrm{~m}$. For the last case, results are shown at $\mathrm{L}_{2}=0.1$, $0.2,0.4,0.5$ and $0.6 \mathrm{~m}$. This is an important consideration since $\mathrm{L}_{2}+0$ for the two-layer model and $1 t$ is desirable to determine the results that apply for that idealized case. In Fig. 22, the upward momentum is shown in solid lines and the downward momentum in broken lines. It is seen that, in all cases, the flow initially increases and then decreases as the flow becomes negatively buoyant. The computed momentum at the top of the stratified region is found to decrease as $\mathrm{L}_{2}$ increases. A similar trend is found for the flow rate, though the inaccuracy of the numerical results increases as $L_{2}$ decreases. However, the results indicate that as $\mathrm{L}_{2}+0$, the flow momentum change across the stratified region becomes smaller. Fig. 23 shows the height of the separation point at two values of $L_{1}$ for various values of $L_{2}$. A stronger effect is seen at the smaller $\mathrm{L}_{1}$, since the flow in the lower layer is weaker and the downward flow may penetrate into the lower layer instead. Fig. 24 shows $\dot{m}$ and $M$ at the top of the stratified layer for various values of $\mathrm{L}_{2}$ at $\mathrm{L}_{1}=1.2 \mathrm{~m}$. It is interesting to note that $M$ decreases gradually with 


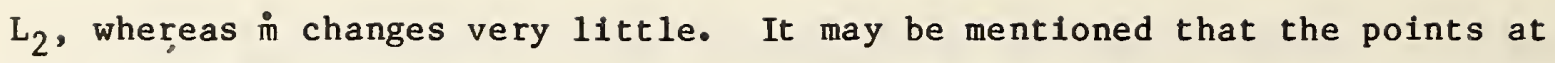
$\mathrm{L}_{2}=0$ obtained by extrapolation give an increase in $\dot{m}$ and $M$ of 5 and $4 \%$, respectively, over the corresponding values just below the stratified region.

The above result is an interesting one since it implies a small change in $\dot{m}$ and $M$ across a stratified region whose thickness goes to zero, $1 . e .$, for a step change. However, it must be remembered that the numerical results are not very accurate at small values of $\mathrm{L}_{2}$ and such an extrapolation may not be valid. Still, it points out a few interesting features which may be employed for the simulation of a two-layer mode 1 , as discussed below.

\subsection{Penetration in a Two-Layer System}

We may now consider flow penetration in a two-zone system, such as the one shown in Fig. 13(b). As the wall flow from below crosses the interface, it is subjected to a step change in the ambient temperature. Under the action of the strong buoyancy forces and the large temperature gradients that arise across the flow, the temperature profile will adjust in a very short distance to attain the wall temperature, $T_{w, u}$, at $y=0$ and the ambient temperature, $\mathrm{T}_{\mathrm{g}, \mathrm{u}}$, at $\mathrm{y}=\delta$. In actual practice, of course, there is a finite region over which this adjustment occurs and a three-layer model, as discussed above, may be employed to consider the adjustment. As suggested by Fig. 24, $\dot{m}$ and M may be taken as unchanged while $\mathrm{T}_{\infty}$ changes from $\mathrm{T}_{\mathrm{g}, 1}$ to $\mathrm{T}_{\mathrm{g}, \mathrm{u}}$. This temperature change implies a considerable energy flux into the flow due to convective flow and diffusion. This can be achieved by a substantial amount of mixing at the interface, as observed in the experiments, which raises the temperature in the flow to the resulting profile. Such a mixing process will obviously lead to a 
finite amount of entrainment into the flow, which being negatively-buoyant is expected to shed flow further downstream. In view of the disturbed nature of this penetration, an analytical or experimental study of the flow in the region of the interface is very desirable. If the entire increase in convected energy $q$ is assumed to come from entrainment, a step change in $\dot{m}$ occurs along with that in $q$, contrary to what is observed for a finite stratified region. Since there are shear and buoyancy forces, M will change downstream, though right across the interface it may be taken as unchanged. For the results presented here for the step change in $T_{g}$, $\dot{m}$ and $M$ are taken as unchanged across the interface and $q$ obviously changes. A more realistic approximation would be a change in $\dot{m}$ along with $q$. But more information on the mixing process is needed for a satisfactory model. Due to large temperature gradients across the flow, a substantial amount of energy transfer also occurs due to convective transport mechanisms.

Fig. 25 shows the mass flow rate, $\dot{m}$, and the momentum flow rate, $M$, per unit perimeter for laminar flow. Two values of $n$, along with the boundary layer analysis results are shown. The separation point may be determined by employing the upward flow momentum, as before. Fig. 26 shows the results for turbulent flow. Fig. 27 shows the penetration distance $\delta_{p}$ as a function of the interface height $z_{1}$ with and without opposing flow for the turbulent case. A considerable difference between the two is seen. Without the opposing stream, the flow always penetrates, with $\delta_{p}$ becoming smaller as the interface height $Z_{1}$ becomes smaller. But with opposing flow, the penetration is restricted. For $\mathrm{Z}_{i} \leqslant 0.9 \mathrm{~m}$, the flow from the upper layer penetrates into the lower layer. Also note that at large $Z_{i}(>1.6 \mathrm{~m})$, the flow from below does not stagnate at any height, but ultimately hits the ceiling whose helght is $2.18 \mathrm{~m}$ in this case. 


\subsection{Concluding Remarks on Penetration}

It is seen that the penetration of the wall flow from one isothermal layer into another at a different temperature is a very involved process. The penetration depends on the temperature profile and the opposing flow that arises in the other layer. The flow separates from the wall when the two opposing streams have equal momentum. The flow turns away from the wall and descends or rises towards the interface since it is negatively buoyant. A considerable amount of mixing occurs in this region and flow stability considerations are important. The actual profiles may be considered for experimental results and a two-zone idealized profile for zone modeling. In two-layer consideration, a computation of the momentum for the two streams indicates which zone the flow enters and gets mixed with the fluid there, conveying mass and energy. For the actual profiles, a three-layer system may be considered and the location of the separation point determined. The corresponding interface relevant to a two-zone idealization may be located as outlined by Steckler [10] and also confirmed from some of the results in this study. The flow rates and the energy transported across the interface may be determined in order to provide inputs into the zone models.

\section{FLOW OF FIRE PLUME ACROSS THE INTERFACE}

In order to further study the basic mechanisms underlying flow penetration from one isothermal layer into the other, some consideration is given to the flow of the fire plume across the interface. The plume is generally buoyant with respect to the upper layer, unless the heat input is reduced after the layers are established by a higher energy input source. The wall 
flow, on the other hand, is negatively buoyant as it crosses the interface. The temperature and velocity levels in the wall flow are also much lower than those encountered for the corresponding fire plume, though the much larger flow perimeter makes the flow rate in the wall boundary layer comparable to that in the plume, as seen earlier. These differences in characteristics may be expected to lead to differences in the penetration across the interface. The wall flow generally penetrates a given distance and then turns back, whereas the plume would penetrate and flow in the upper layer at a reduced buoyancy level because of the higher gas temperature there.

Some of the relevant aspects may be considered in terms of Fig. 28. As the plume enters the upper layer, the gas temperature rises sharply. As a result, some portion of the flow is buoyant and some negatively buoyant, with respect to the upper layer temperature. The buoyancy flux in the flow is the convected thermal energy $q$, given by Eqn. (2). Therefore, the net buoyancy of the flow with respect to the upper layer temperature $\mathrm{T}_{\mathrm{g}, \mathrm{u}}$ is given by:

$$
q=\int_{0}^{\delta} \rho C_{p} u\left(T-T_{g, u}\right) d y
$$

This quantity may be negative, zero or positive. As pointed out by cooper [49], a negative buoyancy leads to a finite penetration height, zero buoyancy to a nonbuoyant jet and a positive buoyancy to a flow which penetrates and rises as a buoyant plume. Note that any entrainment into the flow in the upper layer does not alter $q$, since the entering fluid is at temperature $\mathrm{T}_{\mathrm{g}, \mathrm{u}^{*}}$ The wall flows considered earlier are clearly negat 1 vely buoyant and have a finite penetration distance, whereas the plumes, in the context of the present work, would be positively buoyant. 
As the fire plume enters the upper layer from below, its buoyancy, with respect to the local environment, is reduced, since $\mathrm{T}_{\mathrm{g}, \mathrm{u}}$ is $\operatorname{larger}$ than $\mathrm{T}_{\mathrm{g}, 1}$. Consequently, the outer regions of the plume become negatively buoyant, causing flow there to stagnate and reverse, as shown qualitatively in Fig. 28(b). This implies that some flow may be shed at the interface and further entrainment of the upper layer gas occurs as the plume moves downstream. Since in actual practice, there is always a finite region over which such changes occur, one may think of a region of adjustment over which $\dot{m}, M$ and $q$ change, while the temperature profile becomes consistent with the changed value of $T_{\infty}$, as shown in Fig. $28(\mathrm{c})$. However, the changes in temperature do occur over a very short distance and an idealization of a two-zone model is appropriate in most cases. This implies a step change in $T_{\infty}$, which results in a step change in temperature in the outer region of the plume. These large temperature gradients lead to large energy transport rates, due to conduction as well as ambient fluid entrainment, leading to a smoothening of the profiles, so that an esentially Gaussian profile is obtained further downstream. The nature and height of this region of adjustment are not known in detail. For a three-layer model, the intermediate layer allows a consideration of these adjustments, whereas in a two-layer mode1, one assumes an Immediate adjustment, followed by the plume flow in the 1sothermal upper region.

A simple model, based on the dynamics of the fluid elements that constitute the flow, is first considered. If one considers the fluid at any given location in the flow, just below the interface, one could determine its vertical velocity and temperature. This fluid element is exposed to an increasing temperature in the stratified zone of height $\mathrm{L}_{2}$, where the two- 
layer model is obtained for $\mathrm{L}_{2} \rightarrow 0$, until it emerges in the upper zone at temperature $\mathrm{T}_{\mathrm{g}, \mathrm{u}^{*}}$ Neglecting viscous effects, a balance between the kinetic and potential energy leads to:

$$
\frac{d}{d x}\left(\frac{u^{2}}{2}\right)=g B\left(T-T_{\infty}\right)
$$

or,

$$
u^{2}=u_{0}^{2}+\int_{0}^{x} 2 g B\left(T-T_{\infty}\right) d x
$$

where $\mathrm{x}$ is the vertical distance above the isothermal lower region of height $L_{1}$, $u_{0}$ is the local velocity just below this height, $u$ the velocity at height $x$ for the given fluid element, $T$ the temperature and $T_{\infty}$ the local ambient temperature. Thus, if $\mathrm{T}$ is assumed unchanged over the stratified layer, or a chosen region of adjustment, a step change in temperature, from $T_{g, 1}$ to $T_{g, u}$, exists at the edge of the flow. This is the maximum temperature defect that could arise, where the temperature defect $D_{T}$ is the amount by which the smallest temperature in the flow is less than the gas temperature at the same height, as outlined earlier in Section 5.1. One may also consider a defect which varies from zero at $\mathrm{Z}=\mathrm{L}_{1}+\mathrm{L}_{2}$, with a parabolic variation and a maximum value $\mathrm{D}_{\mathrm{T}}$ at mid-height. For the wall flow, $\mathrm{D}_{\mathrm{T}}$ was taken as zero, because of analytical work done earlier on the flow that indicated that the temperature in the outer region of the boundary layer flow was only slightly less than the local ambient temperature, giving a temerature defect of less than $5 \%$ of the total temperature difference in the flow. For a plume, it has been seen to be higher [45], though still on $1 \mathrm{y}$ a few percent of the total temperature difference. We shall consider a range of values for $\mathrm{D}_{\mathrm{T}}$ and deter- 
mine its effect on penetration. This is, obviously, an approximate model for penetration and is used only to study the effects qualitatively.

The above model was first used for the wall flow rising from below and penetrating into the upper layer, with no temperature defect, that is, the assumed profiles of Eqn. (4) or Eqn. (12), for laminar or turbulent flow, respectively. Fig. 29 shows the results obtained. The trends observed are similar to those obtained from the integral analysis given earlier. A viscous model was also considered by including the viscous force $\nu \frac{\partial^{2} u}{\partial y^{2}}$ along with the buoyancy force. The corresponding results are shown in Fig. 29 and it is seen that the integral results lie within the inviscid and viscous models, lending support to the basic features obtained by such a simplistic mode1. Fig. 30 shows the velocity profiles as the flow penetrates and the lowering of the maximum velocity and stagnation at the two ends propagating inwards is seen. The viscous model constrains the outer region and an outward shift in the profiles arises. This figure indicates the physical nature of the penetration process. It must be noted that, though not shown here, the flow in the outer region of the wall flow reverses under the action of the negative buoyancy.

Figs. 31 and 32 show the results for a fire plume, employing the inviscid mode1, which is more appropriate due to the absence of the constraining wall of the earlier case. The three layer profile from Fig. 8 is employed and the observed results indicate the physical processes involved in peeling of $f$ of the flow as it penetrates into the upper zone. It is seen that the flow rate initially increases and then decreases in the stratified region, as seen earlier for wall flows. The flow rate increases as the plume emerges into the upper layer. These effects are more significant at larger interface heights 
where the flows are weaker. Fig. 31 is drawn for the maximum temperature defect, so that the negative buoyancy effect is the strongest. F1g. 32 shows the results for various $\mathrm{D}_{\mathrm{T}}$ and it is seen that a decrease in flow rate occurs only for large $\mathrm{D}_{\mathrm{T}}$. It is, therefore, seen that, depending on the interface helght, the flow rate decreases in the stratified layer due to negative buoyancy in the outer region of the flow. The model gives an order of magnitude value of this flow. For high interfaces, which arise for large door openings [11], this effect is large and needs to be accounted for. For low interfaces, under the same conditions, the effect may be neglected. The results presented here give a qualitative picture of the processes involved. Though $\mathrm{D}_{\mathrm{T}}$ is not known and can only be determined by a detailed analysis, a defect of $5-10 \%$ of the total change in $\mathrm{T}_{\mathrm{g}}$ is a reasonable approximation. At this level of $\mathrm{D}_{\mathrm{T}}$, the amount of fluid peeled off is small and may, therefore, be neglected, as a first-order approximation.

In view of the above qualitative picture and the earlier results on wall flows, it is now possible to consider the plume flow across a two layer interface. The flow momentum changes because of the forces acting over a finite distance. Since a step change is considered, momentum remains unaltered Immediately above the interface. The temperature profile is assumed to adjust to the new ambient temperature immediately. This implies a considerable inflow of energy and a lowering of the buoyancy with respect to the upper layer temerature, from that obtained with respect to the lower layer temperature. This inflow of energy occurs due to conduction and mass inflow, arising from large temperature differences. For a step change in the profile, a mass inflow may be included. But as a first approximation, in view of the results presented, it may be taken as unaltered. The governing equations from which the results presented in Eqns. (21-24) are obta1ned are: 


$$
\begin{aligned}
& \frac{d}{d Z}\left(d^{2} u\right)=2 d \alpha u \\
& \frac{d}{d Z}\left(d^{2} u^{2}\right)=2 \lambda^{2} d^{2} g\left(\rho_{\infty}-\rho_{c}\right) / \rho_{0} \\
& \frac{d}{d Z}\left[d^{2} u\left(\rho_{\infty}-\rho_{c}\right)\right]=0
\end{aligned}
$$

These equations may be solved analytically or numerically.

F1g. 33 presents the centerline temperature and velocity, with the above model. At the interface, only the temperature profiles change to accommodate the change in $T_{\infty}$. The rest of the variables remain unchanged, so that mind $M$ are unaltered. The above equations are then solved numerically beyond the interface with the new temperature distribution. As displayed in F1g. 33, the centerline temperature $T_{c}$ varies as $\mathrm{z}^{-5 / 3}$ and the velocity $U_{c}$ as $\mathrm{Z}^{-1 / 3}$ up to the interface. Beyond the interface, the reduced buoyancy leads to a more gradual change in $T_{c}$ and a more rapid decay in $U_{c}$, as expected. The observed trends are quite similar to those shown in Ref. [40]. There is no step change in $U_{c}$ and $T_{c}$, as physically expected. For a lower interface, the downstream temperature decrease is more pronounced, since the buoyancy in the upper region is higher than that for higher interfaces, with the other conditions kept the same. The flow rate continues to increase beyond the interface due to continued entrainment and the momentum also increases at a decreased rate, due to lowered buoyancy.

It is evident from the above discussion that the penetration of the wall flows, as well as of the plume flow, across a sharp amblent temperature change is a fairly complex phenomenon. It is not a boundary layer effect, since 
stagnation and flow reversals may arise. Some simple analytical models are considered in order to study the basic features of the flow. The results obtained are physically realistic and some quantitative information is also obtained. Though several aspects need detalled further effort, some of the major considerations and conclusions may be outlined. Let us first consider the relevance of these effects in zone-modeling and in experimental studies of enclosure fires.

\section{ESTIMATION OF WALL FLOW EFFECTS}

Let us consider the two-layer zone model for the circumstance shown in Fig. 1. In addition to the flow rates shown, let us denote the total wall flow rate by $\dot{\mathrm{m}}_{w}$, the plume flow rate that crosses the interface by $\dot{\mathrm{m}}_{\mathrm{p}}$, and the plume flow that is peeled of $f$ and is unable to penetrate by $\dot{m}_{p}^{\prime}$. For steady state conditions in a lower layer control volume that excludes the fire plume, a mass balance gives:

$$
\dot{\mathrm{m}}_{f}+\dot{\mathrm{m}}_{\mathrm{a}}+\dot{\mathrm{m}}_{\mathrm{j}}=\dot{\mathrm{m}}_{\mathrm{p}}+\dot{\mathrm{m}}_{\mathrm{w}}
$$

where $\dot{m}_{f}$ is the mass flow rate of the fuel. Therefore,

$$
\dot{\mathrm{m}}_{\mathrm{p}}=\dot{\mathrm{m}}_{\mathrm{a}}+\dot{\mathrm{m}}_{j}+\dot{\mathrm{m}}_{\mathrm{f}}-\dot{\mathrm{m}}_{\mathrm{w}}
$$

Als o,

$$
\dot{\mathrm{m}}_{\mathrm{e}}=\dot{\mathrm{m}}_{\mathrm{p}}+\dot{\mathrm{m}}_{\mathrm{p}}^{\prime}
$$


This gives the plume flow entering the upper layer, normalized by the flow through the opening, as:

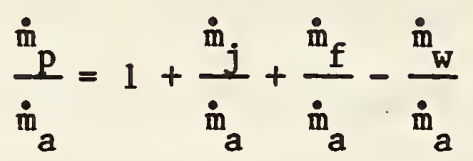

and the rate of entrainment over height $\mathrm{Z}_{1}$ as:

$$
\frac{\dot{\mathrm{m}}_{\mathrm{e}}}{\dot{\mathrm{m}}_{\mathrm{a}}}=1+\frac{\dot{\mathrm{m}}_{\mathrm{j}}}{\dot{\mathrm{m}}_{\mathrm{a}}}+\frac{\dot{\mathrm{m}}_{\mathrm{f}}}{\dot{\mathrm{m}}_{\mathrm{a}}}-\frac{\dot{\mathrm{m}}_{\mathrm{w}}}{\dot{\mathrm{m}}_{\mathrm{a}}}+\frac{\dot{\mathrm{m}}_{\mathrm{p}}^{\prime}}{\dot{\mathrm{m}}_{\mathrm{a}}}
$$

A comparison between the theoretical models of Refs. $[6,15,39]$ and experimentation is made in terms of the fire plume entrainment. For a wind-blown plume, there would be an increase in the entrainment and that additional effect must also be considered when a comparison with the results from a theoretical model for a free standing plume is belng made [17].

It has been shown that, in a three layer system, some of the plume flow is shed in the intermediate stratifled region. However, the effect is not large for the range of physical variables considered here and, for the twolayer approximation, the flow rate may be assumed to remain essentially unaltered. The fuel flow rate is generally much smaller than the opening flow rate. Neglecting these two quantities, the rate of entrainment becomes

$$
\frac{\dot{\mathrm{m}}_{\mathrm{e}}}{\dot{\mathrm{m}}_{\mathrm{a}}}=1+\frac{\dot{\mathrm{m}}_{\mathrm{j}}}{\dot{\mathrm{m}}_{\mathrm{a}}}-\frac{\dot{\mathrm{m}}_{\mathrm{w}}}{\dot{\mathrm{m}}_{\mathrm{a}}}
$$

The air flow rate may be measured experimentally with good accuracy $[10,11]$. If we consider an energy balance for the lower layer, the energy input into the plume flow at the source and into the wall flow is conveyed to the upper 
layer, unless a significant amount of these flows peel off and get mixed with the lower layer, this being a negligible effect according to the results obtained here. Thus, the energy balance gives:

$$
\dot{\mathrm{m}}_{\mathrm{a}}\left(\mathrm{T}_{\mathrm{g}, 1}-\mathrm{T}_{\mathrm{o}}\right)=\dot{\mathrm{m}}_{\mathrm{j}}\left(\mathrm{T}_{\mathrm{g}, \mathrm{u}}-\mathrm{T}_{\mathrm{g}, 1}\right)+\frac{\mathrm{Q}_{f}}{\mathrm{C}_{\mathrm{p}}}
$$

where $T_{0}$ is the outside air temerature and $Q_{f}$ is the heat transfer between the floor and the gas. It may be estimated as

$$
Q_{f}=h A\left(T_{f}-T_{g, l}\right)
$$

where $h$ is the convective heat transfer coefficient, A the floor area, and $T_{f}$ the floor temperature, which is greater than the gas temerature in the lower layer. If $Q_{f}$ is neglected, an upper bound for $\dot{m}_{j}$ is obtained as:

$$
\left(\dot{m}_{f}\right)_{\max }=\left(\frac{T_{g, 1}-T_{0}}{T_{g, u}-T_{g, 1}}\right) \dot{m}_{a}
$$

If $T_{f}$ is measured, available heat transfer correlations [18] may be employed to determine $\dot{\mathrm{m}}_{\mathrm{j}}$ more accurately. As discussed in Refs. $[10,11], \dot{\mathrm{m}}_{\mathrm{j}} / \dot{\mathrm{m}}_{\mathrm{a}}$ increases as the door opening is decreased. It must be noted that if the wall flow from the upper layer penetrates into the lower layer, the energy added to the lower layer due to this flow and that due to heat transfer from the lower wall should be included in Eqn. (40) for greater accuracy.

Therefore, the wall flow rate enters into the calculation for $\dot{m}_{e}$. As has been shown earlier, this flow is quite significant as compared to the flow through the opening $\dot{\mathrm{m}}_{\mathbf{a}}$. A comparison between the two may be made by consid- 
ering the results shown in Fig. 15 for $\mathrm{T}_{\mathrm{w}, 1}-\mathrm{T}_{\mathrm{g}, 1}=60^{\circ} \mathrm{C}$ and $30^{\circ} \mathrm{C}$, along with those presented in Table 1 . It is therefore, evident that the estimated value of $\stackrel{\circ}{\mathrm{m}}_{e}$, obtained from the measured value of $\dot{\mathrm{m}}_{a}$, is reduced by $20-40 \%$ by considering the wall flow. This additional consideration could, thus, lead to a better agreement between the theoretical and experimental predictions of the plume entrainment.

The wall flows not only transport mass across the interface, they also lead to an energy transfer. The energy transfer for a two-layer system is given by:

$$
q_{w}=P q=P \int_{0}^{\delta} \rho C_{p} u\left(T-T_{g, 1}\right) d y=\frac{P p \delta U C}{30}\left(T_{w, 1}-T_{g, 1}\right) \text {, for laminar flow, }
$$

and,

$$
=0.0366 P p \delta U C_{p}\left(T_{w, 1} T_{g, 1}\right) \text {, for turbulent flow }
$$

where the physical variables $\delta$ and $U$ are determined in the lower layer just below the interface and $P$ is the perimeter of the wall flow. The perimeter $P$ is the horizontal perimeter of the room minus the door width. Similarly the mass flow rate due to the wall flow is:

$$
\begin{aligned}
\dot{\mathrm{m}}_{\mathrm{w}}=\mathrm{Pm}=\mathrm{P} \int_{0}^{\delta} \rho \mathrm{udy} & =\mathrm{Pp} \delta \mathrm{U} / 12 \text {, for laminar flow, and } \\
& =0.1463 \mathrm{Pp} \delta \mathrm{U}, \text { for turbulent flow }
\end{aligned}
$$


The variables $\delta$ and $U$ are determined from Eqns. (7) and (8) for laminar flow and Eqns. (15) and (16) for fully turbulent flow. As explained in Section 4, the governing equations may be solved with the transition Grashof number $\mathrm{Gr}_{\mathrm{c}} \approx 5 \times 10^{9}$ to obtain these variables, or an average from the 1 aminar and fully-turbulent analyses may be employed as an approximation. The above mass and energy transported across the interface must, therefore, be included in the mass and energy balance equations for the two layers. The energy transport is relatively small compared to the energy input into the upper layer due to the plume because of the much larger temperature levels in the latter case. The energy transfer across the interface due to the fire plume is $Q_{c}$, which is the total energy input minus the radiative loss from the fire.

It must be noted that the wall flow $\dot{\mathrm{m}}_{\mathrm{w}}$ may be positive or negative, depending on the wall and gas temperature levels and the location of the interface. If the downward flow momentum is larger than the upward flow momentum, the flow penetrates from the upper layer into the lower layer and mixes with the fluid there. If the upward flow is stronger, it penetrates into the upper layer, as considered above. The flow moment un is given by:

$$
\begin{aligned}
& M_{W}=P M=P \int_{0}^{\delta} \rho u^{2} d y=P p \delta U^{2} / 105 \text {, for laminar flow, and } \\
& =0.0523 \mathrm{PD} \delta \mathrm{U}^{2} \text {, for turbulent flow }
\end{aligned}
$$

If the downward flow momentum in the upper zone, $\left(M_{w}\right)_{u}$, is much larger than the upward flow momentum in the lowe $r$ zone, $\left(M_{w}\right)_{1}$, both being calculated at the interface height $z_{i}, 1 . e .,\left(M_{w}\right)_{u} \gg\left(M_{w}\right)_{1}$, the flow penetrates 1nto the lower zone from the upper one. Similarly, the flow penetrates into the upper 
zone if $\left(M_{w}\right)_{u} \ll\left(M_{w}\right)_{1}$. Thus, $\stackrel{m}{w}_{w}$ is negative in the first case and positive in the other. It is difficult to predict penetration when $\left(\mathrm{M}_{\mathrm{W}}\right)_{\mathrm{u}} \approx\left(\mathrm{M}_{\mathrm{W}}\right)_{1^{*}}$ The penetrative flow under consideration is a stability problem and a considerable disturbance is expected in the region where the flow turns away from the wal1. When the difference between the two flow momenta is large, this disturbed region is well within one of the zones. But when the two are close in magnitude, it is very difficult to predict the penetrative flows for the two zones. However, some conjectures may be made, a detailed analysis being beyond the scope of the present work.

As mentioned earlier, the interaction region in which the flow turns is expected to be of order $\delta$. If the separation point, as determined from the analysis of Section 5 is farther than distance $\delta$ from the interface, a complete penetration into that zone may be assumed, since the turning region is beyond the interface. If it is less than $\delta$, a proportional distribution of the flow in the two zones may be considered, assuming a uniform flow away from the wall over a flow height $\delta$. If the two momenta are exactly equal, a rather unlikely situation, the wall flows do not penetrate. Similar considerations are outlined in Refs. $[43,48]$ and the experimental observations in these studies support these conjectures. In many cases, information on the separation point, as a function of the physical variables of the problem, may not be available. In zone modeling, for instance, the temperature levels and the interface height at a given time is all that is known. For such cases, $\dot{m}_{w}$ may be determined for various interface heights, going from a large positive value to a large negative value as $Z_{i}$ decreases. The value of $Z_{i}$ at which the two momenta are equal may be taken as zero $\dot{m}_{w}$ and an interpolation employed to determine $\dot{m}_{w}$ at other values of $z_{i}$. Depending on the desired accuracy in 
considering the wall flow effects, one may construct the scheme to determine the penetrative flow. The simplest one is the one that assumes complete penetration when the two momenta are different, as shown in Fig. 34.

If experimental results are available on the wall and gas temperatures, one may approximate the profiles as a two-layer system $[10,11]$ and apply the above considerations. For greater accuracy, the exact profiles may be employed to determine mass flow rate, momentum and energy at the estimated Interface by solving the governing equations, as outlined in section 5 . This would then indicate the location of the point where the two momenta are equal and allow one to consider the case when the two are close to each other at the Interface, as outlined above.

In sumary, the approximate method discussed above for incorporating the wall flow effects in the present zone models may be outlined. Let us assume that the upper layer temperatures, $T_{g, u}$ and $T_{w, u}$, the lower layer temperatures, $T_{g, 1}$ and $T_{w, 1}$, and the interface helght are avallable from the zonemodel analysis or from experimentation. For the experimental results, as pointed out earlier, the model of Pef. [10] may be employed to obtaln the characteristic quantities for a two-layer system. The first step is to determine the momentum flow rates, for the downward flow in the upper zone and for the upward flow in the lower zone, at the interface helght, from the boundary layer analysis. For laminar and turbulent flows, respectively, $M$ Is glven by:

$$
M=\rho \nu^{2}\left(\operatorname{Pr}+\frac{20}{21}\right)^{-3 / 4} \operatorname{Pr}^{-1 / 2}\left(\frac{g B \Delta T}{\nu^{2}}\right)^{3 / 4} z^{5 / 4}
$$


and,

$$
M=0.04149 \rho v^{2}\left(\frac{g B \Delta T}{v^{2}}\right)^{0.9} \operatorname{Pr}^{-8 / 15}\left[1+0.494(\operatorname{Pr})^{2 / 3}\right]^{-0.9} z^{1.7}
$$

The corresponding mass flow rates are:

$$
\dot{\mathrm{m}}=1.6932 \rho \nu\left(\operatorname{Pr}+\frac{20}{21}\right)^{-1 / 4} \operatorname{Pr}^{-1 / 2}\left(\frac{\mathrm{gB \Delta T}}{v^{2}}\right)^{1 / 4} \mathrm{z}^{3 / 4}
$$

and,

$$
\dot{\mathrm{m}}=0.09795 \rho \nu\left(\frac{\mathrm{g \beta \Delta T}}{v^{2}}\right)^{0.4} \operatorname{Pr}^{-8 / 15}\left[1+0.494(\mathrm{Pr})^{2 / 3}\right]^{-0.4} \mathrm{z}^{1.2}
$$

These values are given per unit flow perimeter. The laminar as well as the turbulent values are computed and their average taken to approximately give the flow momentum and mass flow rate. For more accurate results, the considerations outlined in section 5 may be followed.

The downward flow momentum in the upper layer $\left(M_{W}\right)_{u}$ and that in the lower layer $\left(M_{W}\right)_{1}$ are compared. If $\left(M_{W}\right)_{u}>\left(M_{W}\right)_{1}$, the upper region flow penetrates Into the lower layer and the corresponding value of $\dot{m}$ is determined. If $\left(M_{w}\right)_{u}<\left(M_{w}\right)_{1}$, the lower region flow penetrates into the upper layer. This approximation amounts to the replacement of a sharp variation of $\dot{m}$ with $Z_{i}$, near the location where the two momenta are equal, by a step change, as shown in Fig. 34. For this figure, the temperature data of Fig. 8 are employed and the effect of a variation in the interface height is indicated. The solid curve refers to a three layer model and the broken lines to the two-layer approximation. The interpolated curve around $\mathrm{z}_{1}=0.97$ is also obtained 
approximately as outlined earlier and the step change assumption is reasonable. The determined wall flow rate may then be employed in the determination of $\dot{m}_{e}$ from Eqn. (39). Thus an insitu plume entrainment rate could be compared with idealized free plume models.

\section{SUMMARY AND CONCLUSIONS}

A study of the buoyancy-induced flow generated adjacent to the vertical walls of a room with an opening due to fire in the room has been carried out. Experimental results on wall and gas temperatures are obtained for a full-scale fire in a room. Though some data are taken at the very early stages of the fire, most of the measurements are taken for the quasi-steady and the essentially steady state circumstance attained after the initial transient. The boundary layer flows generated adjacent to the walls due to the temerature differences that arise are studied for laminar as well as turbulent flow. The corresponding physical quantities, such as mass flow rate, momentum flow rate and the convected thermal energy, are computed for the experimentally-determined temperatures. The study is considered largely in terms of the two-layer zone mode1, which assumes an isothermal hot upper layer lying above a colder isothermal lower layer, and a three-layer model, which considers a stratified intermediate region between the two isothermal zones. In actual practice, a step change in temperature from one zone to the other does not exist and a more gradual variation is observed. However, considerable effort has been directed at the two-zone idealization because of the resulting simplicity. The three-zone model is considered largely to provide insight into the basic fluid flow processes and to provide suitable inputs for the two-layer mode 1 . 
The penetration of the wall flow across the interface between the two isothermal regions is studied. The momentum of the generated wall flows is determined for the upward flow in the lower layer and for the downward flow in the upper layer. The variation of the momentum with height is determined in the boundary layer flow as well as in the negatively-buoyant circumstance that arises following penetration. The point of separation of the flow from the wall is obtained from the condition of net zero momentum for the two opposing gas flows. The penetration of the fire plume across the interface is also considered. The study considers the results obtained in terms of the twolayer zone model and indicates the method that may be adopted to incorporate the wall flow effects in the model.

The main conclusions of the study may now be outlined for the range of experimental conditions considered. Experimentation was carried out over a wide range of heat release and opening size, as related to enclosure fires. The important conclusions obtained from this study are given below, the particular values obtained for specific experiments being given in the various figures and discussed earlier. Of course, it should be realized that all of the computations were based on boundary layer or plume models, and did not address the separated flows. Since the separated flows can redistribute themselves across the interface region, the quantitative results presented here may be over-estimated. Also the fact that the interface is not an ideal plane, but an ill-defined transition region, contributes to uncertainties in these conclusions on transport rates across the interface. Nevertheless the following can be concluded from this analysis subject to these qualifications. 
1. The wall flow effects are found to be quite significant subject to the limitations of the quiescent external flow field picture discussed above. The flow rates were found to be in the range $20-40 \%$ of the flow rate in the plume.

2. The energy transported across the interface by the wall flow is small compared to that due to the plume, being les than about $5 \%$ of the energy input into the fire. Therefore, the energy transfer due to the wall flow may be neglected but the mass transfer across the interface rnust be included in the ana lysis.

3. The fire plume penetration into the upper layer was also studied and a sma 11 amount of f1ow, 5-10\%, was found to be shed in the stratified zone. For the two-layer mode1, the mass flow may be taken as unaltered across the interface.

The general features of the study may be summarized as:

1. A downward flow arises in the upper layer and an upward flow in the lower layer. Depending on which flow has a larger momentum at the interface, the flow penetrates into the other 1ayer. When the two momenta are close to each other, the flow gets distributed over the two layers and interpolation may be employed to determine the flow that penetrates. 
2. Employing the integral formulation for plume flow, its penetration across the interface is studied and physically realistic results are obtained.

3. An approximate method for taking the wall flow effects into account is outlined for zone-models as well as for experimental studies, on the basis of the results obtained in this study .

\section{FUTURE WORK}

This study has considered approximate integral models for the evaluation of the wall flow effects due to fire in a room. Though the general trends and approximate values of the relevant physical quantities have been obtained, a more detailed analytical and experimental study is needed to justify some of the assumptions made and to obtain more accurate results. In particular, future analytical effort may be directed at solving the governing flow equations for two-dimensional wall flows and the axisymetric plume flow to provide further information and insight into the following aspects:

1. Temperature field in the wall flow as it penetrates a stratified intermediate layer, particularly any temperature defect or reverse flow that might arise, effect of a variation in the height $\mathrm{L}_{2}$ of this layer on the flow, particularly as $\mathrm{L}_{2} \rightarrow 0$ which corresponds to a two-layer system, and the effect of the shed flow on the flow adjacent to the wall. The problem does not allow boundary layer simplification and the full equations need to be considered. 
2. Interaction of opposing wall flows needs further study with respect to the dependence of penetration on the difference between the momenta of the two streams, particularly when the two are close to each other. It is a nonboundary layer problem, which may possibly be studied in terms of avallable results on flows in corners.

3. Plume penetration across the stratifled layer, followed by a consideration of the two-layer mode1. The boundary layer results would indicate regions of reverse flow and separation, but a nonboundary layer analysis would give the desired quantitative information on flow rates, momentum flow and buoyancy flux.

4. A parametric study of the general problem is needed to determine the governing dimensionless parameters. This would allow a generalization of the physical processes. Though the present results may be presented in dimensionless terms, a more detalled study is needed to study the effect of the various physical variables in the problem.

Further experimental work is also desirable in order to provide inputs for the analytical work. Though some visualization of the interface region was done in this study, clearly more work is needed to obtain a better understanding of the interaction of the wall flows with the interface and with each other. Temperature measurements in the flow near the interface would also help in the analysis. The mineral oil smoke generator may be employed to 
visualize the flow adjacent to the walls at various operating conditions and recorded on video. Of particular interest would be an estimation of the penetration distances, height and location of the region where flow separates from the wall and the nature of the flow. Also of interest would be further results on the transient effects, both at start up and at shut down of the fire. This would permit a consideration of the very early stages of the fire, in terms of the boundary layer transients versus the interface movement $[50,51]$

When the fire is turned off, the walls and the gases cool down gradually due to energy loss to the environment. Since the walls remain hot for a fairly long time following the shutting off of the fire, it is possible to obtain quantitative information on the wall flows penetrating into the upper layer by measuring the outflow at the door and the temperatures in the room. In the absence of wall flow effects, mass balance of the upper layer gives:

$$
\frac{d}{d \tau}\left(A D Z_{i}\right)-\dot{m}_{j}=\dot{m}_{0}
$$

where $A$ is the cross-sectional area of the room, $\tau$ is time and $\dot{m}_{0}$ is the mass outflow rate at the opening. If a flow rate of $\dot{m}_{w}$ penetrates into the upper laye $r$, the governing equation is:

$$
\frac{d}{d \tau}\left(A \circ Z_{i}\right)+\dot{m}_{w}-\dot{m}_{j}=\dot{m}_{0}
$$

Therefore, if $\dot{m}_{0}(\tau)$ and $z_{i}(\tau)$ are determined experimentally, the wall flow rate may be determined as a function of the conditions at a given time. If the process can be approximated as quasi-steady, which appears reasonable 
glven the slow rate of cooling of the walls, these results may be employed to yield wall flow rates when the fire is present, by considering the corresponding temperature profiles. Though further work is needed on ascertaining the validity of this approach, the results obtained are expected to be valuable in the verification of the analytical model predictions.

Experimental work on the wall flows may also be carried out on a laboratory scale. The work would need to be directed at the magnitude of the wall flow and its penetration as a function of the physical variables of the problem. Detalled velocity and temperature measurements in the flow would answer most of the questions raised in the present study and would permit the development of more accurate models for determining the wall flow effects. Similarly, the penetration of the fire plume into the upper layer may be studied to provide suitable inputs into the analysis of the flow as it goes from one zone to the other, across a sharp interface.

\section{ACXNOWLEDGEMENTS}

This study was carried out during the sumer of 1982 , while the author was a visiting scientist with the Fire Growth Processes Research Group at the Center for Fire Research, Ntional Bureau of Standards, Gaithersburg, Maryland. The financial support for this work was provided by the center. The author acknowledges the several discussions he had with J. G. Quintiere and L. Y. Cooper on the mathematical modeling of the basic processes and the extensive help he had from K. D. Steckler and W. J. Rdnkinen on the experimentation. He also had several interesting and stimulating discussions with B. J. McCaffrey and H. R. Baum. 


\section{REFERENCES}

1. Quintiere, J.G., Growth of Fire in Building Compartments, Fire Standards and Safety, ASTM STP 614, 131-167 (1977).

2. Quintiere, J.G., An Approach to Modeling Wall Fire Spread in a Room, Fire Sa fety Journal, 3, 201-214 (1981).

3. Tanaka, T., A Model on Fire Spread in Small Scale Buildings, BRI Rept. No. 79, Building Research Institute, Japan (1978).

4. Cooper, L.Y., Harkleroad, M., Quintiere, J. and Rinkinen, W., An Experimental Study of Upper Hot Layer Stratification in Full-Scale Multiroom Fire Scenarios, Presented at 20th ASME/AIChE National Heat Transfer Conference, Mi Iwaukee, ASME Paper No. 81-HT-9 (1981).

5. Rockett, J.A., Fire Induced Gas Flow in an Enclosure, Combustion Science and Technology, 12, 165 (1976).

6. Zukoski, E.E., Development of a Stratified Ceiling Layer in the Early Stages of a Closed Room Fire, Fire and Materials, 2, 54-62 (1978).

7. Emmons, H., The Prediction of Fires in Buildings, 17th Symp. (Int.) on Combustion, The Combustion Inst., Pittsburgh, PA, 1101-1111 (1978).

8. Quintiere, J.G., McCaffrey, B.J. and DenBraven, K., Experimental and Theoretical Analysis of Quasi-Steady Smal1-Scale Enclosure Fires, 17th Symp. (Int.) on Combustion, The Combustion Inst., Pittsburgh, PA, 1125-1135 (1978).

9. Quintiere, J.G., Steckler, K.D. and McCaffrey, B.J., A Model to Predict the Conditions in a Boom Subject to Crib Fires, lst Specialists Meeting (Int.) of the Combustion Inst., France (1981).

10. Steckler, K.D., Fire Induced Flows Through Boom openings - Flow Coefficients, Tech. Res. Rep., Armstrong World Industries, Lancaster, PA (1981).

11. Steckler, K.D., Quintiere, J.G. and Rinkinen, W.J., Flow Induced by Fire in a Compartment, 19th Symp. (Int.) on Combustion, The Combustion Inst., Pittsburgh, PA (1982).

12. Rehm, R.G. and Baum, H.R., The Equations of Motion for Thermally Driven, Buoyant Flows, J. Res., Nat. Bur. Stds., 83, 297-308 (1978).

13. Rehm, R.G., Baum, H.R. and Barnett, P.D., Buoyant Convection Computed in a Vorticity, Stream-Function Formulation, J. Res., Nat. Bur. Stds., 87, 165-185 (1982).

14. McCaffrey, B.J., Purely Buoyant Diffusion Flames: Some Experimental Results, Nat. Bur. Stds. Rep. NBSIR 79-1910 (1979). 
15. Zukoski, E.E., Kubota, T. and Centegen, B., Entrainment in Fire Plumes, Nat. Bur. Stds., NBS-6CR-80-294 (1980). Also, Entrainment in the Near Field of a Fire Plume, NBS-6CR-81-346 (1981).

16. McCaffrey, B.J. and Rockett, J.A., Static Pressure Measurements of Enclosure Fires, J. Res., Nat. Bur. Stds., 82, 107 (1977).

17. Quintiere, J.G, Rinkinen, W.J. and Jones, W.W., The Effect of Room Openings on Fire Plume Entrainment, Comb. Sc1. Tech., 26, 193-201 (1981).

18. Jaluria, Y., Natural Convection Heat and Mass Transfer, Pergamon Press, Oxford, U.K. (1980).

19. Turner, J.S., Jets and Plumes with Negative or Reversing Buoyancy, J. Fluid Mech., 26, 779-792, 1966.

20. Turner, J.S. Buoyancy Ef fects in Fluids, Cambridge Univ. Press, U.K. (1973).

21. Morton, B.R., Forced Plumes, J. Fluid Mech., 5, 151-163 (1959).

22. Seban, R.A., Behnia, M.M. and Abreu, J.E., Temperatures in a Heated Afr Jet Discharged Downward, Int. J. Heat Mass Transfer, 21, 1453-1458 (1978).

23. Quintiere, J.G., McCaffrey, B.J. and Rinkinen, W., Visualization of Room Fire Induced Smoke Movement and Flow in a Corridor, Fire and Materials, 2, 18-24 (1978).

24. Veronis, J., Penetrative Convection, Astrophys. J., 137, 641-663 (1963).

25. Musman, S., Penetrative Convection, J. Fluid Mech., 31, 343-360 (1968).

26. Moore, F.K. and Jaluria, Y., Thermal Effects of Power Plants on Lakes, J. Heat Transfer, 94, 163-168 (1972).

27. Mitry, A.M. and Ozisik, M.N., A One-Dimensional Model for Seasonal Variation of Temperature Distribution in Stratified Lakes, Int. J. Heat Mass Transfer, 19, 201-205 (1976).

28. Gupta, S.K. and Jaluria, Y., An Experimental and Analytical Study of Thermal Stratification in an Enclosed Water Region Due to Thermal Energy Discharge, Energy Conversion, 22, 63-70 (1982)

29. Jaluria, Y., Heat Rejection and Energy Extraction Within Solar Ponds, Solar Energy Res. Inst., Rep. No. SERI/RR-252-1393 (1982).

30. Ostrach, S., An Analysis of Laminar Free Convection Flow and Heat Transfer About a Flat Plate Parallel to the Direction of the Generating Body Force, NACA TR-1111 (1953).

31. Sparrow, E.M. and Gregg, J.L., Similar Solutions for Free Convection from a Nonisothermal Vertical Plate, J. Heat Transfer, 80 379-386 (1958). 
32. Squire, H.B., Referenced in Modern Developments in Fluid Dynamics by S. Goldstein, Oxford Univ. Press, N.Y. (1938).

33. Eckert, E.R.G. and Jackson, T.W., Analysis of Turbulent Free Convection Boundary Layer, NACA TN2207 (1950).

34. Kato, H., Nichiwaki, N. and Hi rata, M•, On the Turbulent Heat Transfer by Free Convection from a Vertical Plate, Int. J. Heat Mass Transfer, 11 , 1117-1125 (1968).

35. Noto, K. and Matsumoto, R., Turbulent Heat Transfer by Natural Convection Along an Isothermal Vertical Flat Surface, J. Heat Transfer, 97, 621-624 (1975).

36. Cheesewright, R., Turbulent Natural Convection from a Vertical Plane Surface, J. Heat Transfer, 90, 1-8 (1968).

37. Jaluria, Y. and Gebhart, B., On Transition Mechanisms in Vertical Natural Convection Flow, J. Fluid Mech., 66, 309-337 (1974).

38. Morton, B.R., Taylor, G.I. and Turner, J.S., Turbulent Gravitational Convection from Maintained and Instantaneous Sources, Proc. Roy. Soc., A2 34, 1-23 (1956).

39. Yokoi, S., Plume Rising from Heat Source, Bul1. J. Assoc. Fire Sci. Eng., 5, 53-59 (1956).

40. Evans, D.D., Determining Sprinkler Actuation Time Phase I - Approximating Fire Plume Temperature and Velocity in a Two Layer Environment, NBS Int. Rep. to appear.

41. McCaffrey, B.J., Some Measurements of the Radiative Power Output of Diffusion Flames, Comb. Inst. West. States Sect. Meeting, Pullman, WA (1981).

42. Eichhorn, R., Natural Convection in a Thermally Stratified Fluid, Prog. Heat Mass Transfer, Pergamon Press, U.K., 2, 41-53 (1969).

43. Chen, C.C. and Eichhorn, R., Natural Convection from a Vertical Surface to a Thermally Stratified Fluid, J. Heat Transfer, 98, 446-451 (1976).

44. Jaluria, Y. and Gebhart, B., Stability and Transition of Buoyancy-Induced Flows in a Stratified Medium, J. Fluid Mech., 66, 593-612 (1974).

45. Himasekhar, K. and Jaluria, Y., Laminar Buoyancy-Induced Axisymmetric Free Boundary Flows in a Thermally Stratified Medium, Int. J. Heat Mass Transfer, 25, 213-221 (1982).

46. Fox, D.G., Forced Plume in a Stratified Fluid, J. Geophys. Res., 75, 6818-6835 (1970).

47. Morton, B.R., Coaxial Turbulent Jets, Int. J. Heat Mass Transfer, 5, 955-965 (1962). 
48. Schetz, J.A. and Eichhorn, R., Natural Convection with Discontinuous Wal1-Temperature Variations, J. Fluid Mech., 18, 167-176 (1964).

49. Cooper, L.Y., Personal Comm. (1982).

50. Slege 1, R., Transient Free Convection from a Vertical Flat Plate, Trans. ASME, 80, 347-359 (1958).

51. Ede, A.J., Advances in Free Convection, Advances in Heat Transfer, Academic Press, 4, 1-64 (1968).

52. Emmons, H.W., Personal Communication with K. Steckler (1979). 
Table 1.

\begin{tabular}{|c|c|c|c|c|}
\hline Test No. & Door Opening* & $\begin{array}{l}\text { Heat Input, Q } \\
(\mathrm{kW})\end{array}$ & $\begin{array}{l}\text { Location and } \\
\text { No. of Burners } \\
\end{array}$ & Opening F1 ow $(\mathrm{kg} / \mathrm{s})$ \\
\hline 168 & $6 / 6$ & 63.2 & 1, Front Left corner & 0.424 \\
\hline 169 & $6 / 6$ & 63.2 & 1, Back Right Corner & 0.426 \\
\hline 300 & $6 / 6$ & 31.6 & 1, Back Wall & 0.372 \\
\hline 301 & $6 / 6$ & 126.4 & 4, Back Wa 11 & 0.622 \\
\hline 302 & $8 / 6$ & 31.6 & 1, Back Wa11 & 0.436 \\
\hline 303 & $8 / 6$ & 126.4 & 4, Back Wa 11 & 0.741 \\
\hline 304 & $4 / 6$ & 31.6 & 1. Back Wa11 & 0.290 \\
\hline 305 & $4 / 6$ & 126.4 & 4, Back Wall & 0.484 \\
\hline 306 & $2 / 6$ & 126.4 & 4, Back Wall & 0.267 \\
\hline 307 & $4 / 6$ & 126.4 & 4, Back Wall & 0.478 \\
\hline 308 & $2 / 6$ & 31.6 & 1, Back Wal1 & 0.171 \\
\hline
\end{tabular}

All door openings are $1.83 \mathrm{~m} \mathrm{high}$. The width $180.74 \mathrm{~m}$ for the $6 / 6$ door, $0.99 \mathrm{~m}$ for the $8 / 6$ door, $0.49 \mathrm{~m}$ for the $4 / 6$ door and $0.24 \mathrm{~m}$ for the $2 / 6$ door. 


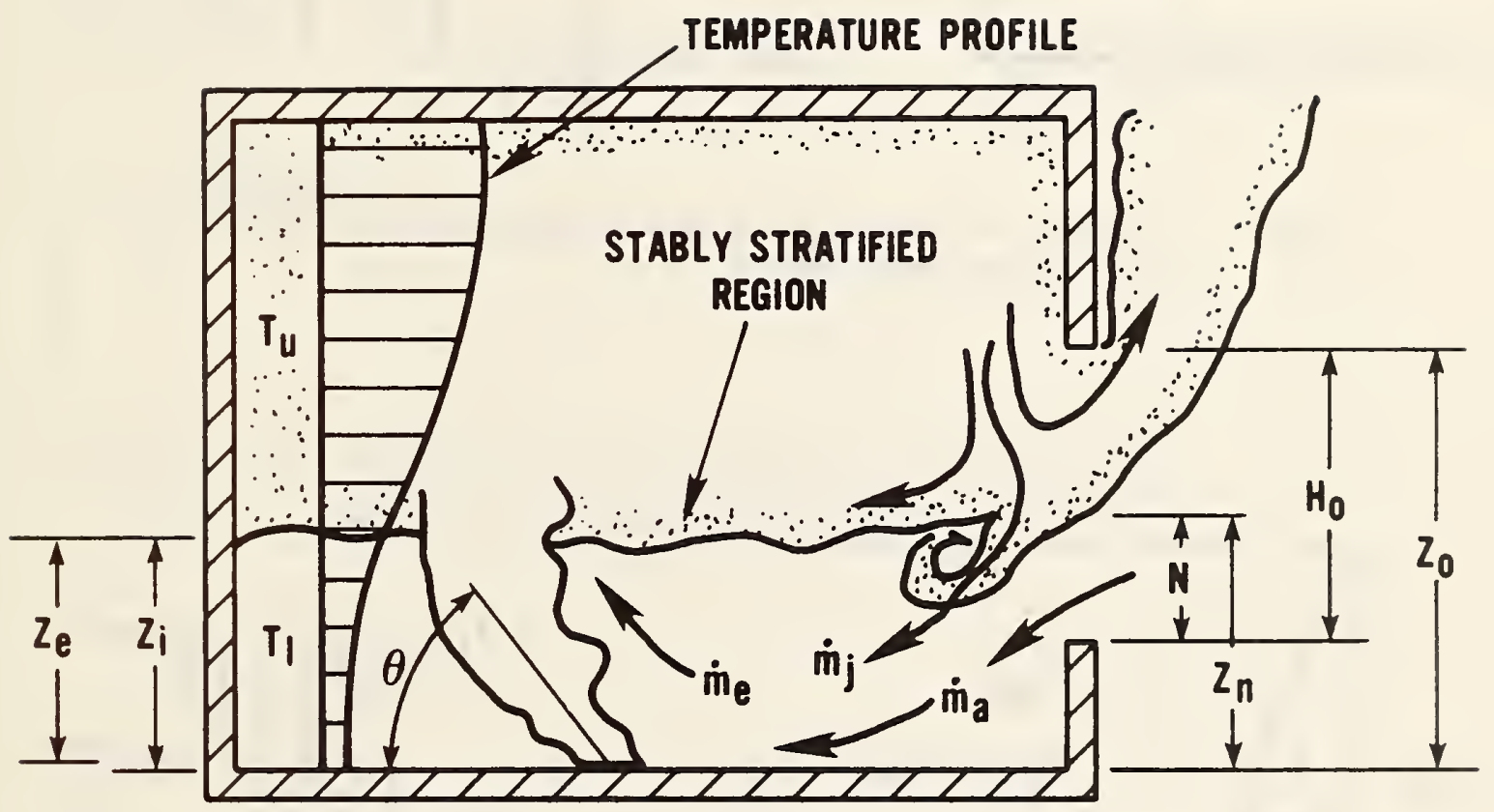

Fig. 1. Flow configuration considered 


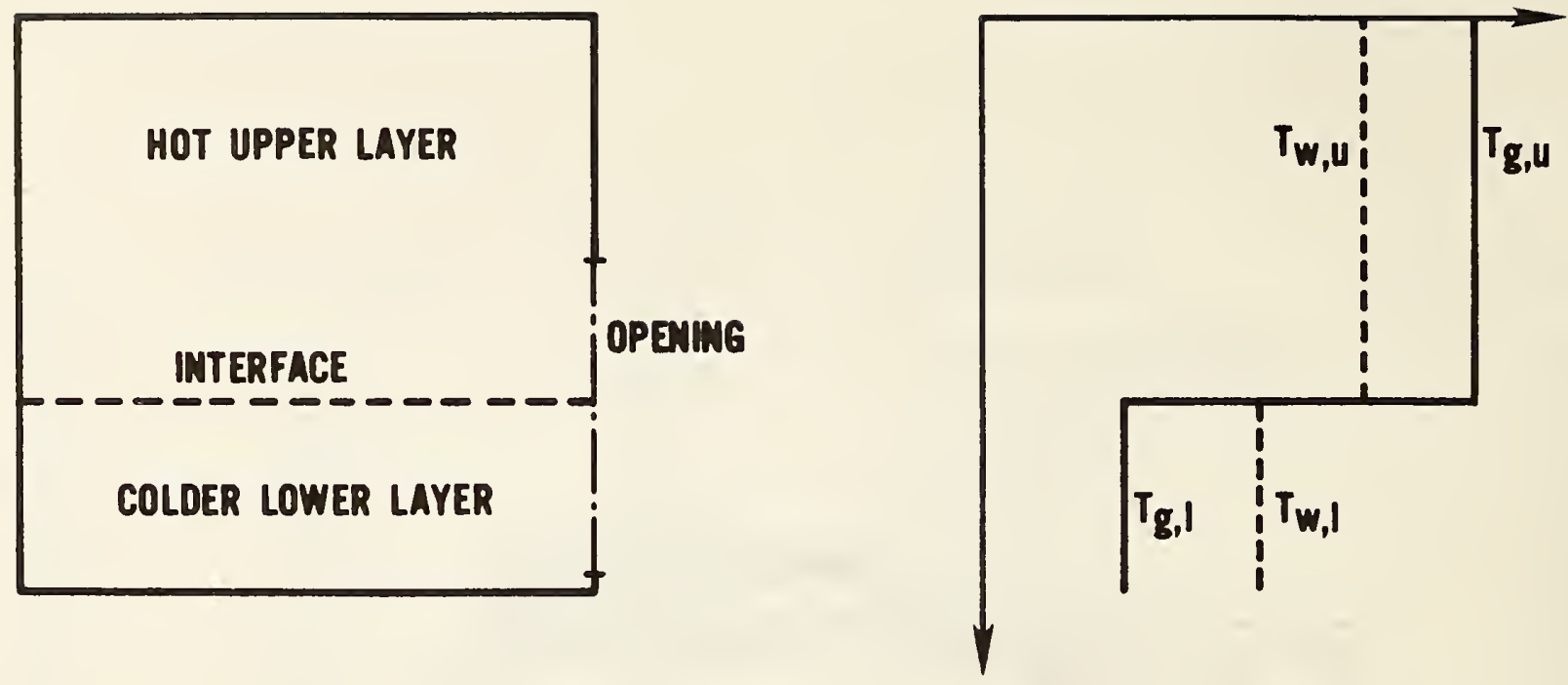

Fig. 2. Sketch of the temperature distribution in a two-layer zone mode 1 .
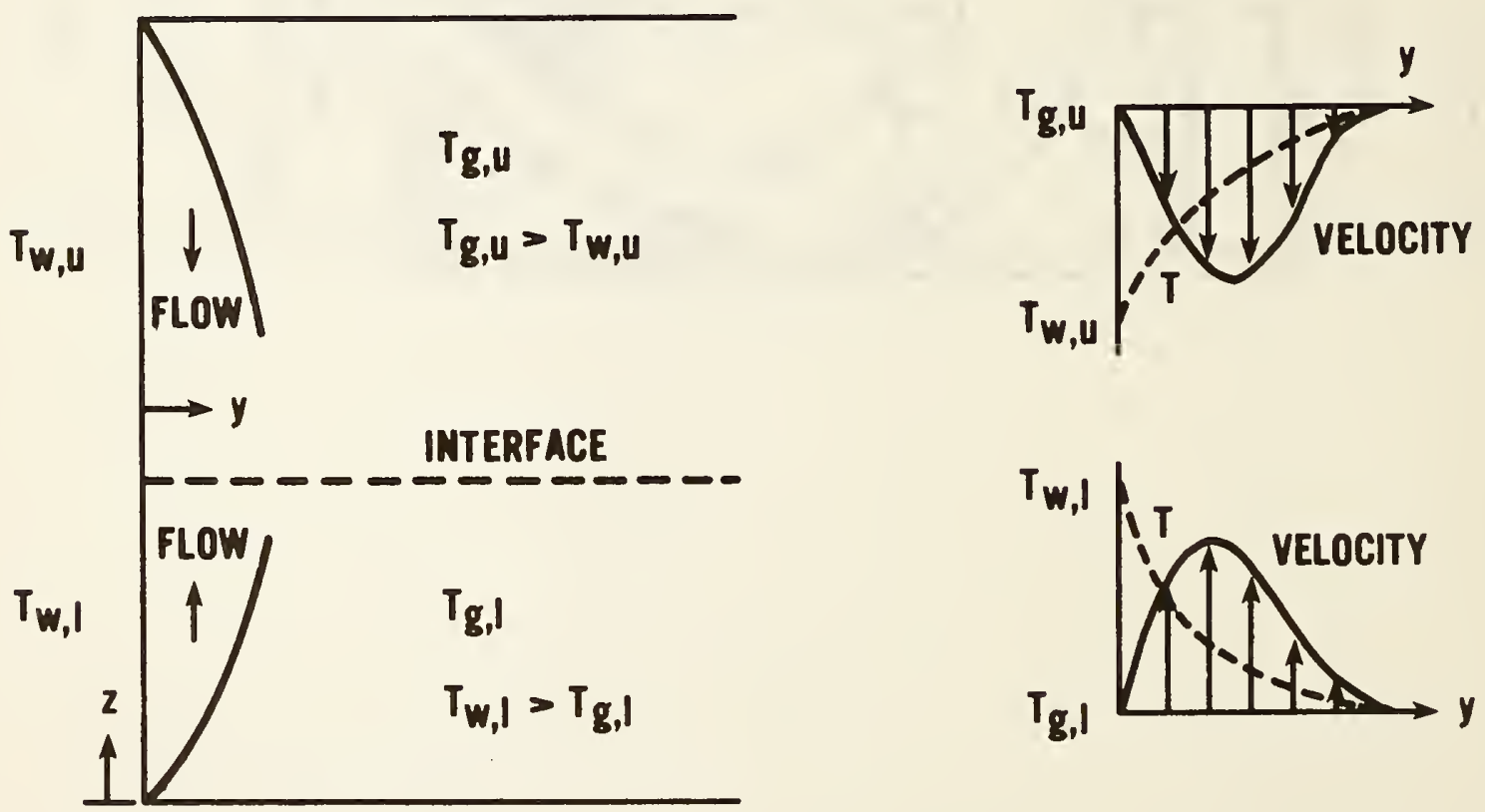

Fig. 3. Sketch of the velocity and temperature profiles in the wall flow.

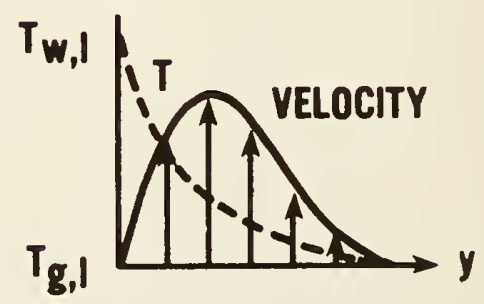




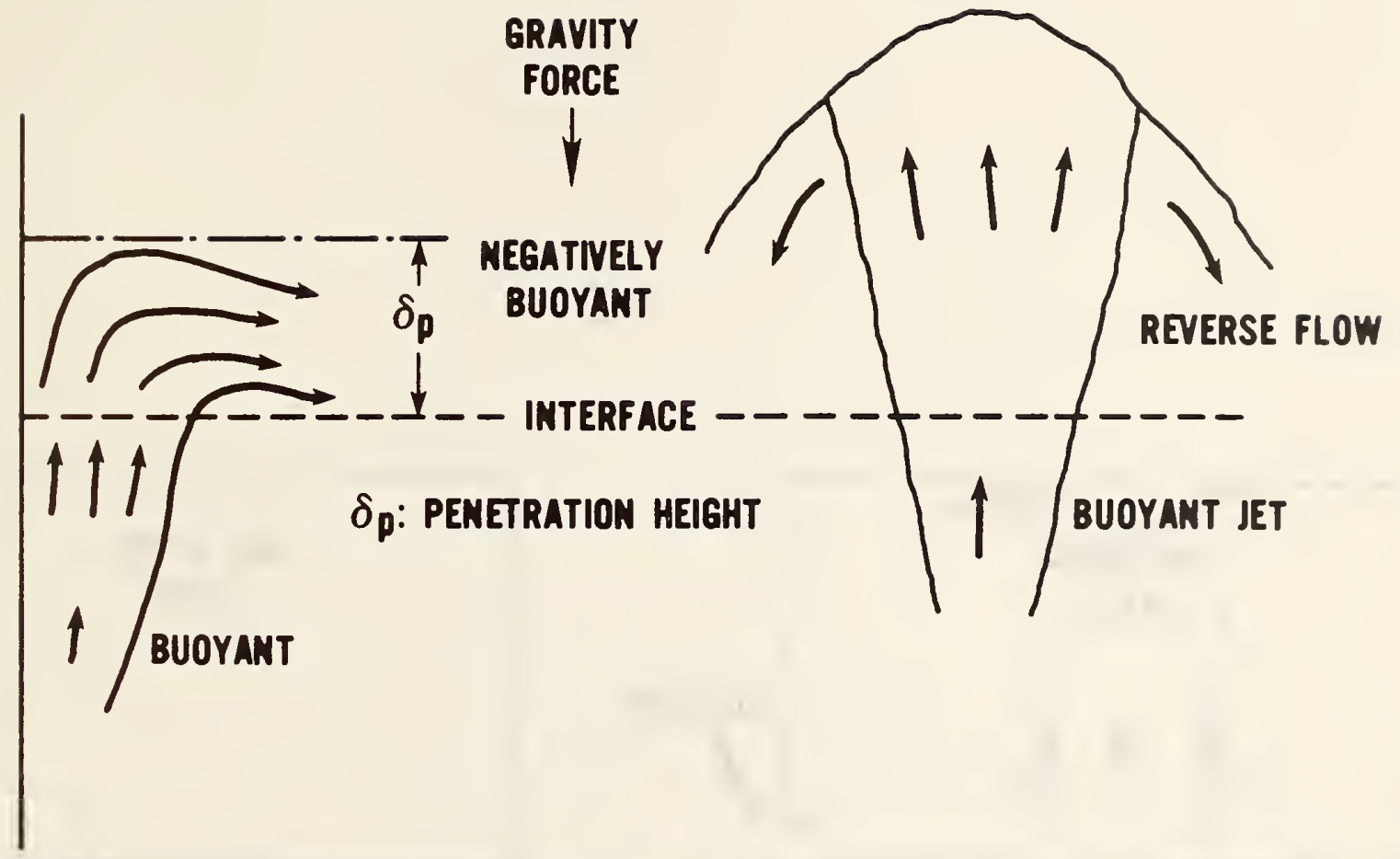

Fig. 4. Flow in the negatively-buoyant wall flow and in a corresponding jet.
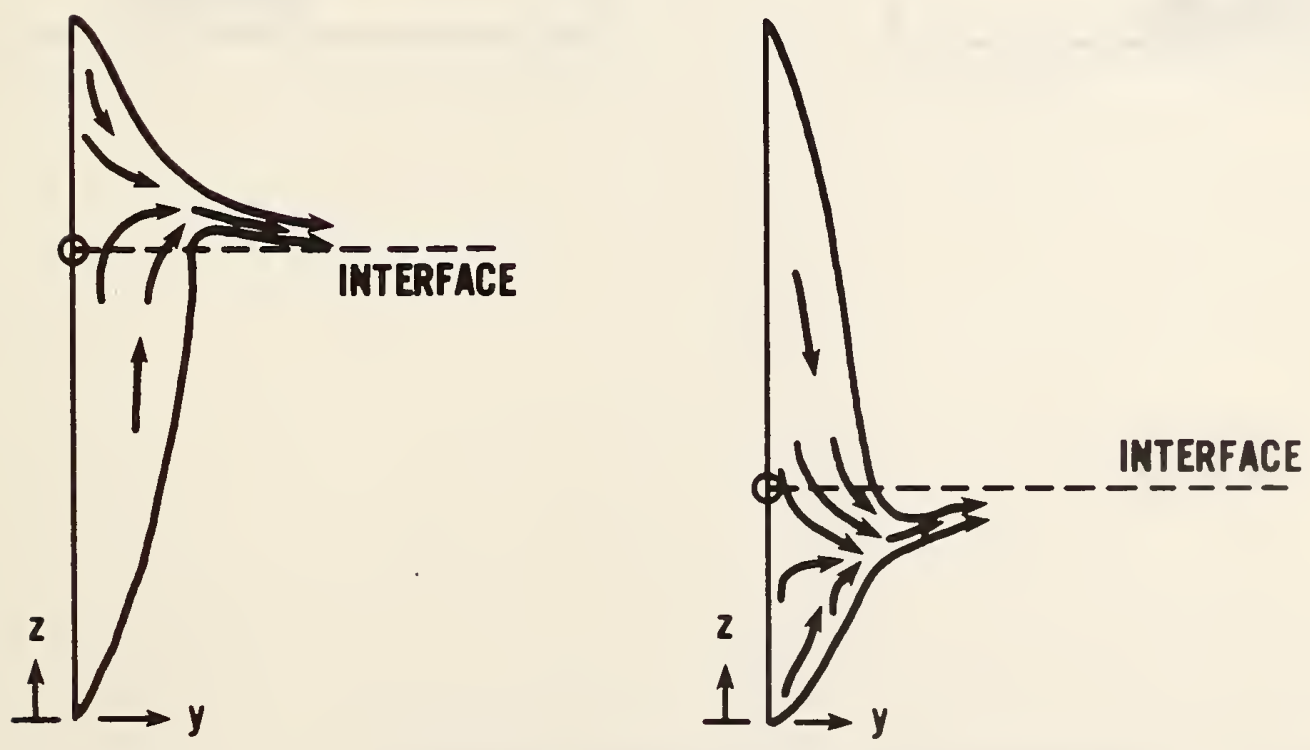

Fig. 5. Interaction of opposing wall flows. 

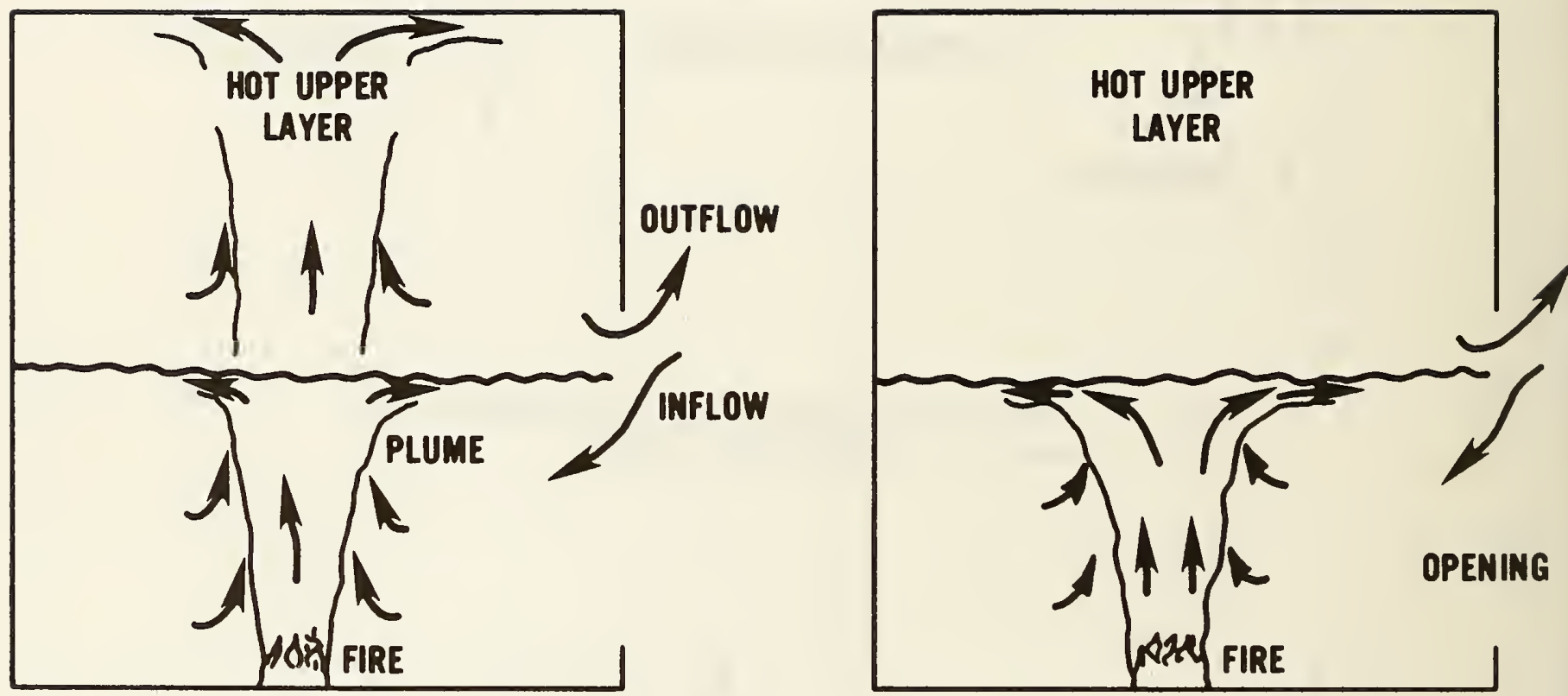

Fig. 6. Interaction of a fire plume with the stably stratified upper layer. 


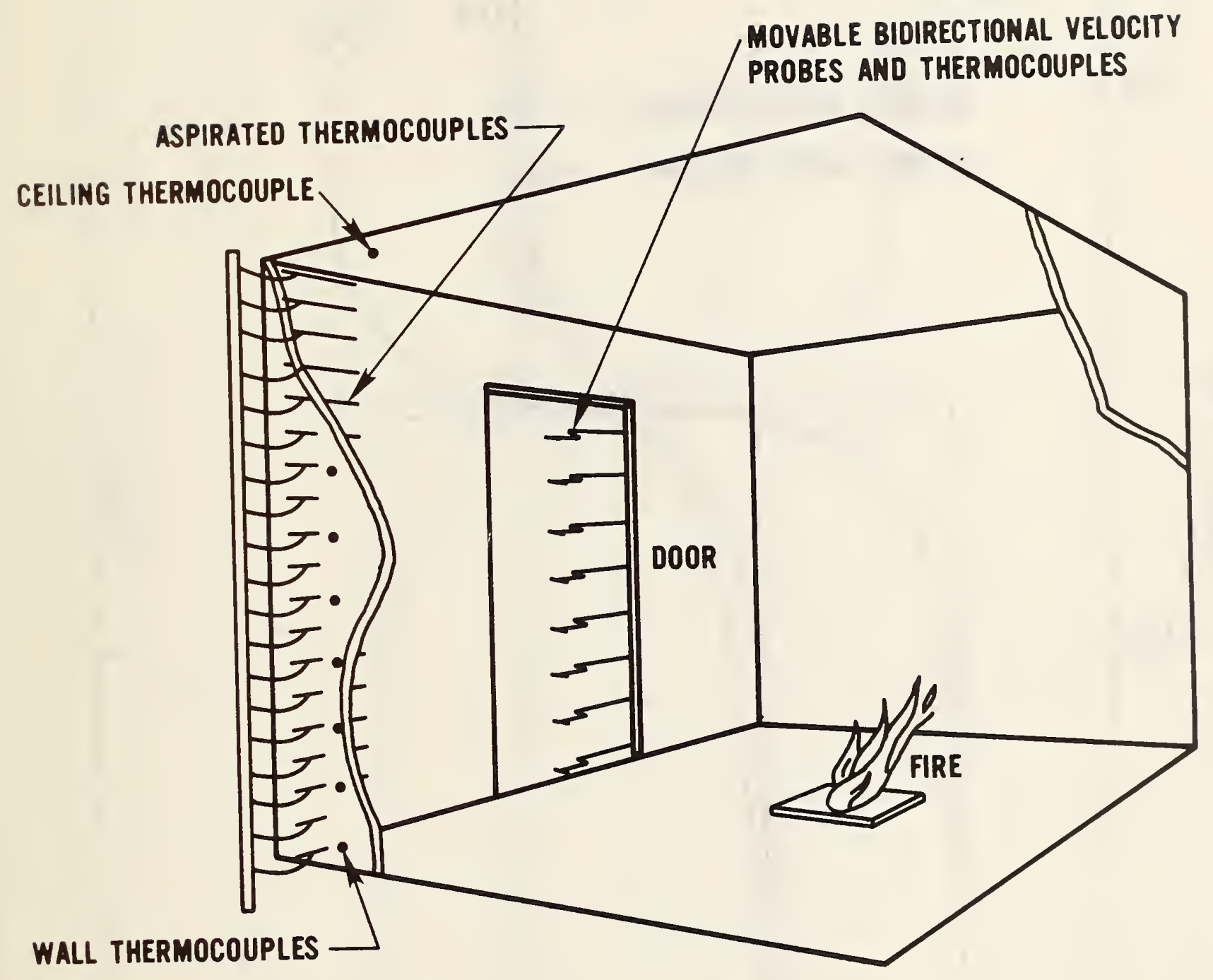

Fig. 7. Experimental arrangement. 


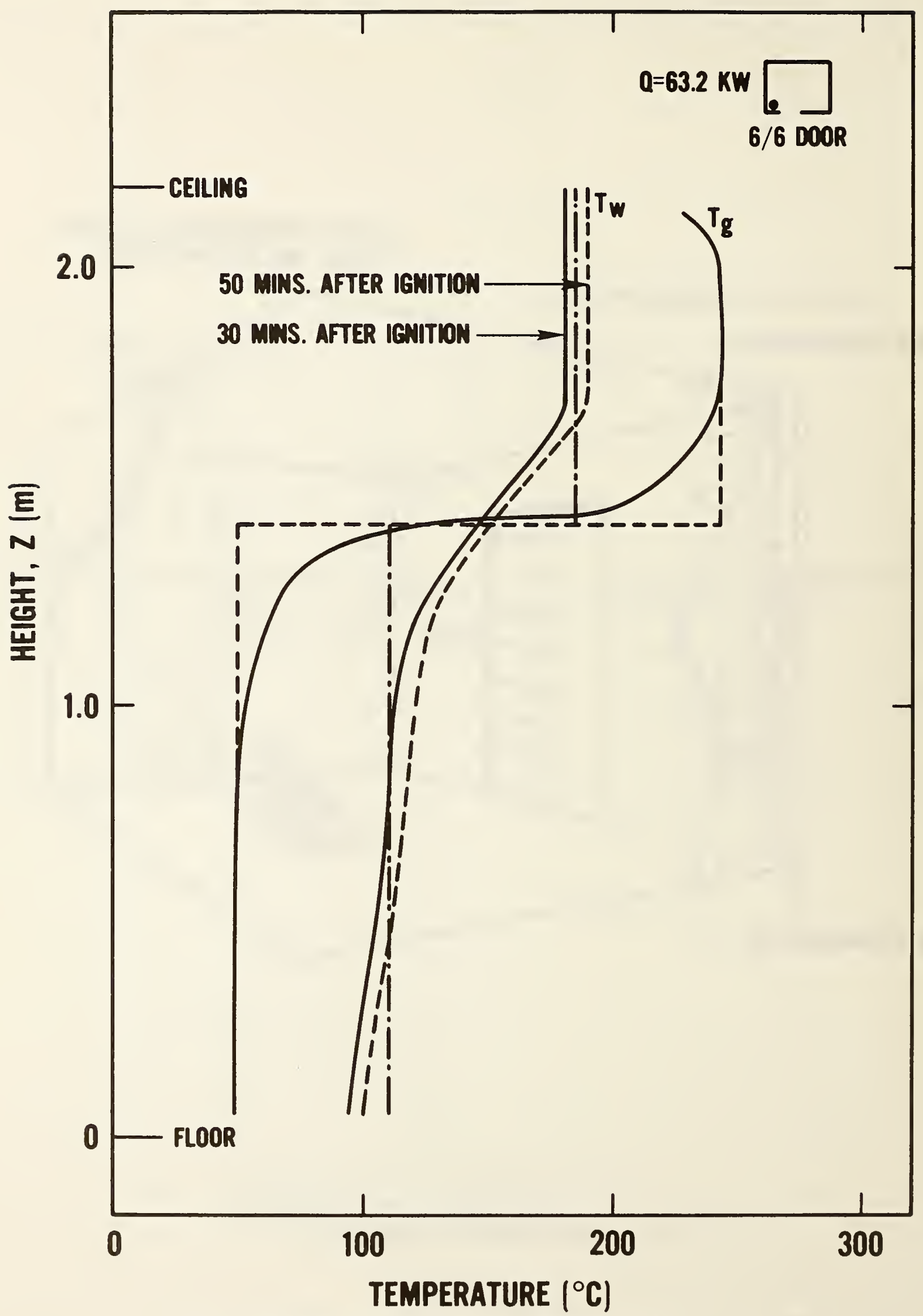

Fig. 8. Measured gas and wall temperatures in the room for a circular burner and $Q=63.2 \mathrm{~kW}$. 


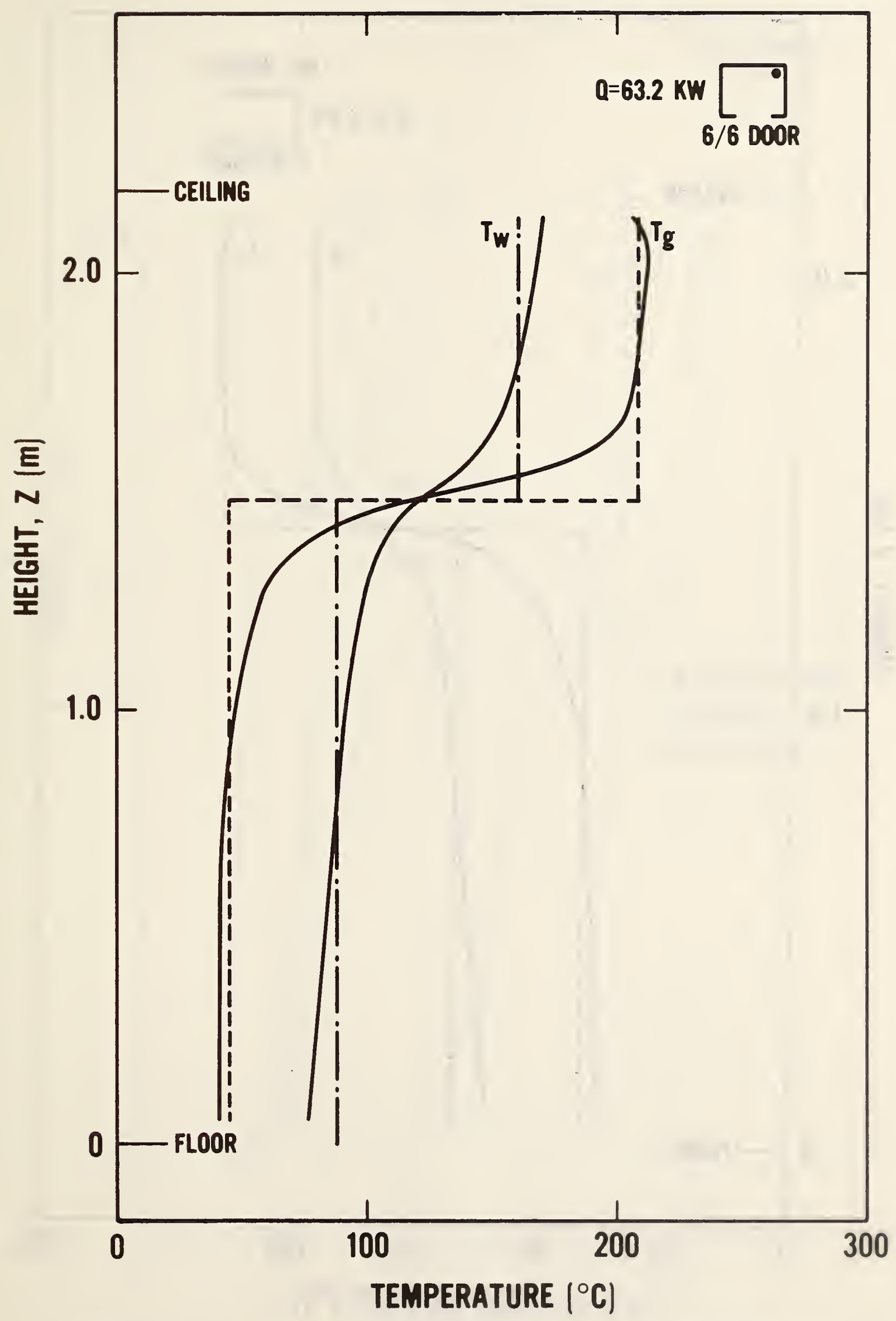

Fig. 9. Measured gas and wall temperatures in the room for a circular burner and $Q=63.2 \mathrm{~kW}$, at a different location. 


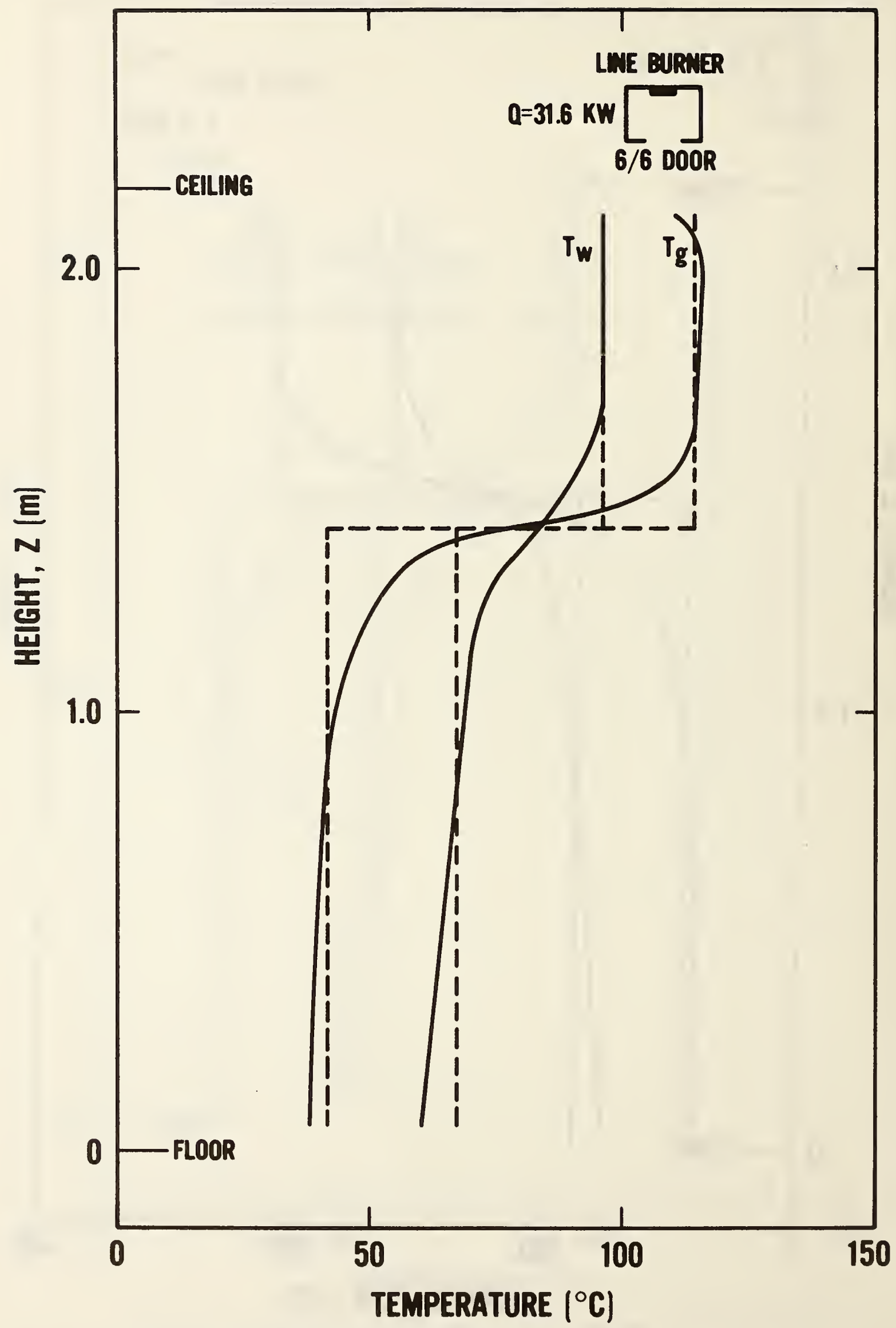

Fig. 10. Measured gas and wall temperatures for a single line burner and $Q=63.2 \mathrm{~kW}$, at a different location. 


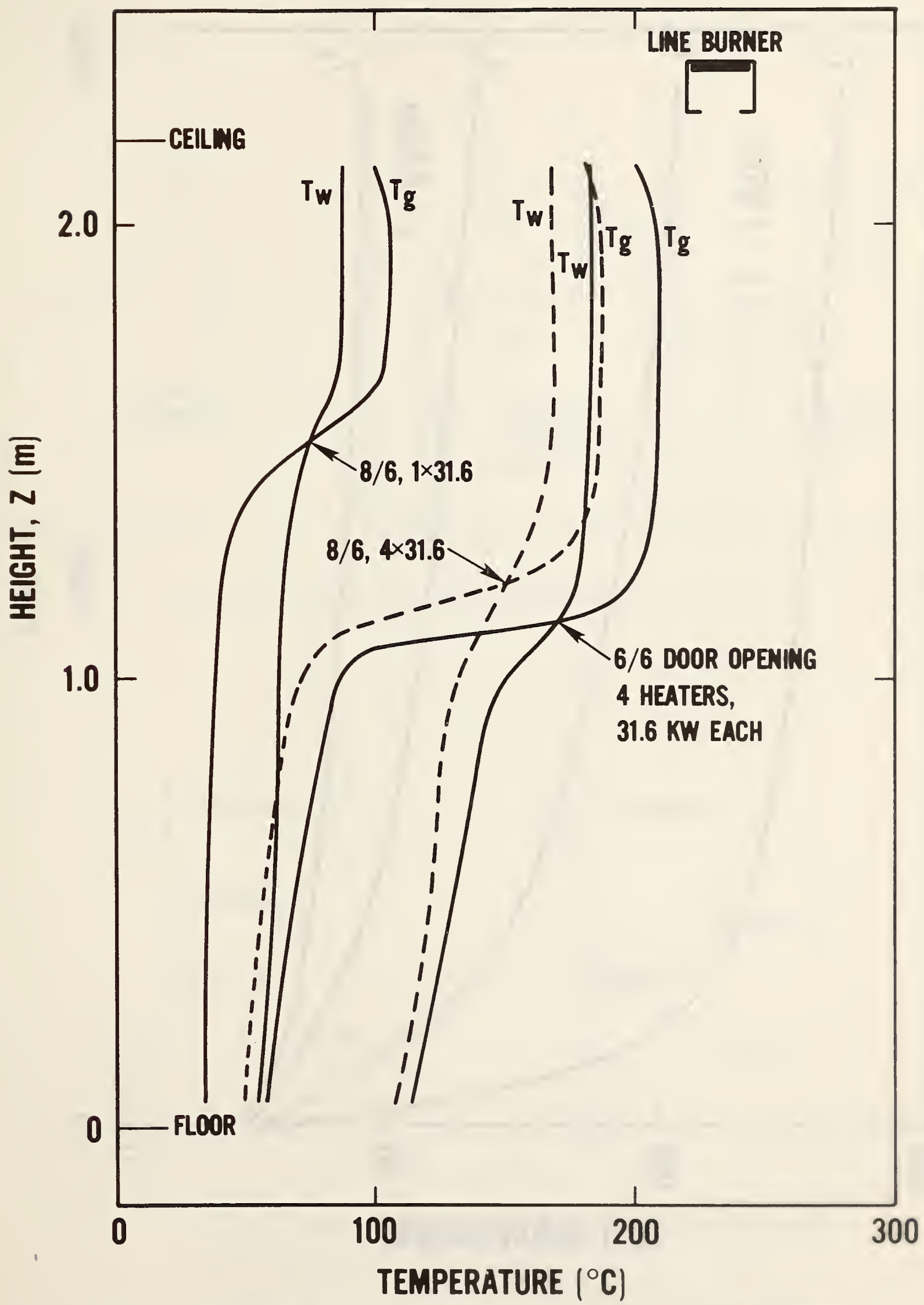

Fig. 11. Measured gas and wall temperatures for the line burner at various door openings and heat input values. 


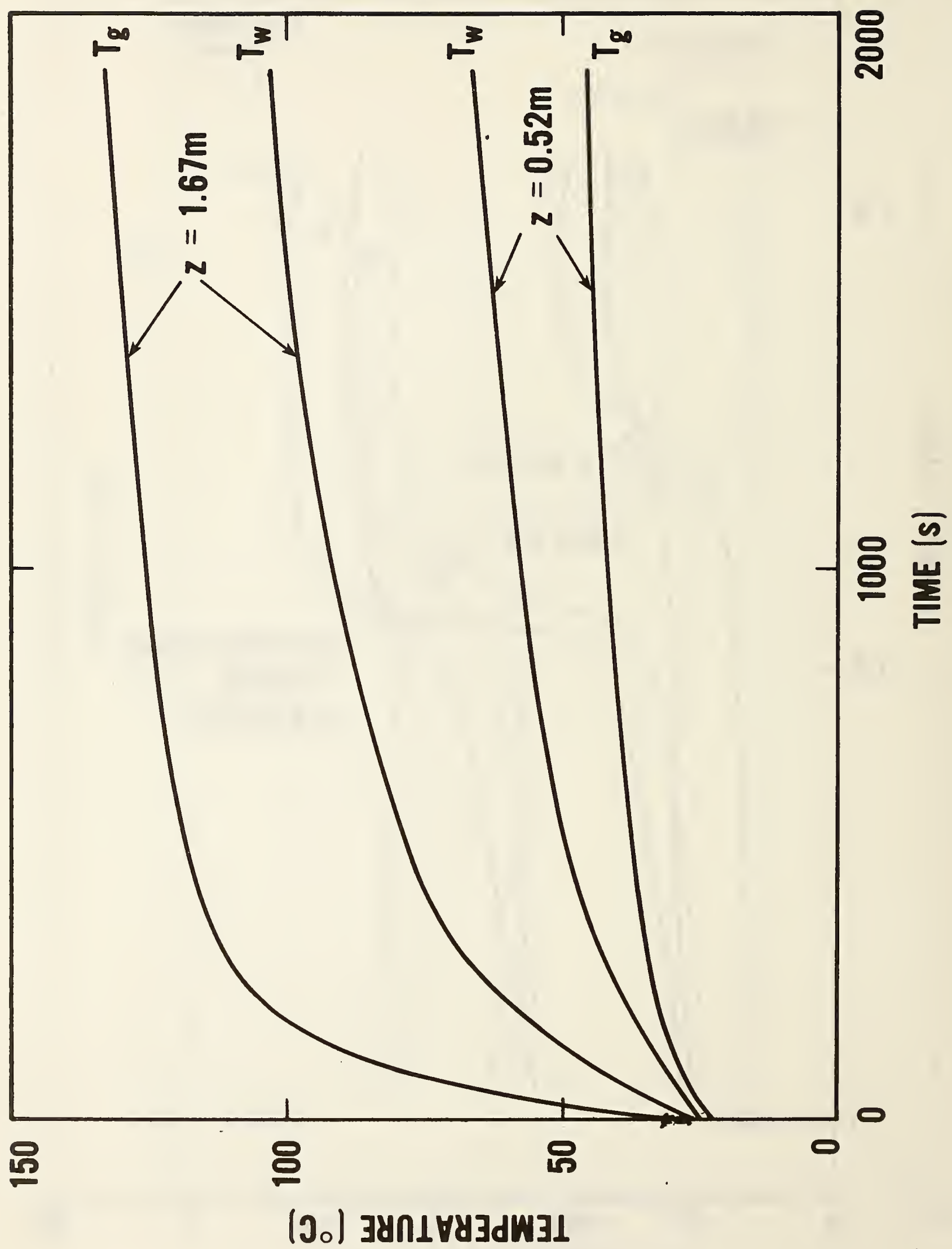

告

药

하

II

$\circ$

¿্ర

嵌

号

$\infty$

눈

()

光

.

品 品

돌

ต คิ

o

들 움

हี

간

3 :

岸 $x$

모

ह

,

$\underset{\sim}{\sim}$

in 

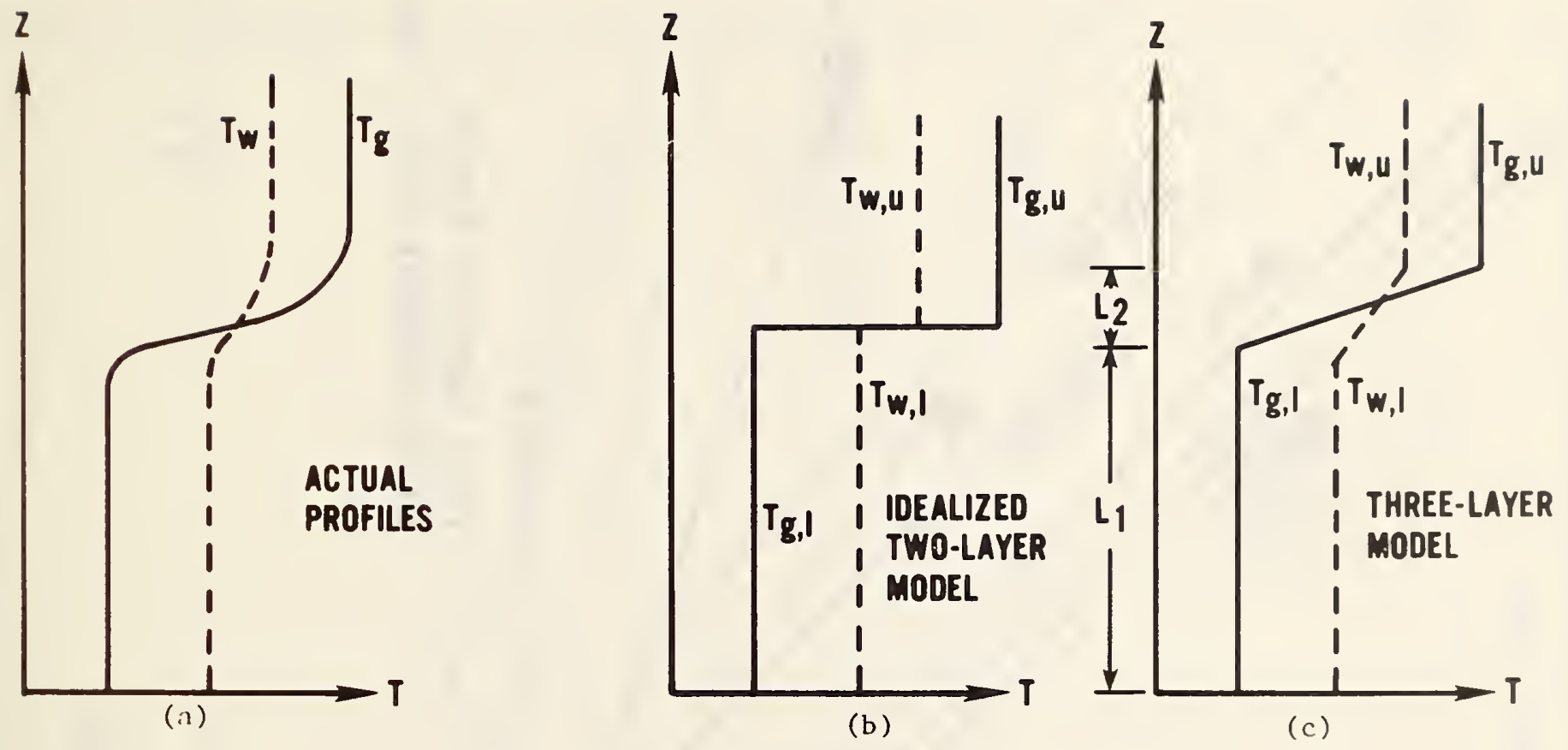

Fig. 13. Actual and idealized temperature profiles.
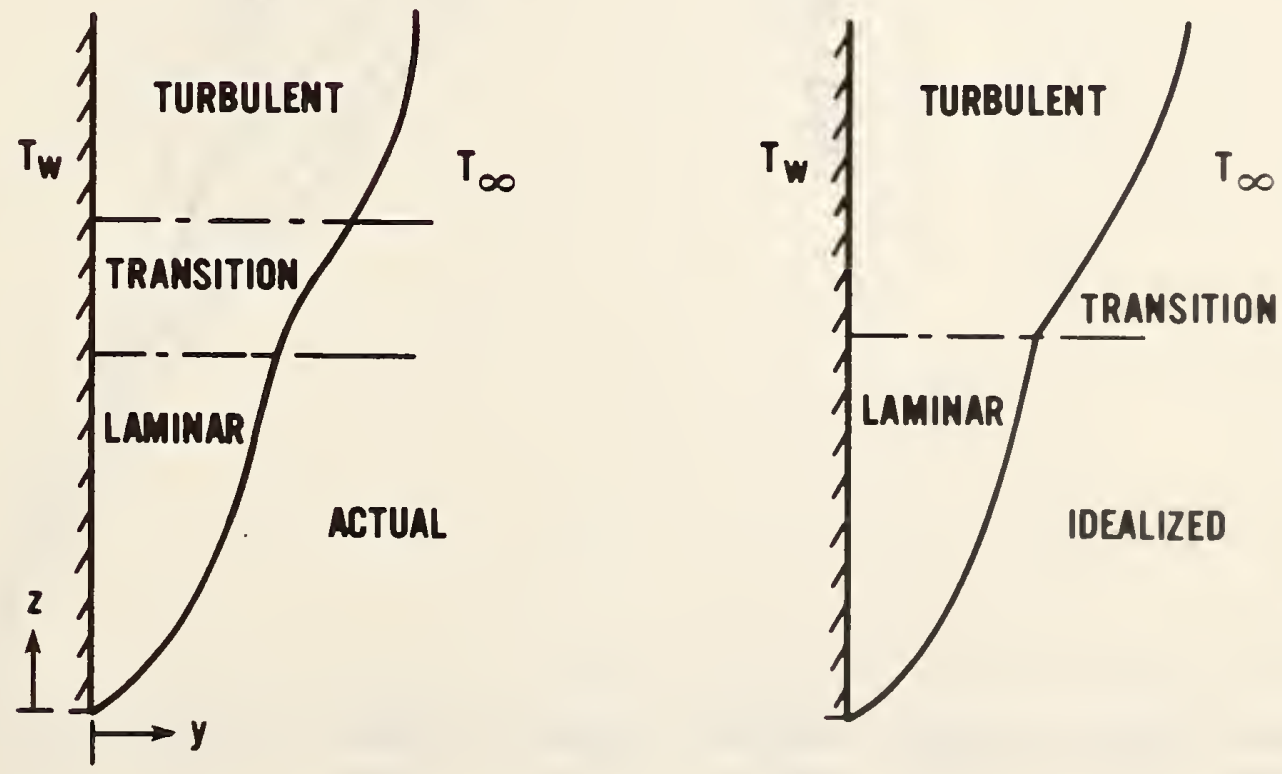

Fig. 14. Actual and idealized boundary layer wall flow. 


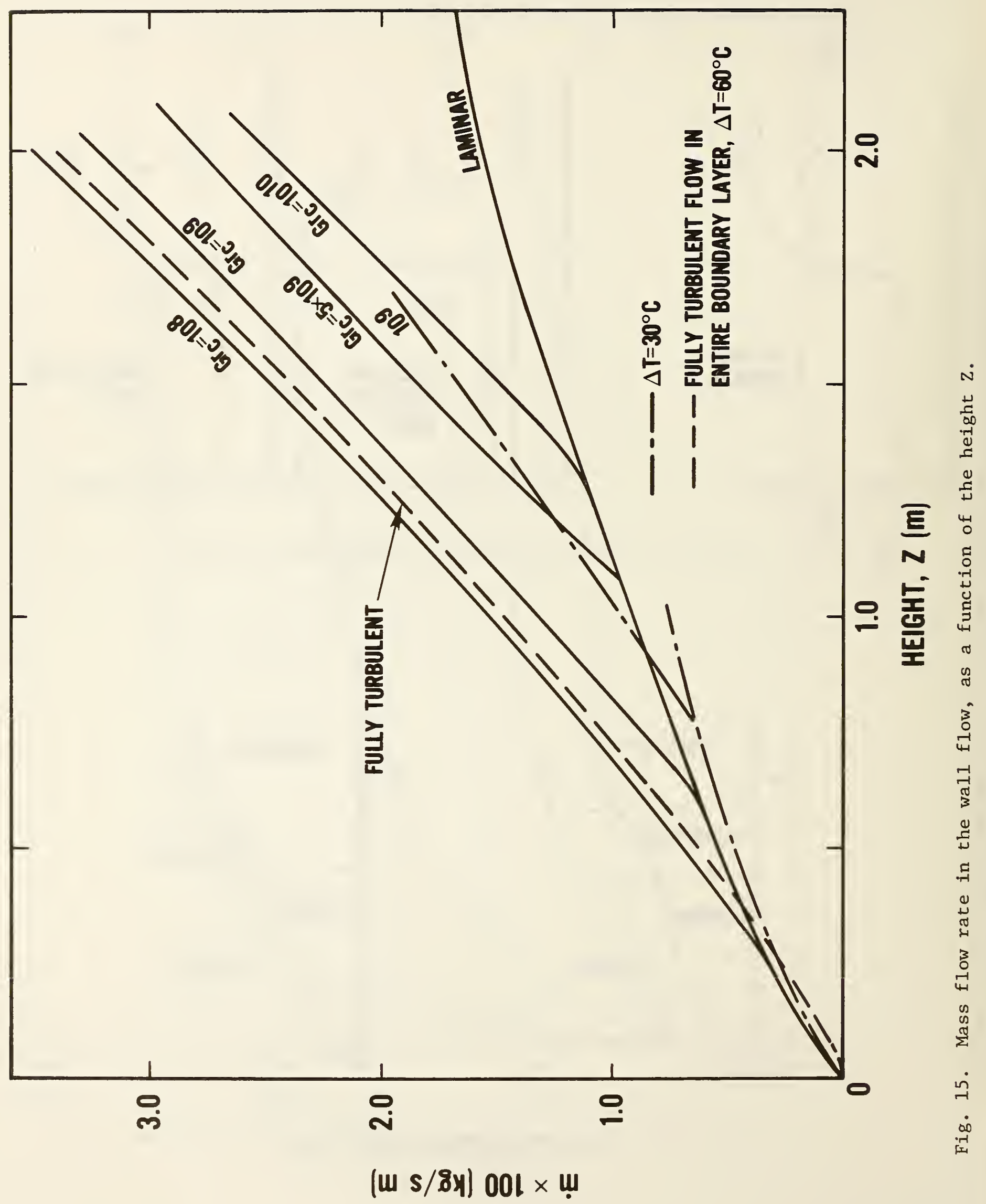




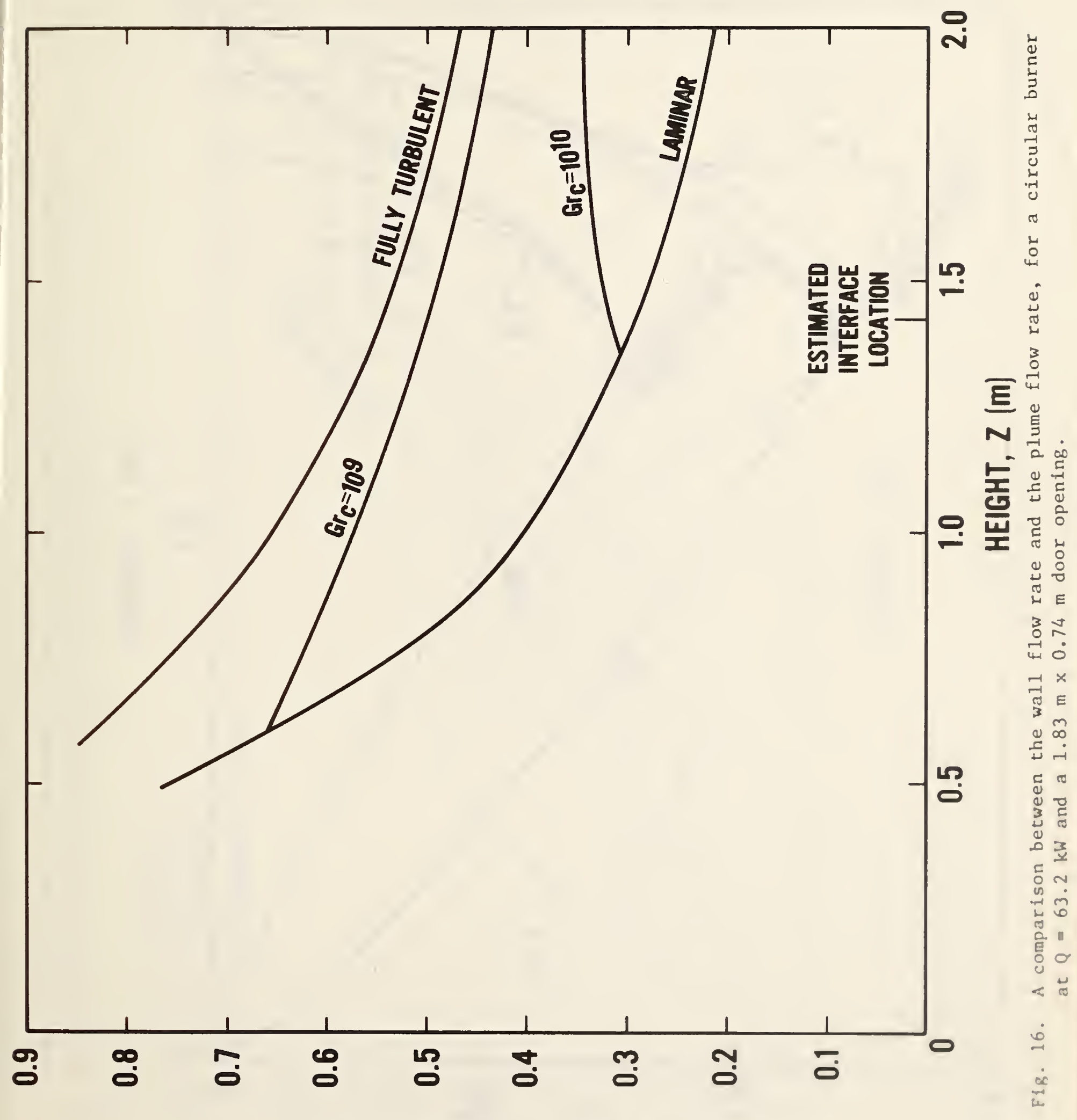

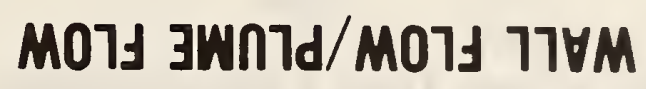




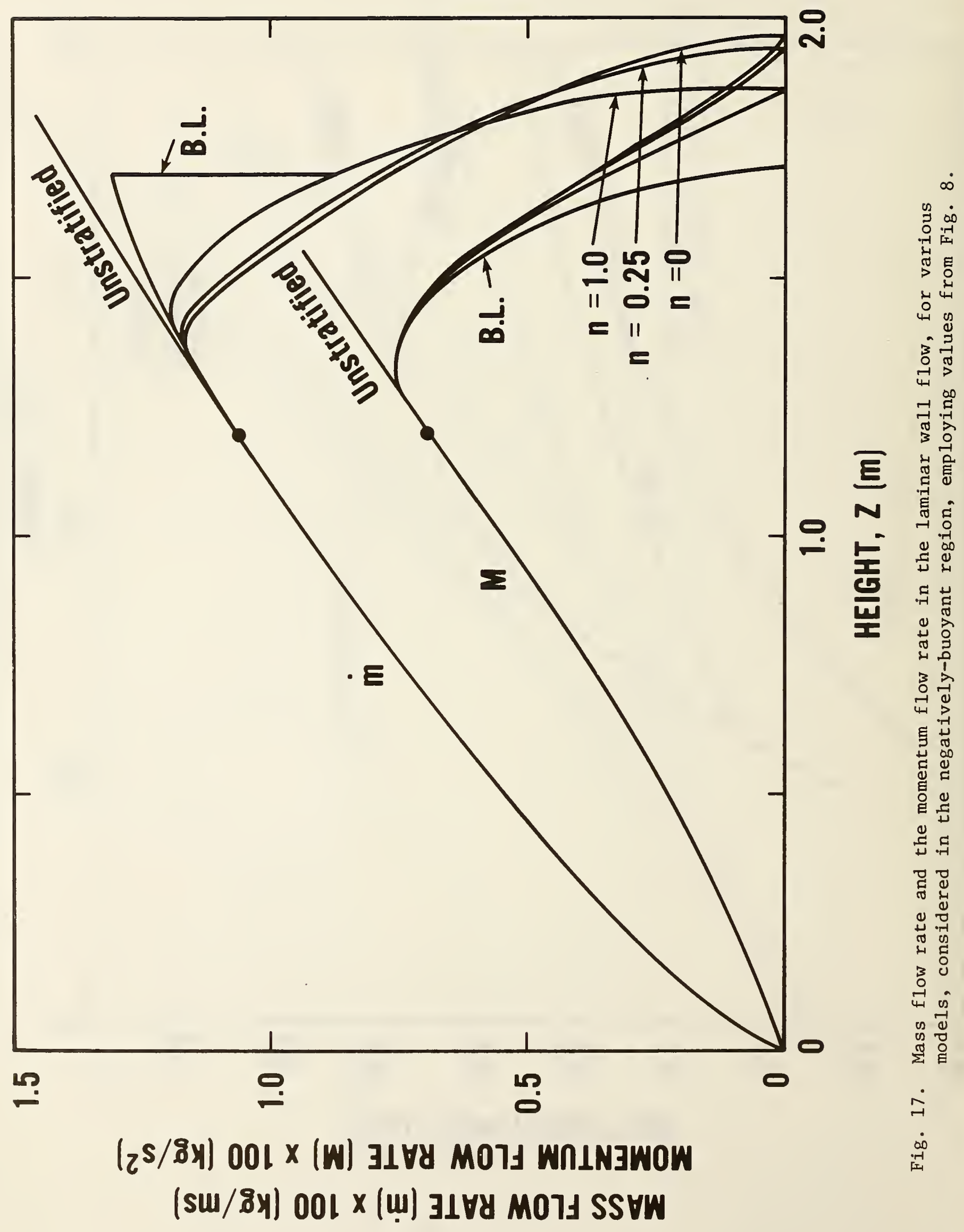




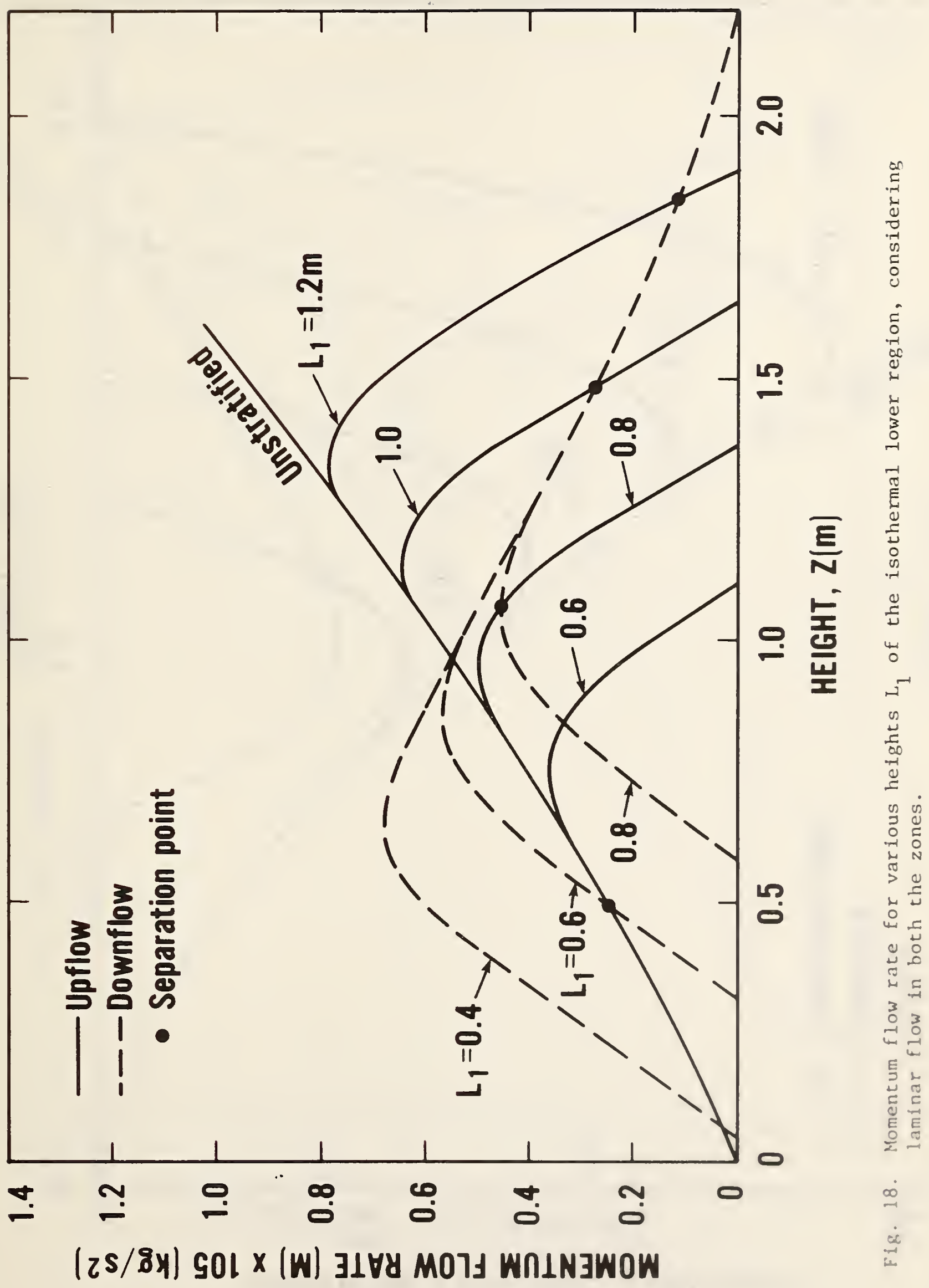




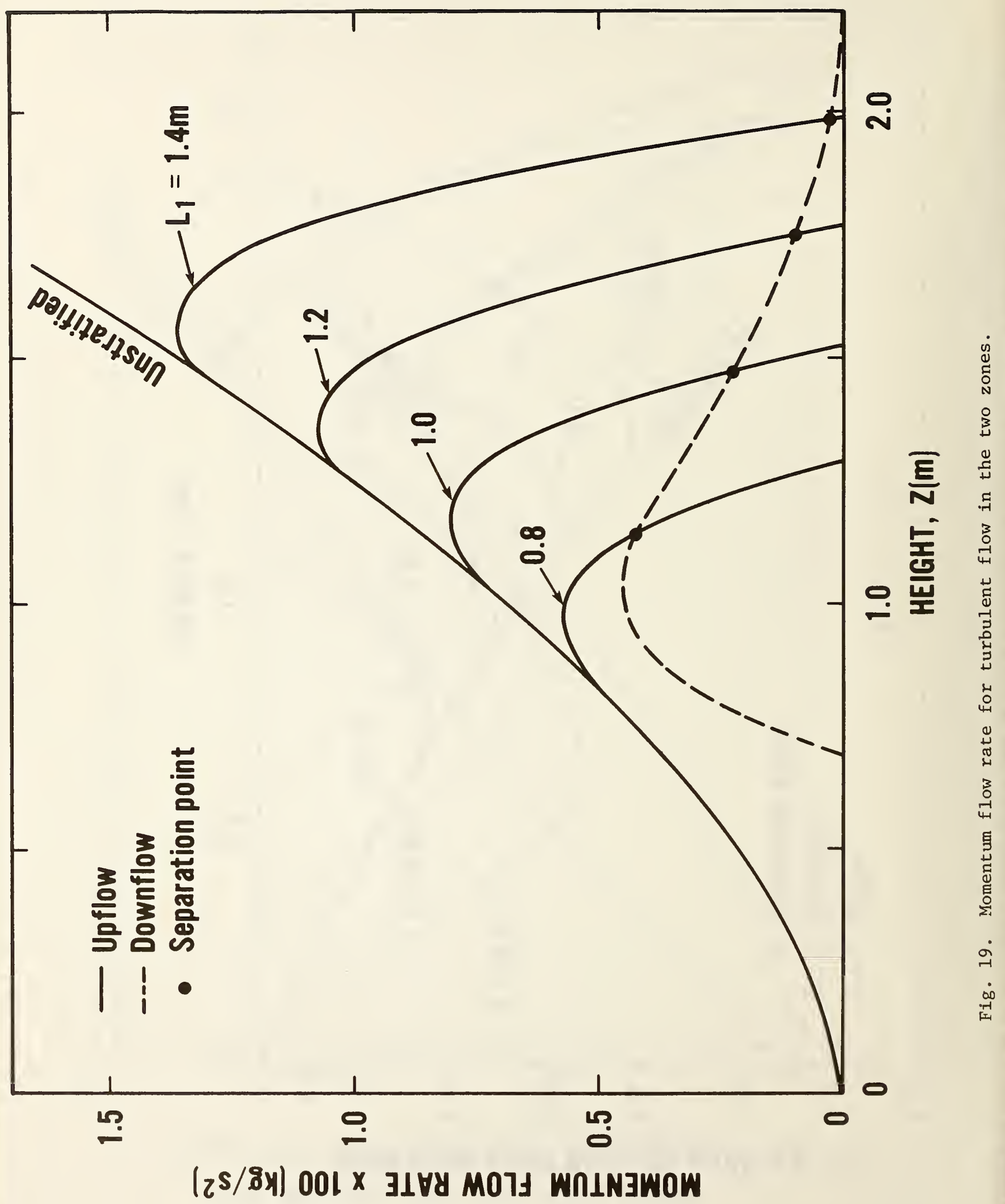




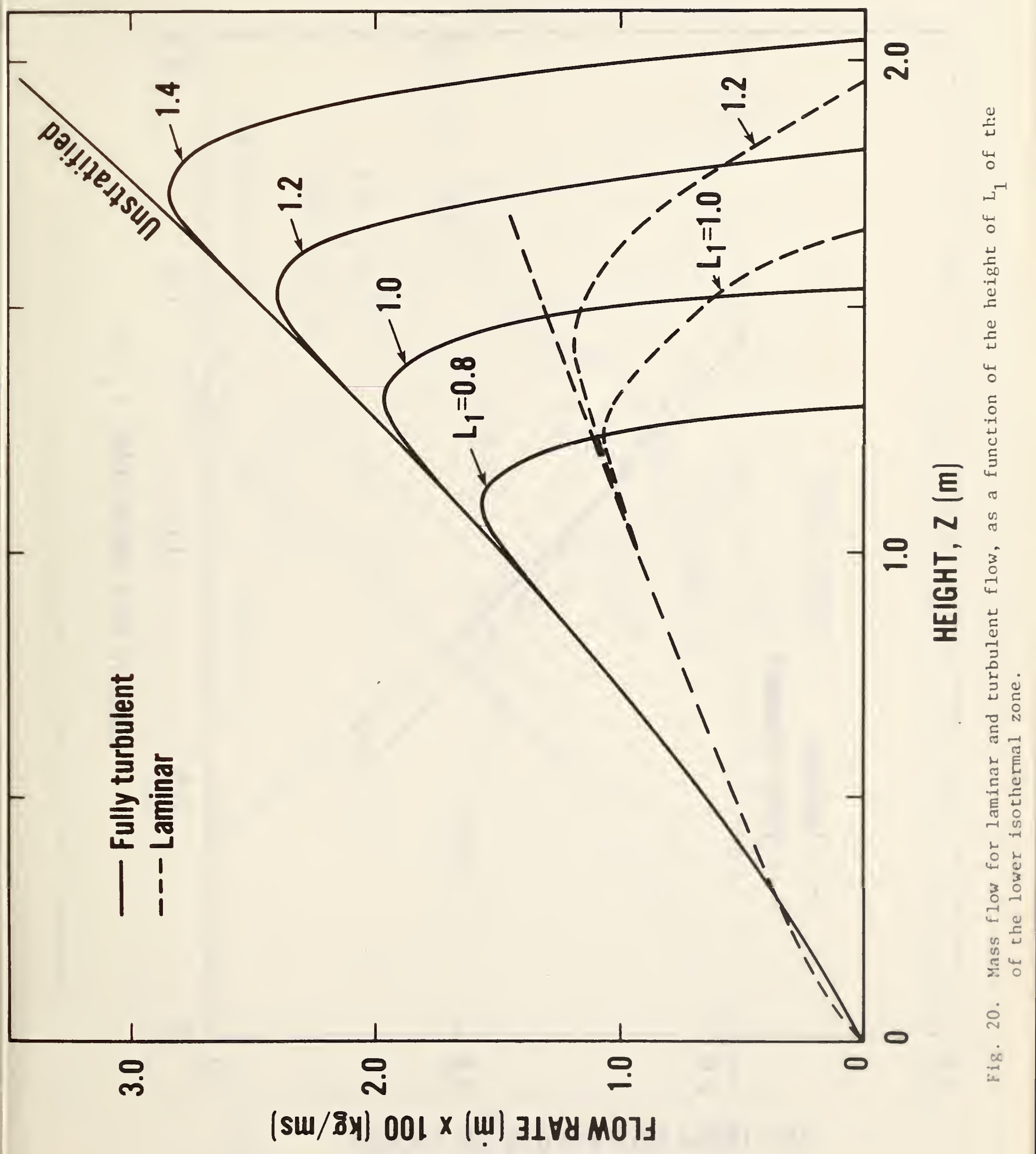




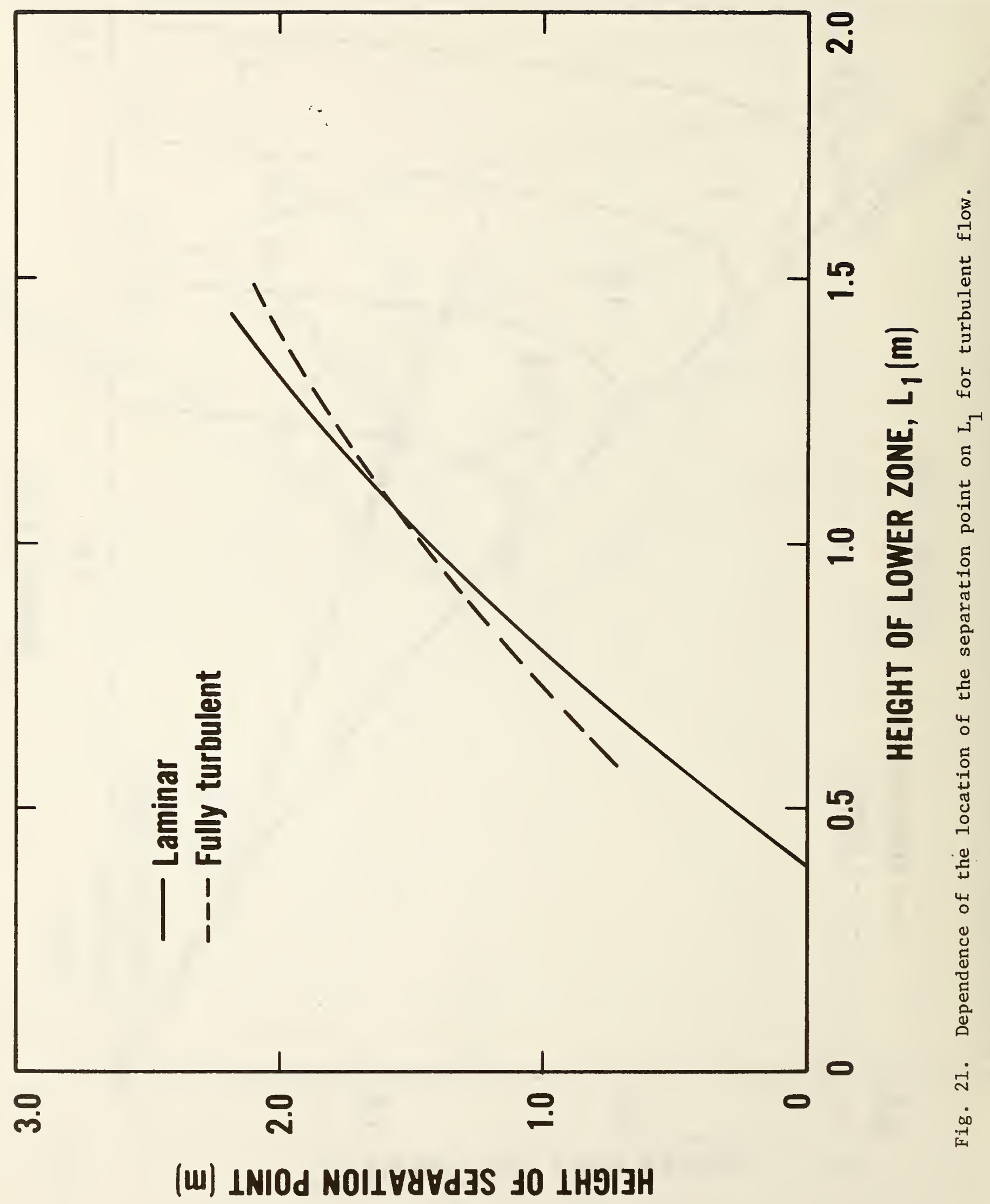




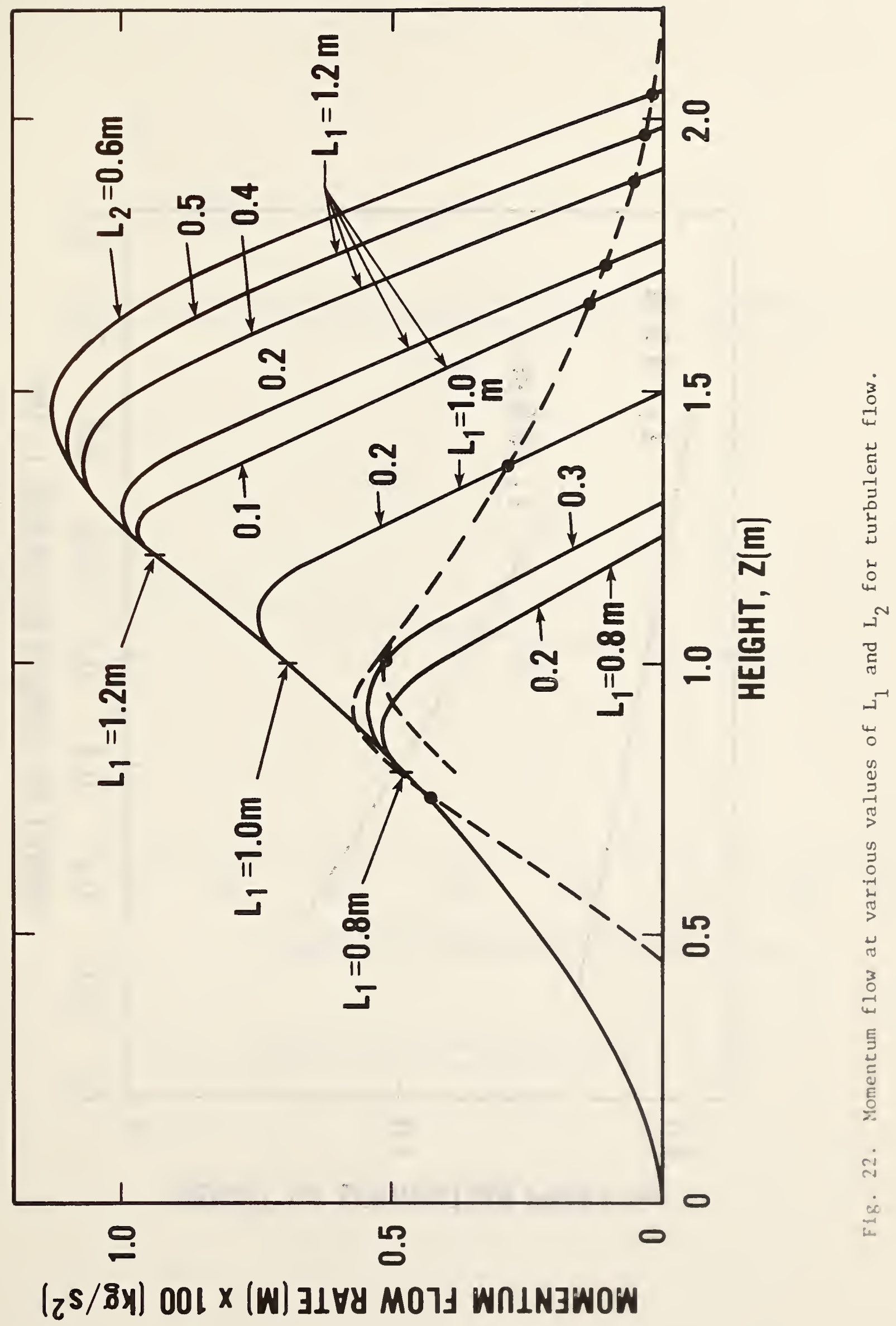




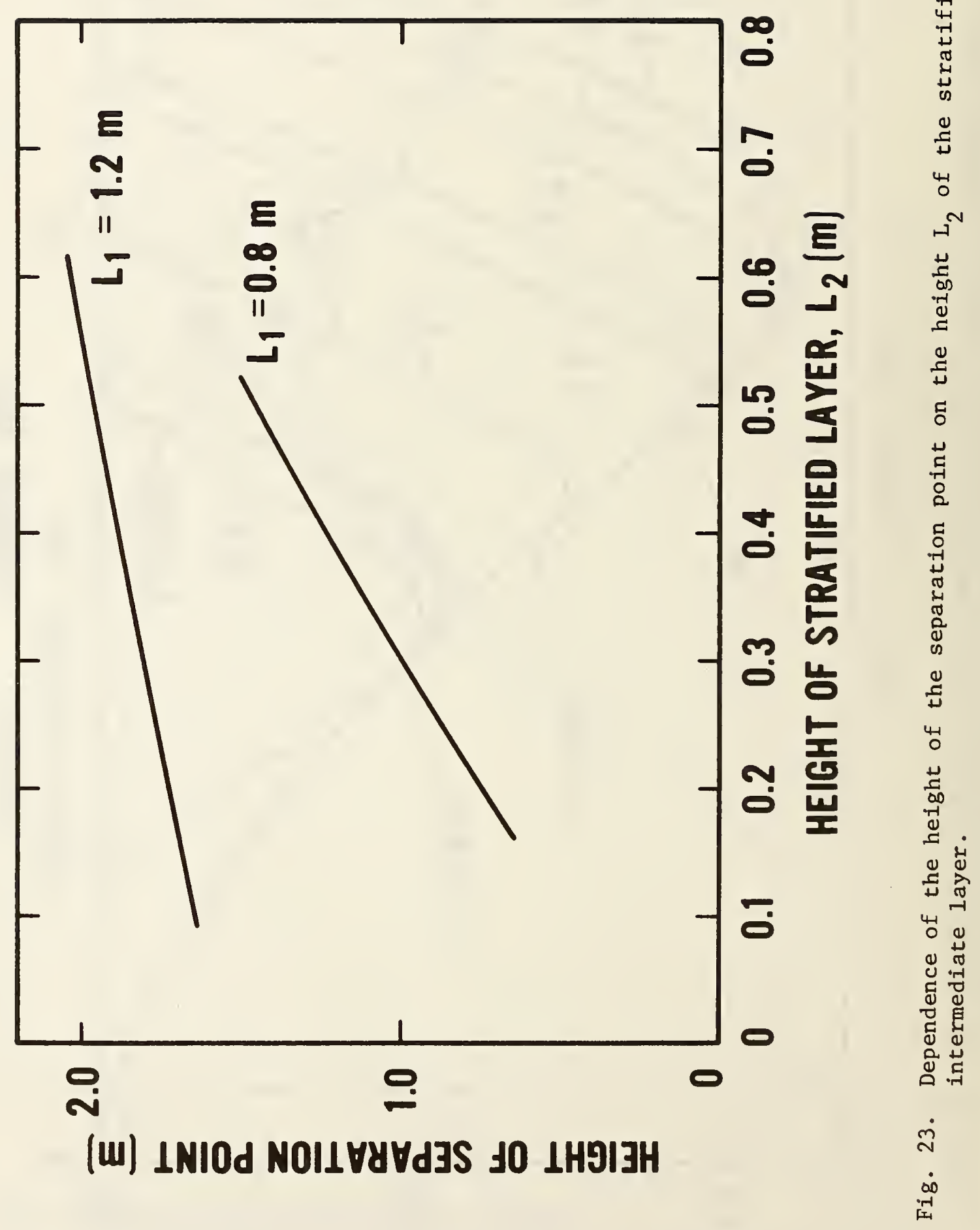




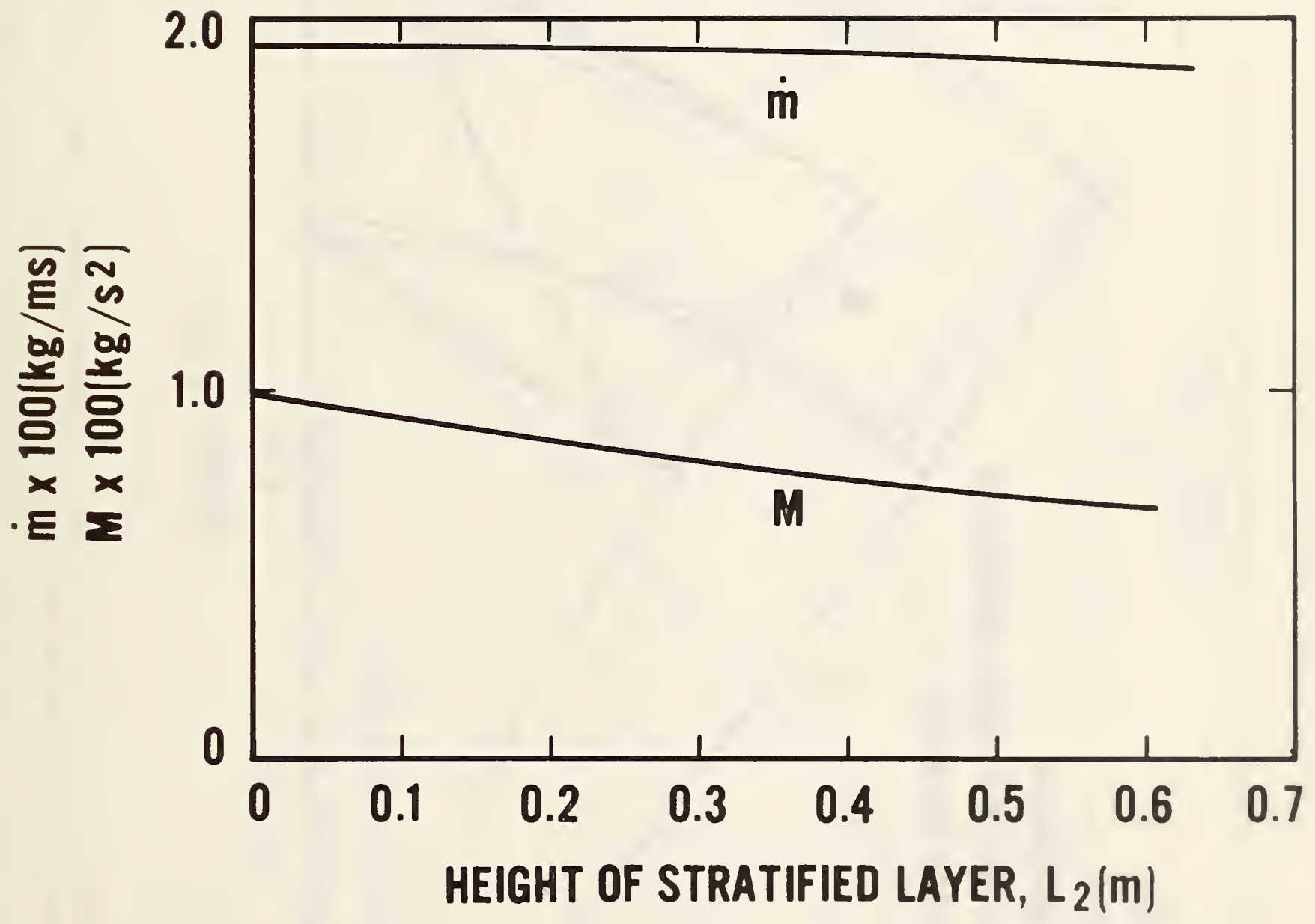

Fig. 24. Variation of the mass and momentum flow across the stratified layer with $\mathrm{L}_{2}$. 


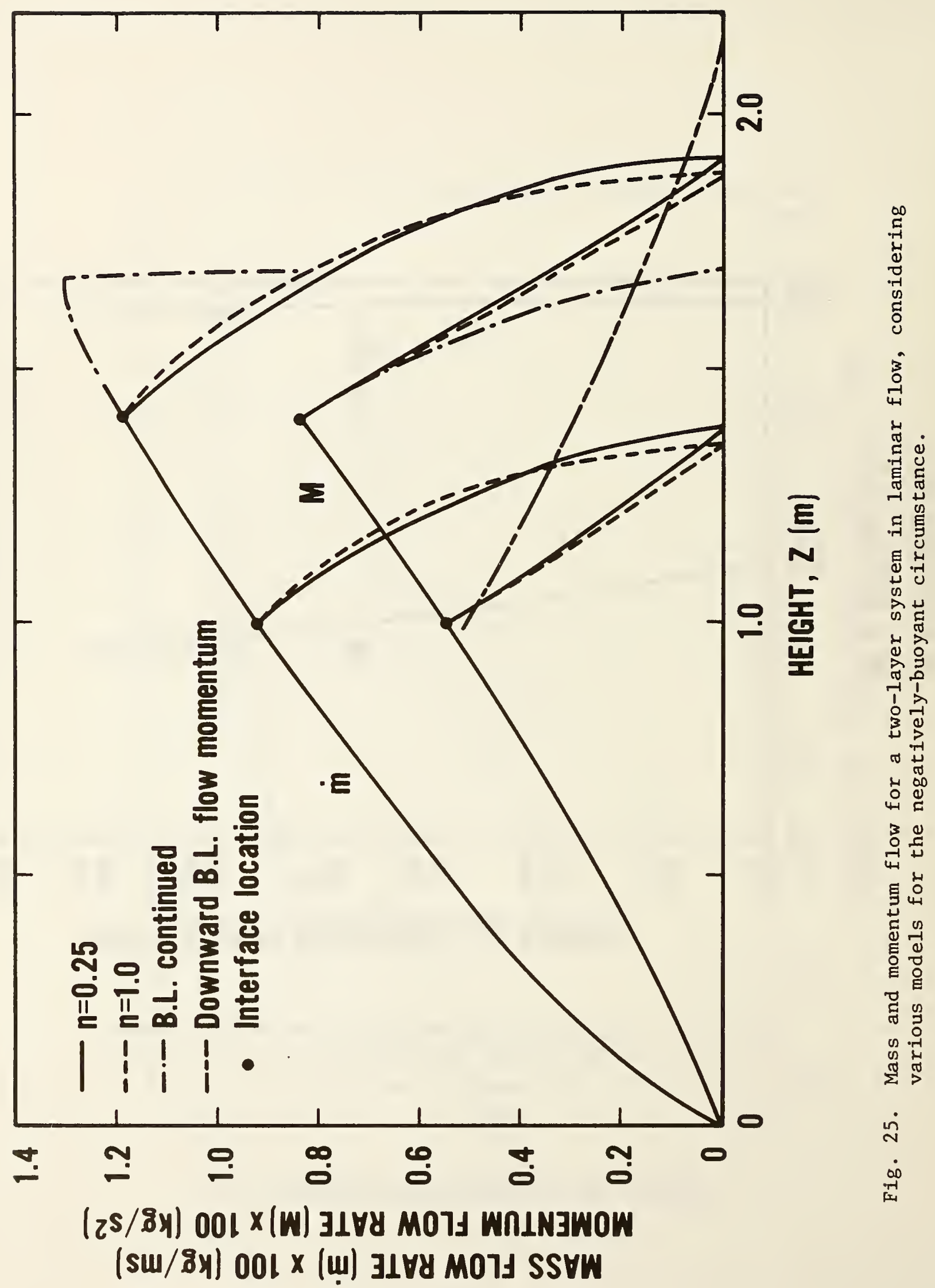




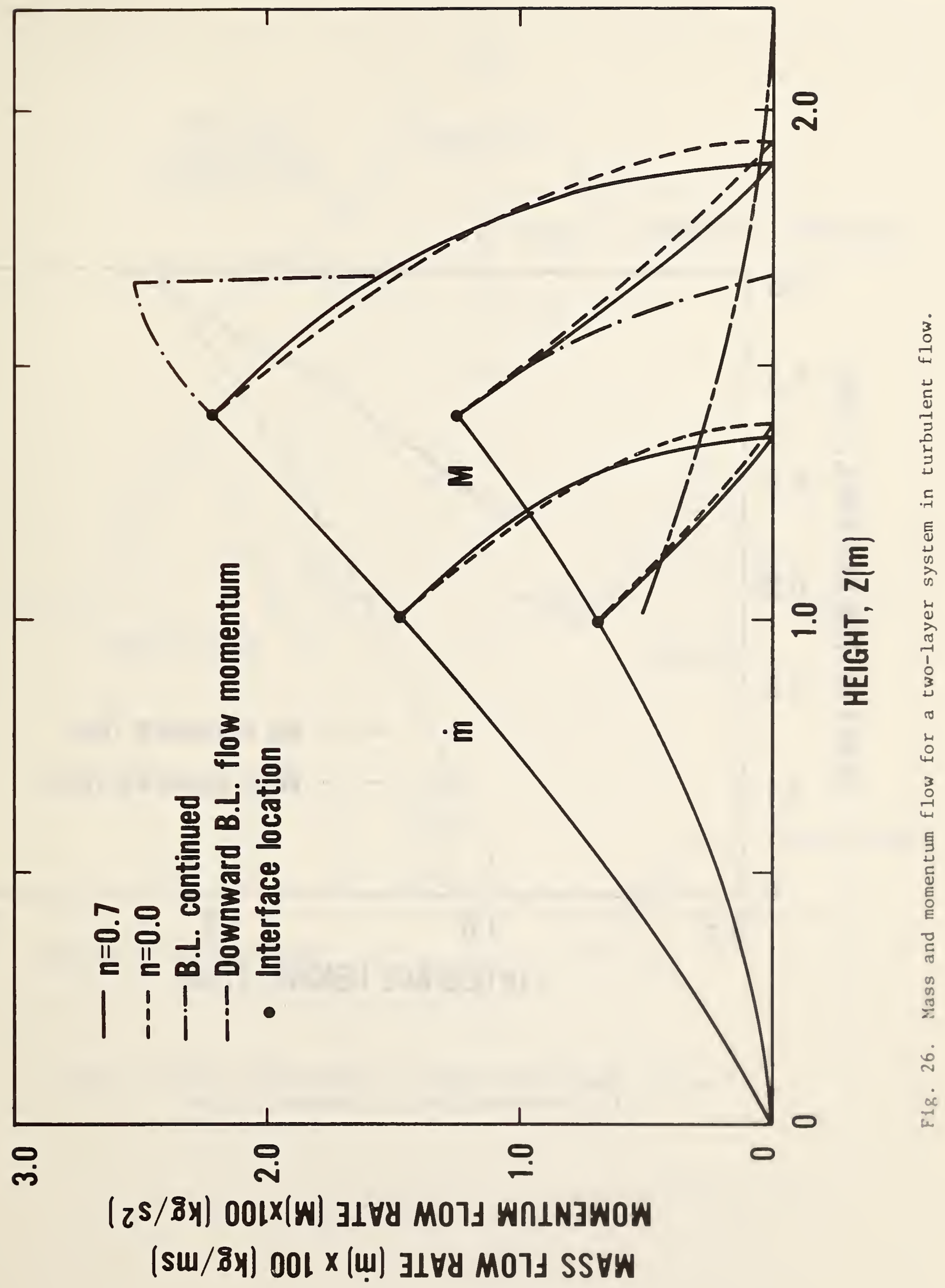




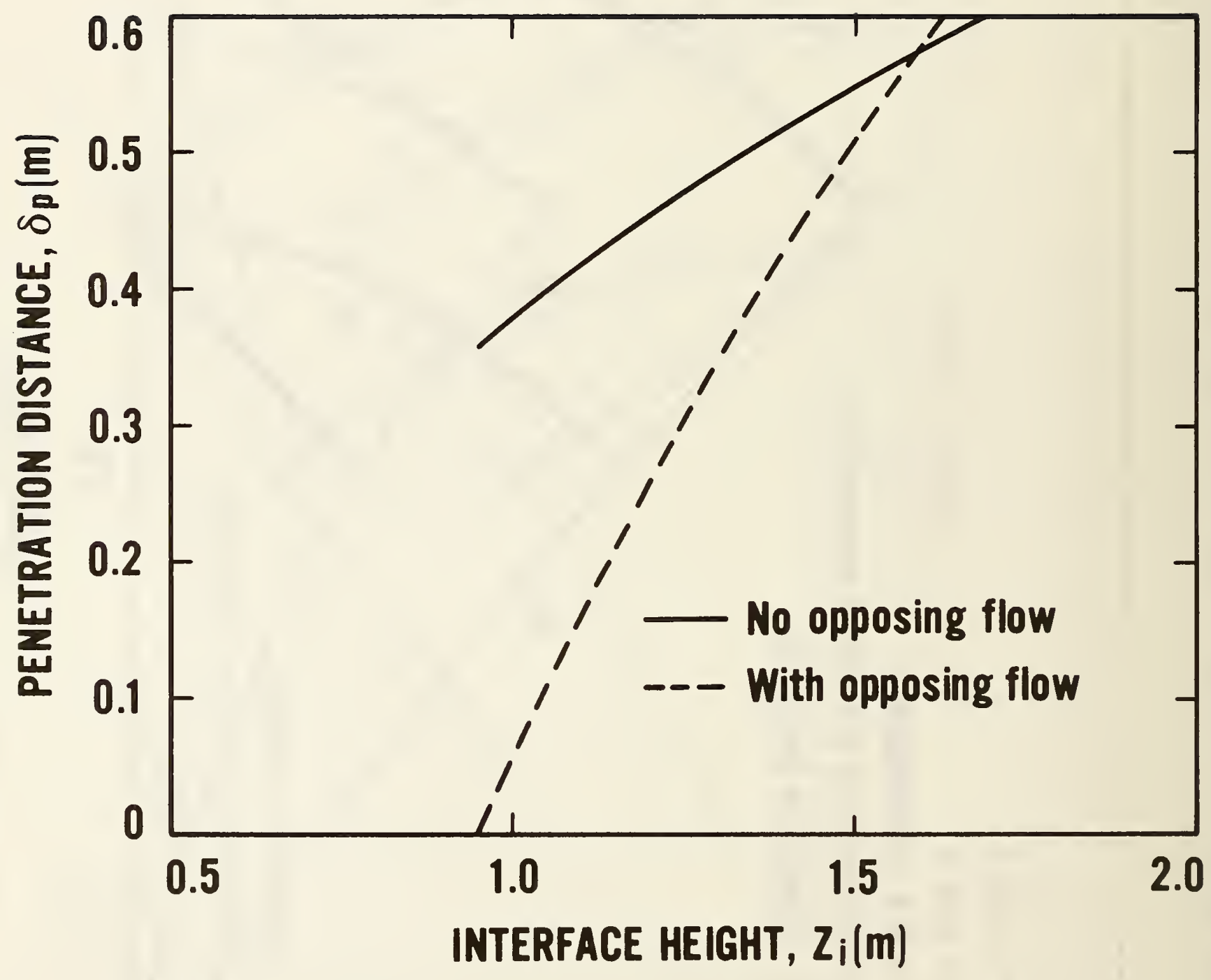

Fig. 27. Penetration depth as a function of interface height for turbulent flow in a two-zone system. 


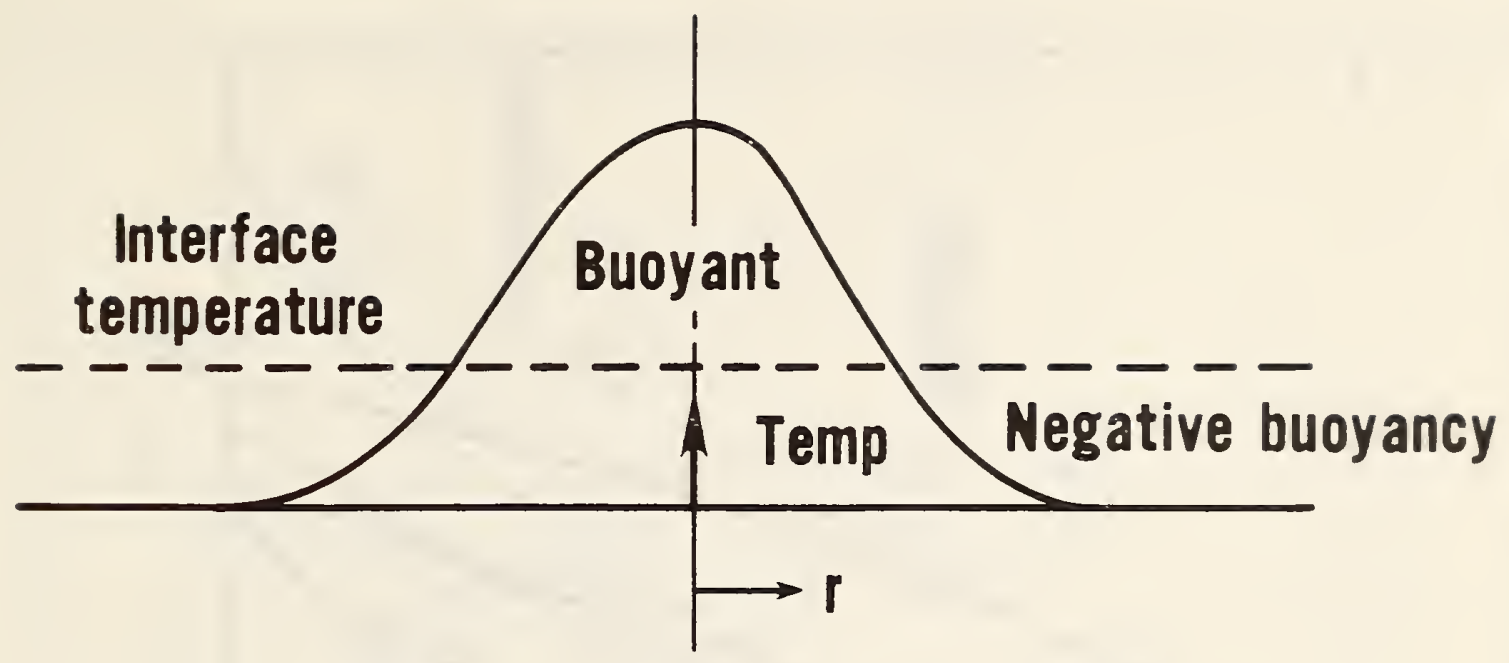

(a)

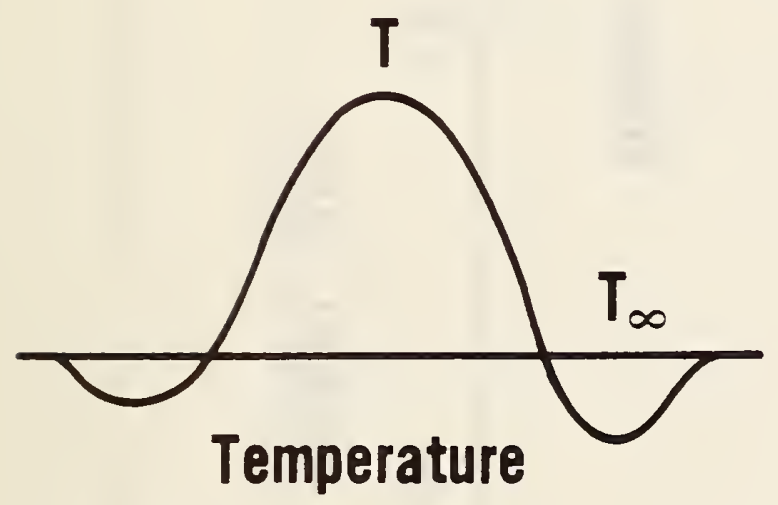

(b)
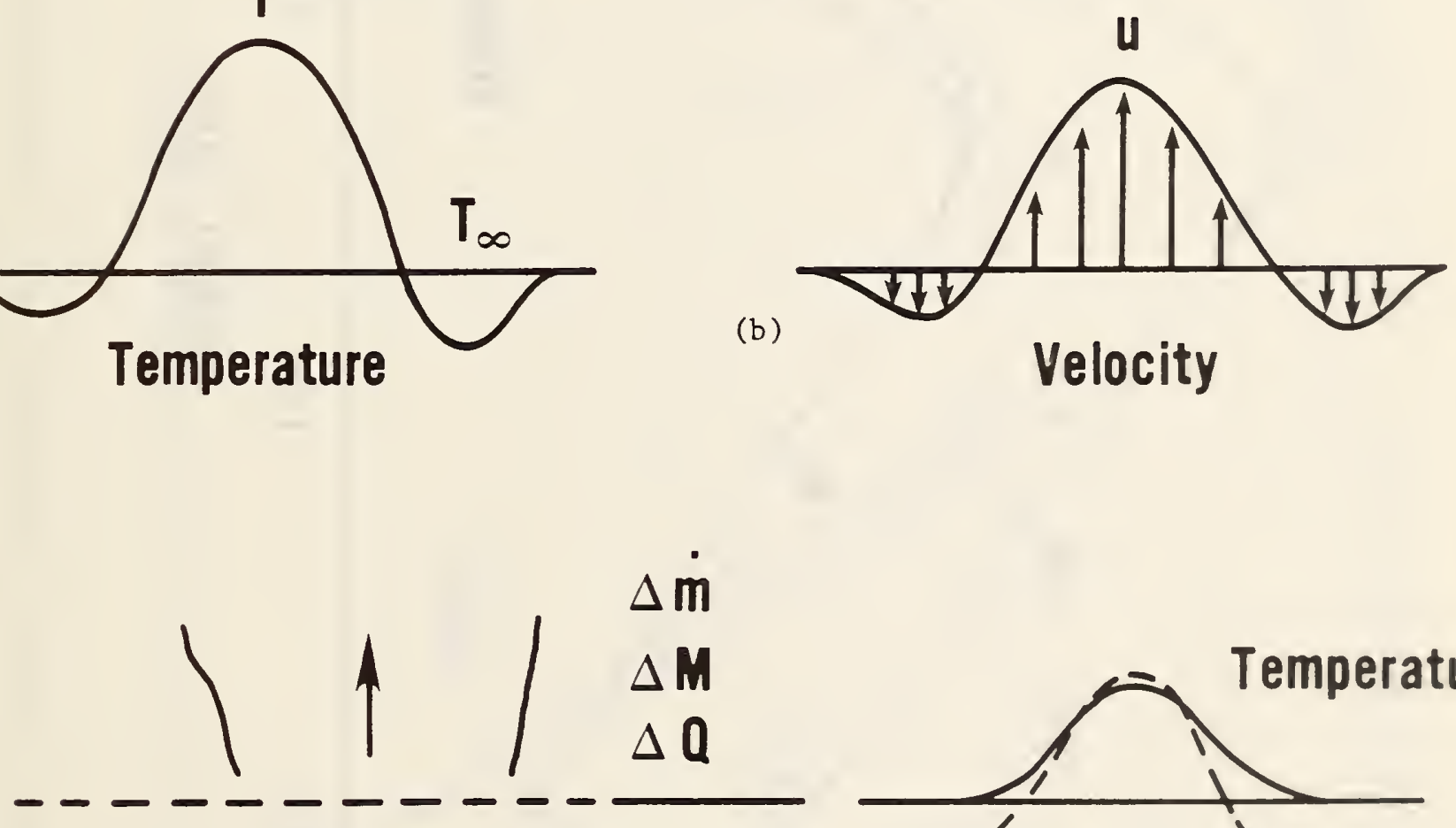

Region of adjustment
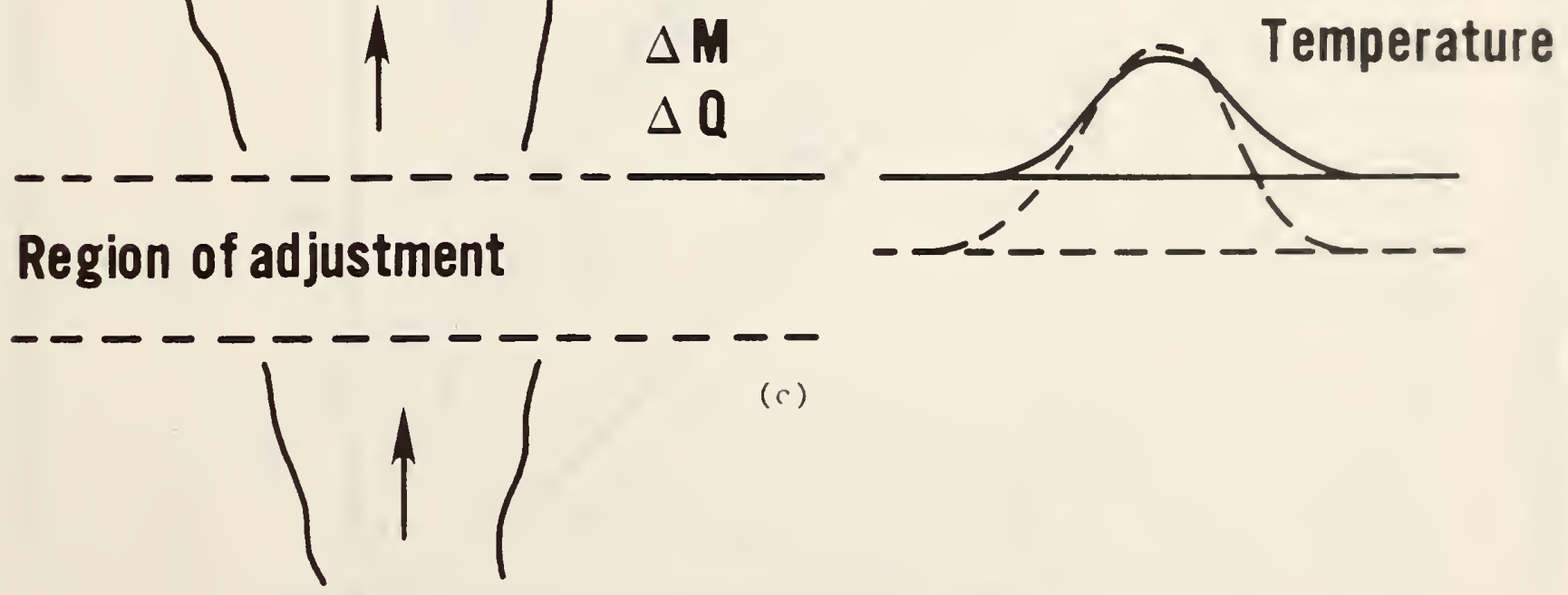

Fig. 28. Sketch of the temperature and velocity profiles as the fire plume flows across the interface. 


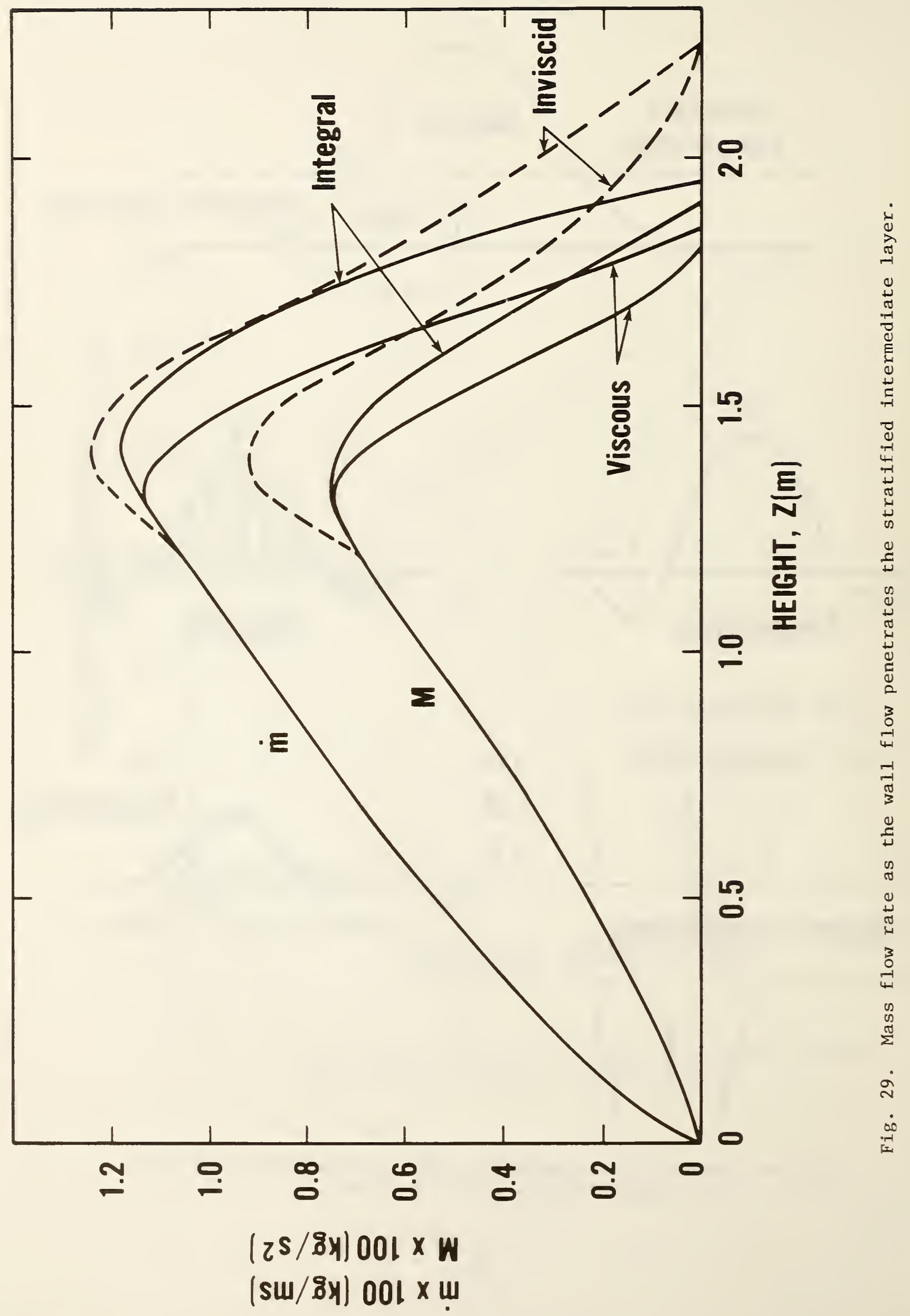




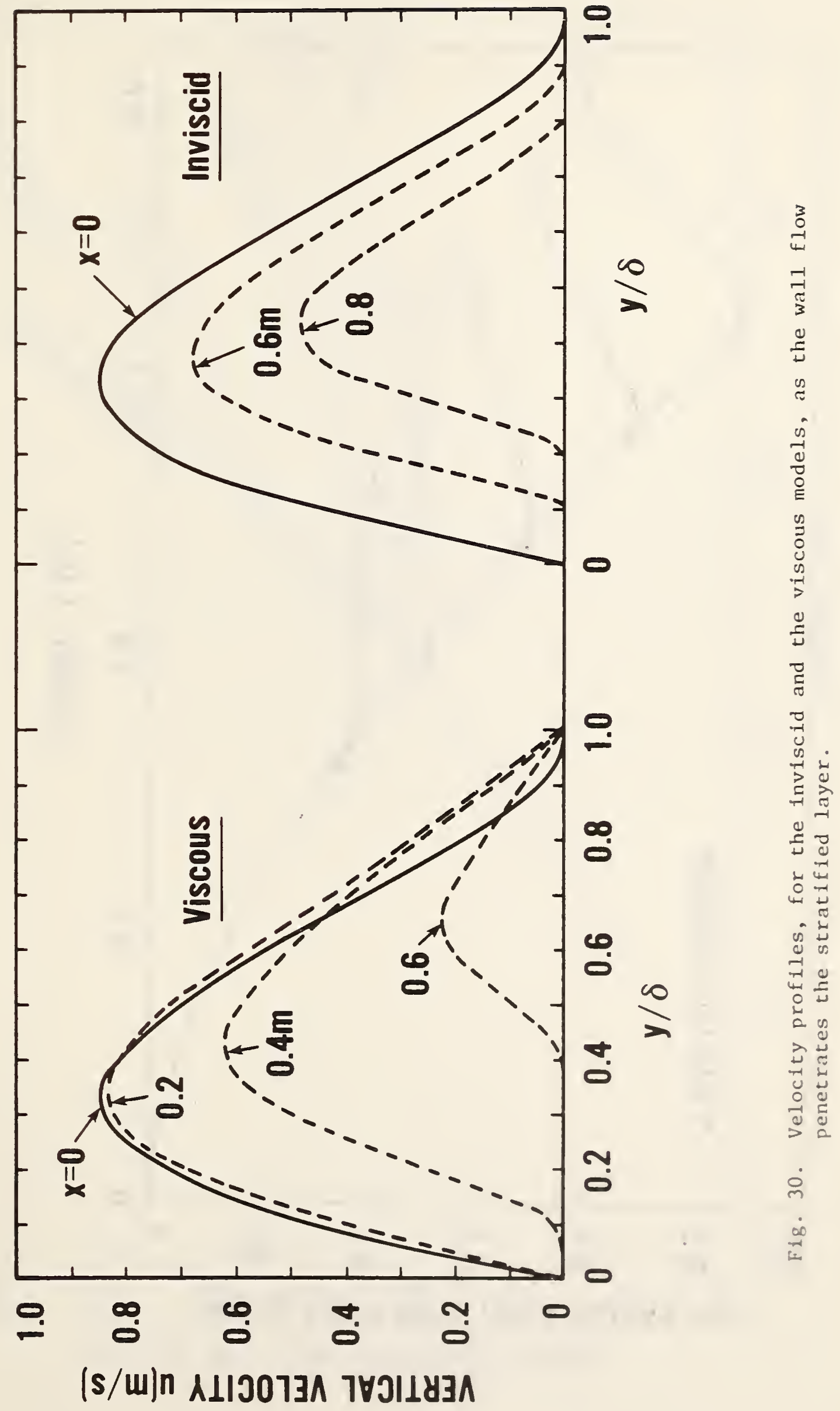




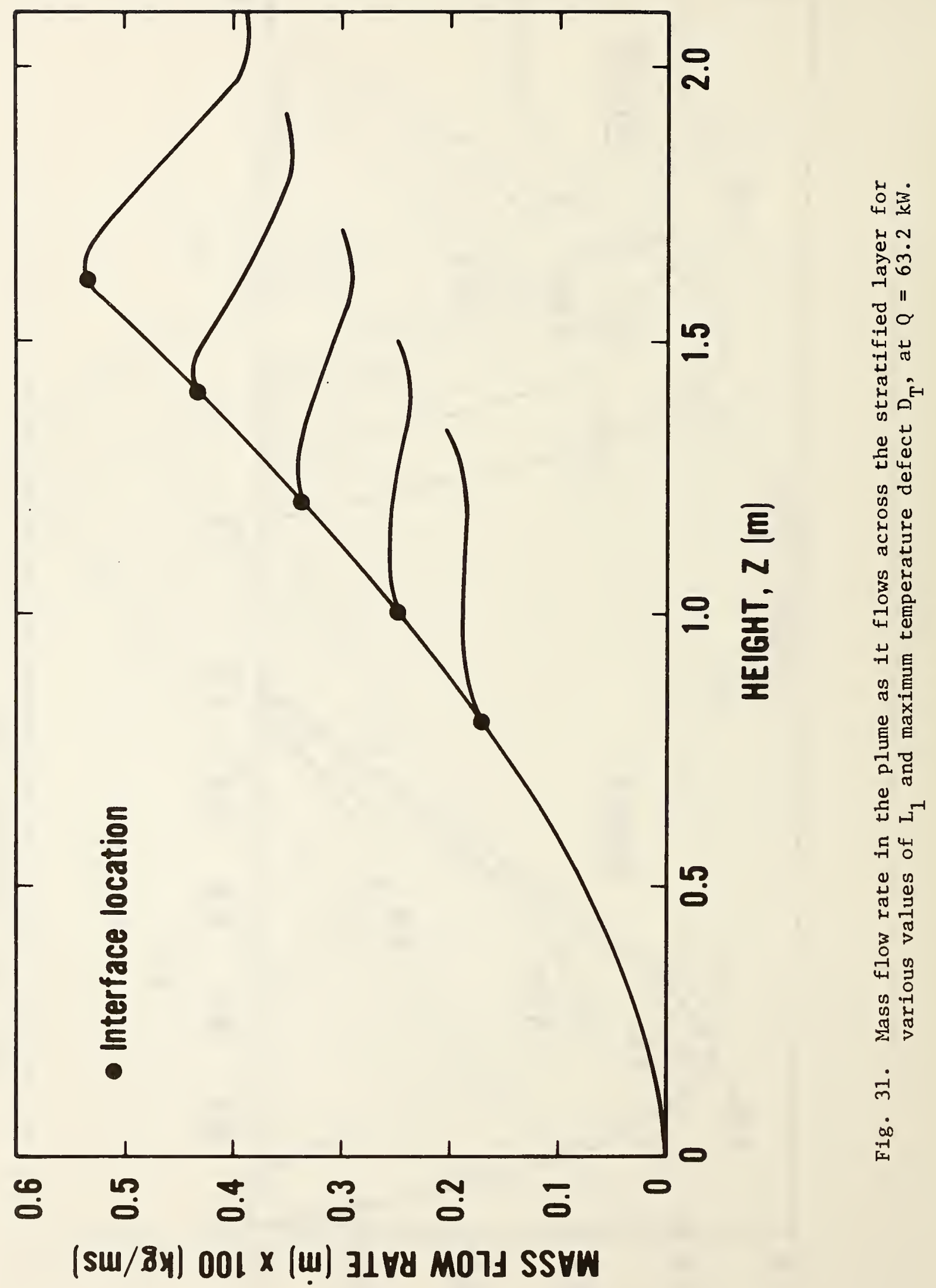




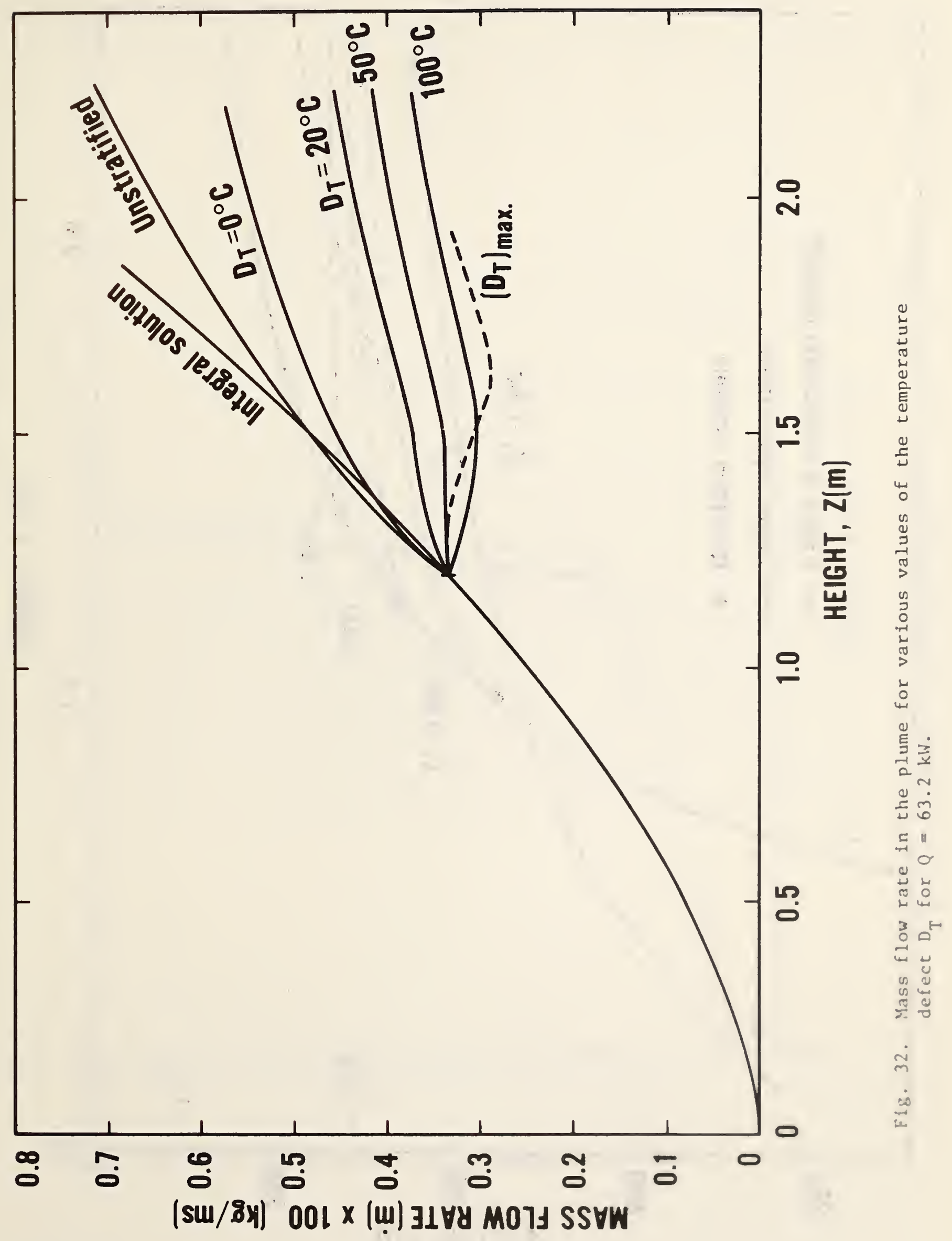




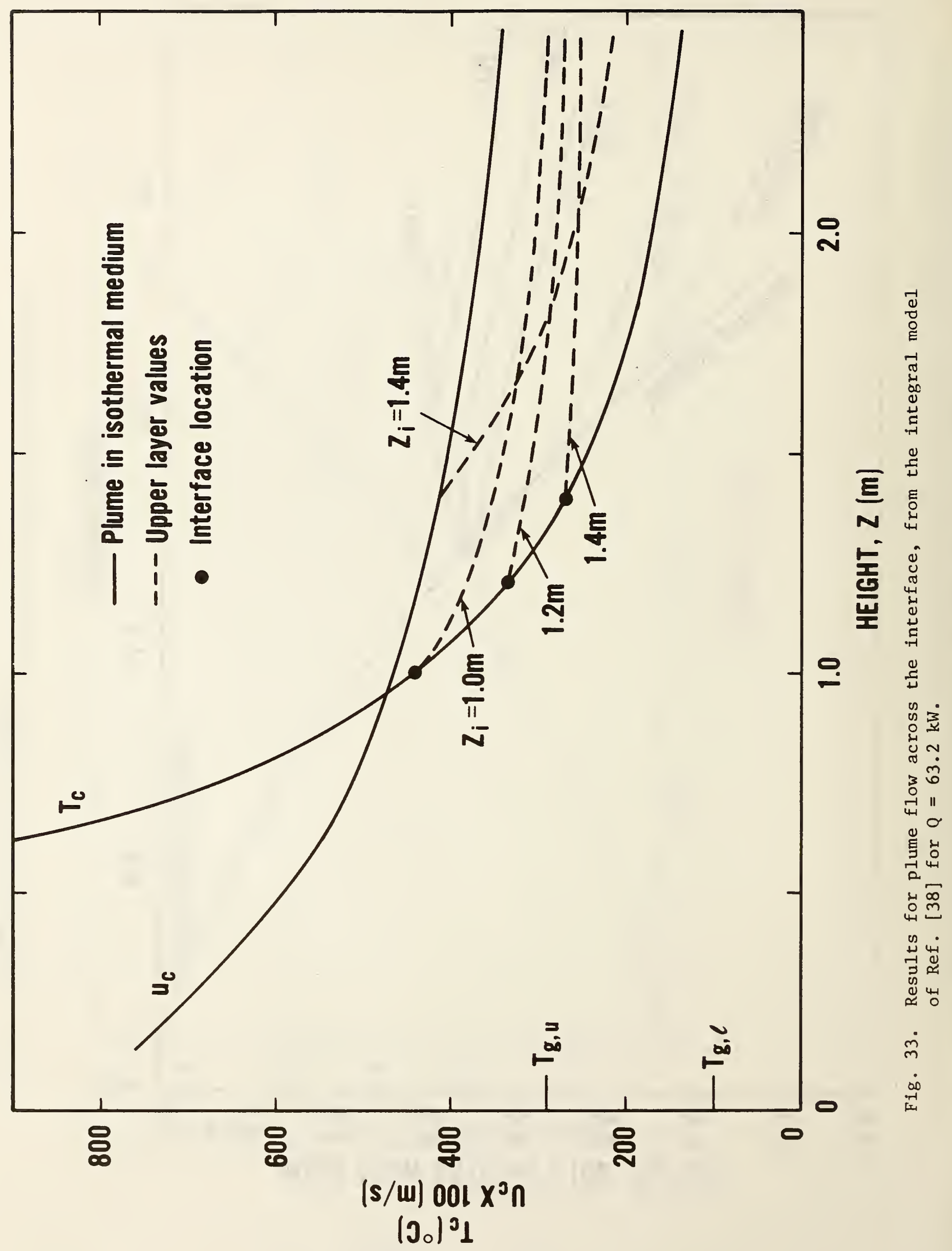




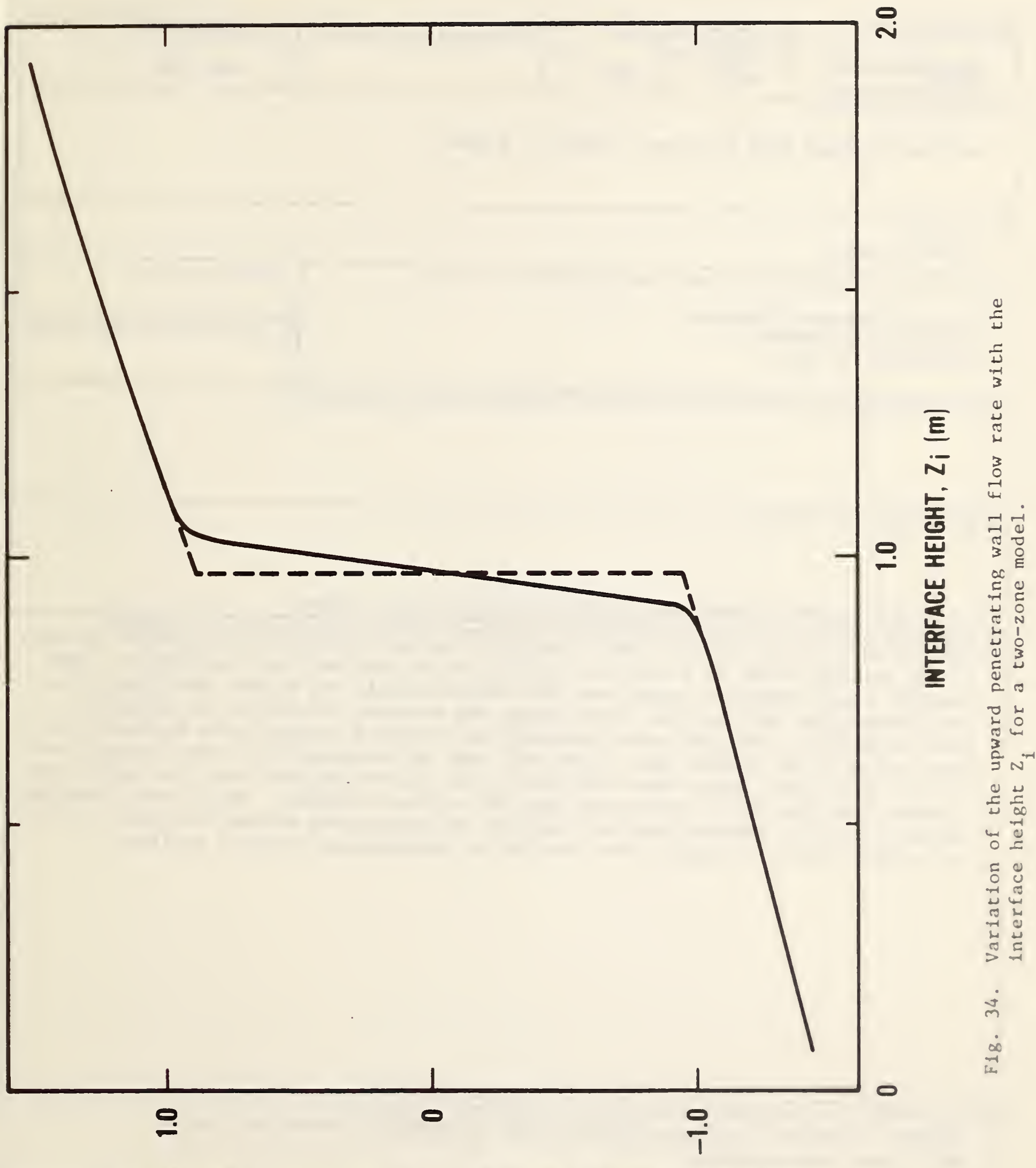

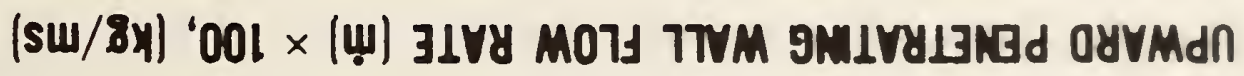


NBS.114A (REV. 2.80)

U.S. DEPT. OF COMM.

1. PUBLICATION OR REPORT NO.

BIBLIOGRAPHIC DATA

SHEET (See instructions)

NBSIR - 84-2841

2. Performing Organ. Report Nod 3. Publication Date

May 1984

4. TITLE AND SUBTITLE

Buoyancy-Induced Wal1 Flow due to Fire in a Room

5. AUTHOR(S)

Yogesh Jaluria

6. PERFORMING ORGANIZATION (If joint or other than NBS, see instructions)

7. Contract/Grant No.

NATIONAL BUREAU OF STANDARDS

DEPARTMENT OF COMMERCE

WASHINGTON, D.C. 20234

9. SPONSORING ORGAIHZATION NAME AND COMFLETE ADDRESS (Street, CIty, StOte, ZIP)

8. Type of Report \& Period Covered

10. SUPPLEMENTARY NOTES

Document describes a computer program; SF-185, FIPS Software Summary, is attached.

11. ABSTRACT (A 200-word or less foctual summary of most significant information. If document includes a significant bibliography or literature survey. mention it here) A study of buoyancy-driven flow generated adjacent to the vertical walls of a room due to fire in the room has been carried out. The boundary layer flow that arises over the vertical walls due to the resulting difference between the wall and gas temperatures was analyzed, employing the integral analysis method. The flow rate, momentum and convected energy in the downward flow that arises in the heated upper layer and those in the upward flow that is generated in the cooler lower layer were determined. The separation point and the region near it where the flow starts separating from the wall are studied. Though more detailed and more accurate computations are included, an approximate method for evaluating the wa11 effects for a two-layer model and for an experimental study is outlined.

12. KEY WORDS (Six to twelve entries; alphabetical order; capitalize only proper names; and separate key words by semicolons) Density interface; enclosure fires; plume penetration; stratified media; wal1 flows; zone-modeling

13. AVAILABILITY

[X] Unlimited

For Official Distribution. Do Not Release to NTIS

Order From Superintendent of Documents, U.S. Government PrInting Office, Washington, D.C. 20402.
14. NO. OF PRINTED PAGES

96

15. Price

$\$ 11.50$

X] Order From National Technical Information Service (NTIS), Springfield, VA. 2216I 

